Portland State University

PDXScholar

\title{
Work-related Outcomes of Financial Stress: Relating Perceived Income Adequacy and Financial Strain to Job Performance and Worker Well-being
}

Lindsay Ellen Sears

Portland State University

Follow this and additional works at: https://pdxscholar.library.pdx.edu/open_access_etds

Part of the Human Factors Psychology Commons, and the Industrial and Organizational Psychology Commons

Let us know how access to this document benefits you.

\section{Recommended Citation}

Sears, Lindsay Ellen, "Work-related Outcomes of Financial Stress: Relating Perceived Income Adequacy and Financial Strain to Job Performance and Worker Well-being" (2008). Dissertations and Theses. Paper 5295.

https://doi.org/10.15760/etd.7174

This Thesis is brought to you for free and open access. It has been accepted for inclusion in Dissertations and Theses by an authorized administrator of PDXScholar. Please contact us if we can make this document more accessible: pdxscholar@pdx.edu. 


\section{THESIS APPROVAL}

The abstract and thesis of Lindsay Ellen Sears for the Master of Science in

Psychology were presented June 9, 2008, and accepted by the thesis committee and the department.

COMMITTEE APPROVALS:
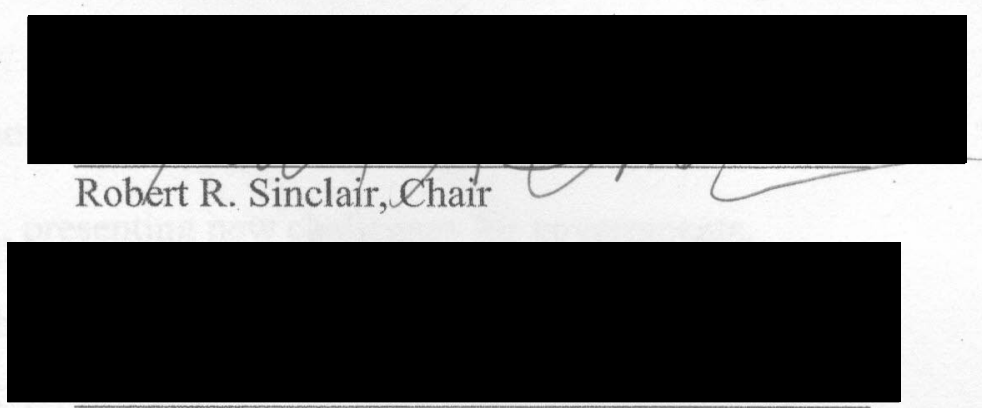

Leslie B. Hammer

DEPARTMENT APPROVAL:
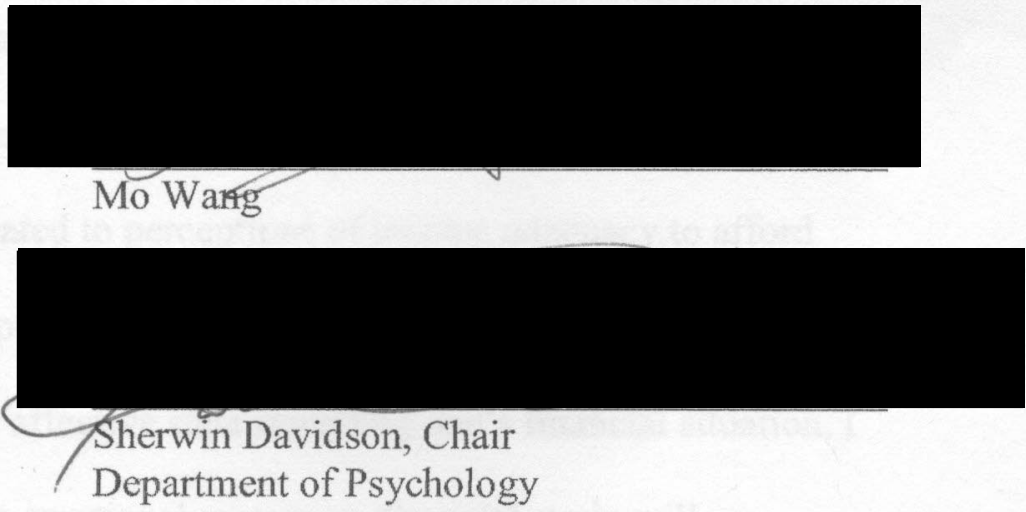


\begin{abstract}
An abstract of the thesis of Lindsay Ellen Sears for the Master of Science in Psychology presented June 9, 2008.
\end{abstract}

Title: Work-related Outcomes of Financial Stress: Relating Perceived Income Adequacy and Financial Strain to Job Performance and Worker Well-being.

With the onset of globalization, the economic contexts and working conditions within many countries are changing, presenting new challenges for governments, organizations, and workers. Amid these challenges, concerns about personal finances are prevalent among employees and detrimental to workers' health, well-being, and families. Research on how this financial stress affects employees at work is lacking. In this thesis, I propose an appraisal-based model of financial stress whereby actual income and expenses are related to perceptions of income adequacy to afford wants and needs. These adequacy perceptions are, in turn, related to financial strain, representing a heightened negative affective state regarding one's financial situation. I hypothesize that, through a drain in emotional resources, financial strain will negatively predict life satisfaction by potentially inhibiting participation in healthy, enjoyable behaviors. I argue that this drain in emotional resources will also inhibit successful task performance and restrict participation in discretionary citizenship behaviors. 
Data from two working samples provide support for the hypothesized financial stress model and establish preliminary evidence of construct validity for new financial stress scales. In a prospective investigation, financial strain fully mediated the effects of income adequacy on subsequent life satisfaction, but was not related to job performance. Instead, perceived income adequacy to afford wants had a direct negative relationship with both task performance and citizenship behaviors at work, while income adequacy to afford needs had a positive direct effect on organizational citizenship behaviors.

This work resolves many conceptual inconsistencies about financial stress in the literature, and contributes to the understanding of how income perceptions and financial stress might influence psychological resources and work motivation. This work has important implications for how organizations manage employees who may be experiencing low income adequacy and high financial strain. Finally, there are several meaningful opportunities for future research that would substantially build upon existing theory and evidence in this new area of financial stress and work. 


\title{
' WORK-RELATED OUTCOMES OF FINANCIAL STRESS' RELATING PERCEIVED INCOME ADEQUACY AND FINANCIAL STRAIN TO JOB PERFORMANCE AND WORKER WELL-BEING
}

\author{
by \\ LINDSAY ELLEN SEARS
}

\begin{abstract}
A thesis submitted in partial fulfillment of the requirements for the degree of
\end{abstract}

\section{MASTER OF SCIENCE \\ in PSYCHOLOGY}

Portland State University 2008 
Financial Stress i

DEDICATION

To my father, Chris Sears. 


\section{ACKNOWLEDGEMENTS}

Thank you to my thesis committee chair, Dr. Robert Sinclair, for his inspirational ideas, feedback, and encouragement. Thanks to my committee, Drs. Leslie B. Hammer and Mo Wang for their great ideas, direction, and support. Thank you to the undergraduate and post-baccalaureate research assistants who helped with scale development, data collection, and information gathering: Leslie Allen, Michael Cady, Samantha South, and John Amadon. Thanks to Dr. Junqi Shi, Dr. Mo Wang, Songqi Liu, and Jessie Zhan for helping to translate scales, and collect, code, and match Chinese data. Thanks to my officemates, cohort, and colleagues in the Department of Psychology for feedback, ideas, help with scale development, and continuous support. Finally, thanks to my partner Douglas Irving for providing me with a steady foundation of unconditional love and support. 


\section{TABLE OF CONTENTS}

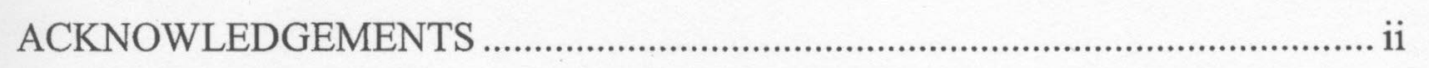

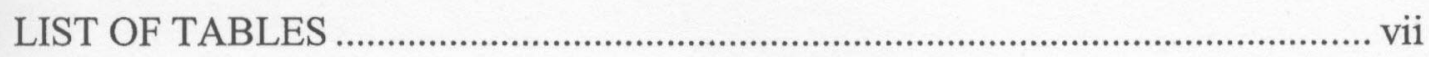

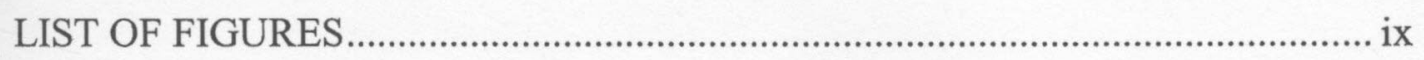

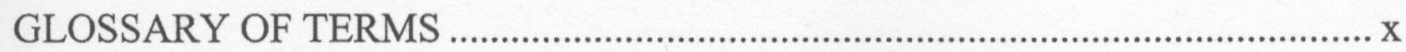

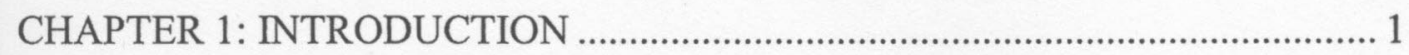

Linking Financial Stress to Work …................................................................... 5

Prevalence of Employee Poverty and Financial Stress ..................... 5

Pervasiveness of Poverty and Financial Stress ………………….... 7

The Organization as a Venue for Intervention .................................. 9

Gaps in Previous Research................................................................................ 10

Theory of Financial Stress ............................................................. 10

Operationalizations of Financial Stress................................................. 11

Lack of Organizational Research ...................................................... 11

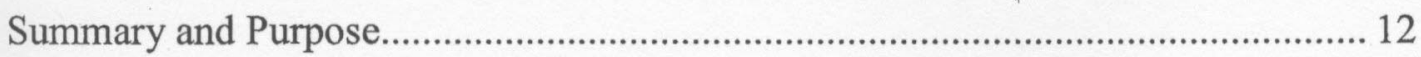

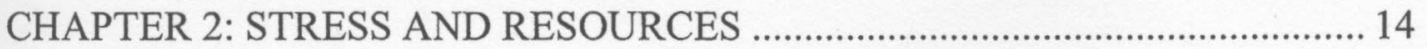

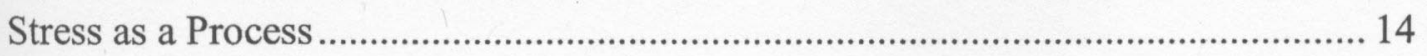

Lazarus’ Transactional Model............................................................ 15

Conservation of Resources Theory ………………………………...... 17

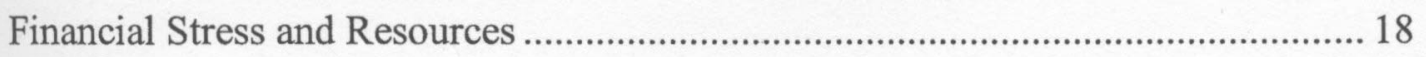

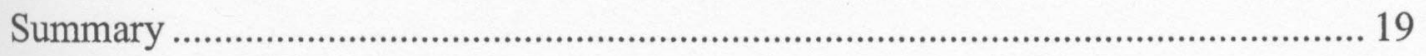

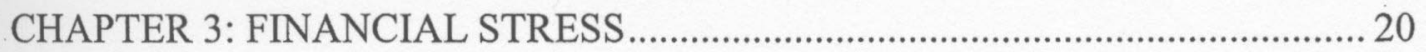


Economic Stress 20

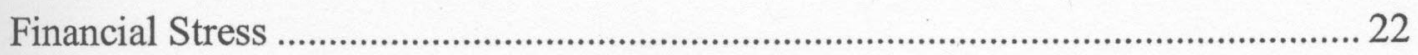

Objective Financial Situation............................................................... 23

Perceived Income Adequacy................................................................ 25

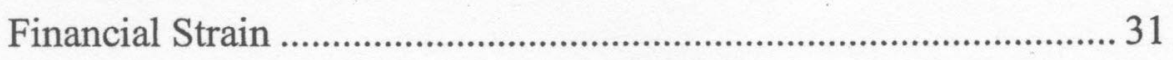

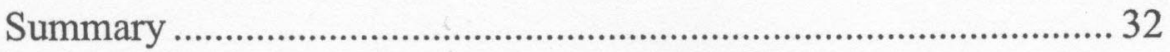

The Financial Stress Process ..................................................................................... 33

A Mediation Model of Financial Stress ............................................. 34

CHAPTER 4: OUTCOMES OF FINANCIAL STRESS............................................ 37

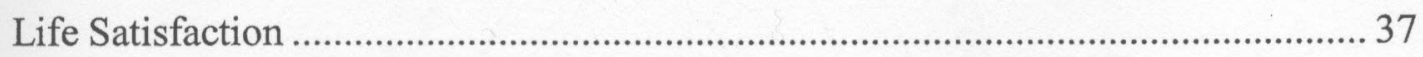

Financial Stress and Life Satisfaction.............................................. 39

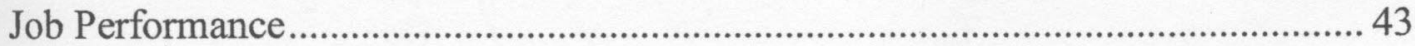

Theories of Stress and Performance.................................................. 47

Financial Stress and Job Performance................................................ 49

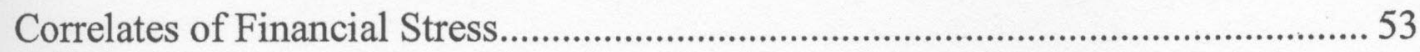

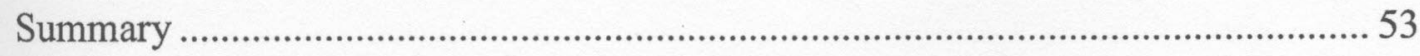

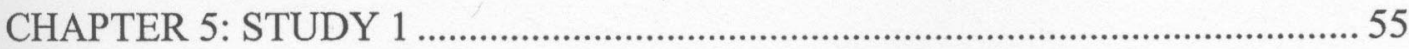

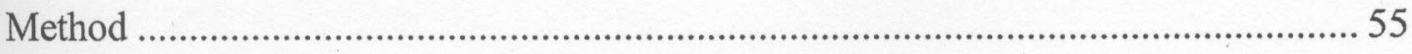

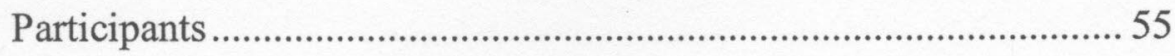

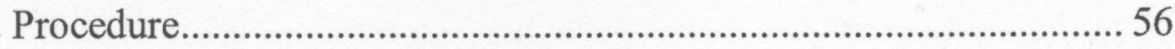

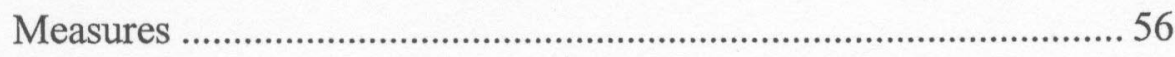

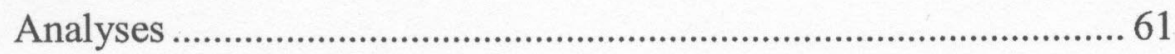




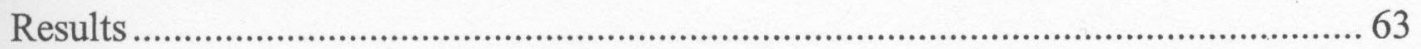

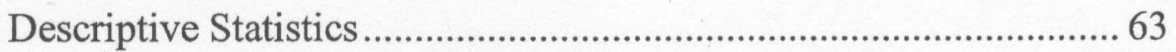

Financial Stress Mediation Model ...................................................... 63

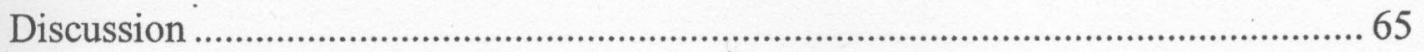

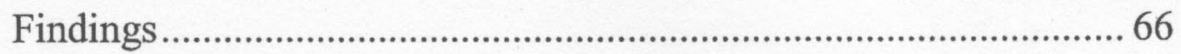

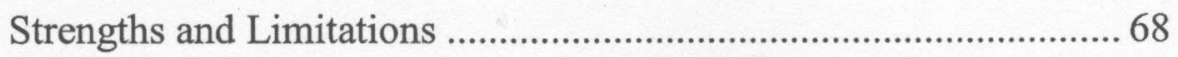

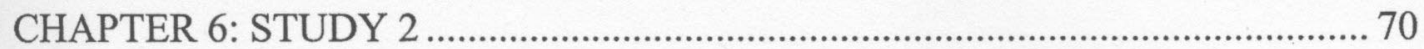

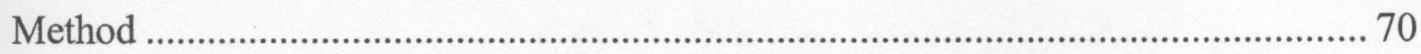

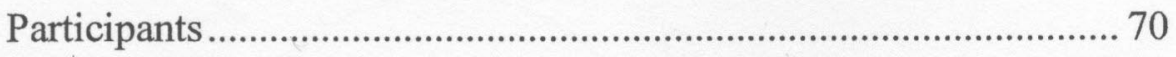

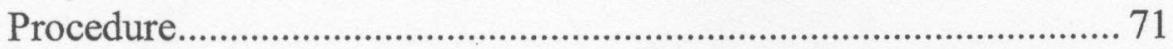

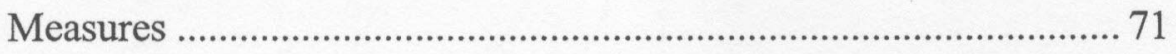

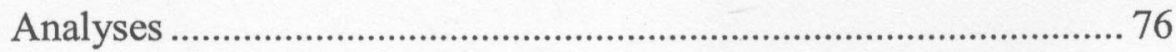

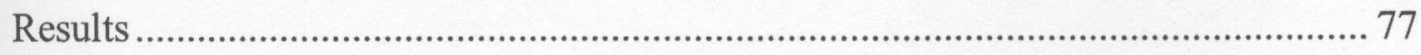

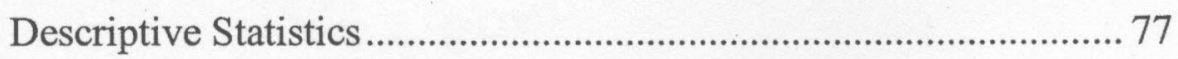

Financial Stress and Outcomes Model............................................. 78

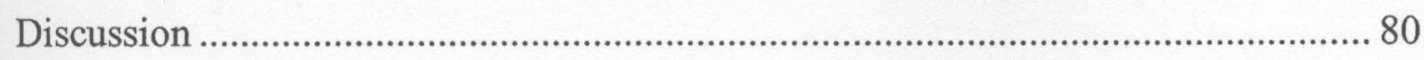

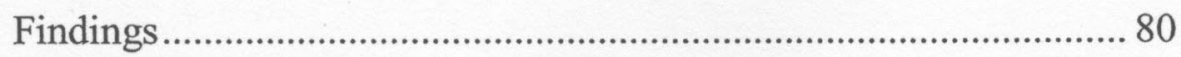

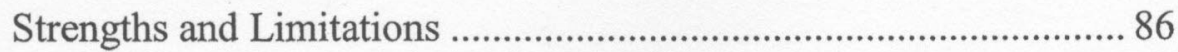

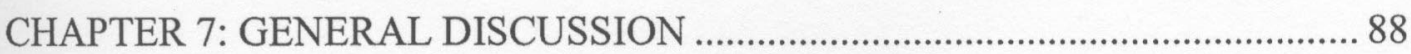

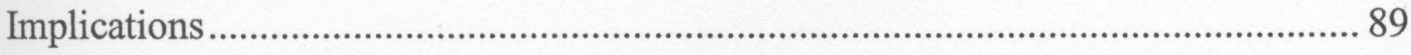

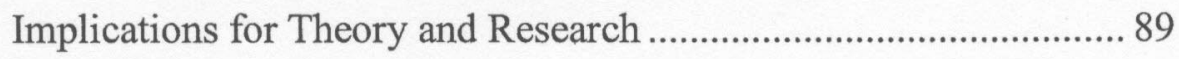

Implications for Practice .................................................................... 91 
Financial Stress vi

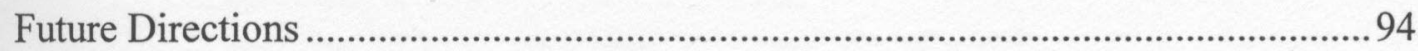

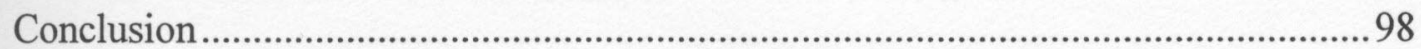

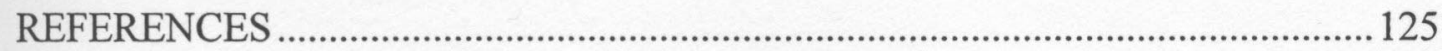

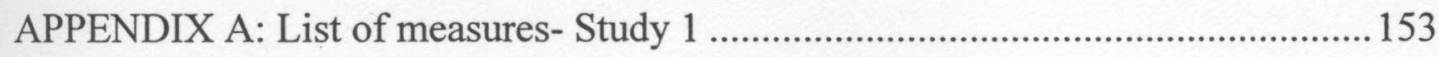

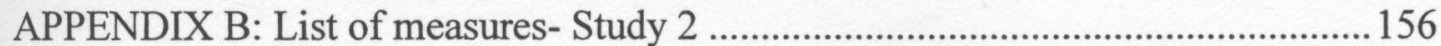




\section{LIST OF TABLES}

Table 1. Empirical Articles Containing Financial Stress Terms Published in

Top-Tier I/O Journals from 1998-2008. 99

Table 2. Sample of Operational Components of Financial Stress from Literature. 100

Table 3.Operational Components of Financial Stress from Graduate Students..... 103

Table 4. Means and Standard Deviations for All Financial Stress Items in

Study 1 104

Table 5. Exploratory Factor Analysis for Current Income Adequacy Scales in Study 1 106

Table 6. Exploratory Factor Analysis for Financial Strain in Study 1 107

Table 7. Descriptive Statistics, Alpha Coefficients, and Bivariate Correlations for Study 1 Variables 108

Table 8. Model comparison results for Study 1. 109

Table 9. Tests of Indirect Effects of Income and Expenses on Financial

Strain for Study 1 110

Table 10. Means and Standard Deviations for All Financial Stress Items in Study 2

Table 11. Exploratory Factor Analysis for Current Income Adequacy Scales in Study 2

Table 12. Exploratory Factor Analysis for Financial Strain in Study 2

Table 13. Descriptive Statistics, Alpha Coefficients, and Bivariate Correlations for Study 2. 
Financial Stress viii

Table 14. Model Comparison Results for Study 2.............................................. 115

Table 15. Bootstrap Confidence Intervals of Indirect Effects Mediated by Financial

Strain in Study 2 116

Table 16. Summary of Findings Across Studies 


\section{LIST OF FIGURES}

Figure 1. Voydanoff's (1990) Taxonomy of Economic Distress ........................ 118

Figure 2. Economic Stress Concept Map and Terminology................................ 119

Figure 3. Two-dimensional Content Domain of Perceived Income Adequacy ... 120

Figure 4. Hypothesized Model of the Financial Stress Process........................... 121

Figure 5. Hypothesized Model of Financial Stress and Outcomes for Study 2... 122

Figure 6. Model Results of the Financial Stress Process for Study 1 ............... 123

Figure 7. Model Results of the Financial Stress and Outcomes Model for

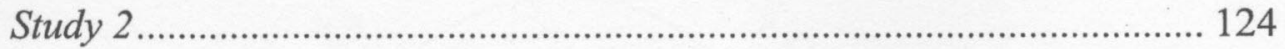




\section{GLOSSARY OF TERMS}

Downward mobility is the extent to which employees are moved to a lower ranking or lower paying job.

Economic stress encompasses both employment-related and financial stress each of which has objective and subjective components (Voydanoff, 1990).

Employment-related stress represents job insecurity and the objective extent and duration of current and past unemployment, underemployment, and extent of downward mobility (Voydanoff, 1990).

Financial satisfaction represents an individual's overall attitude toward their financial situation. It is typically viewed as a facet of life satisfaction.

Financial strain represents the affective response of worry or concern about one's financial situation.

Financial stress is the process by which individuals perceive their financial situation (household income and expenses) to be inadequate for affording their needs and wants (perceived income adequacy), which then leads to an affective strain response (financial strain).

Job insecurity represents an individual's subjective assessment of "prospects for the future regarding onset of, duration of and recovery from unemployment" (Voydanoff, 1990, p. 1103).

Objective financial situation refers to one's household income and household expenses in the currency of the country (e.g., US dollars, Chinese yuan, European euro). 
Pay equity is an individual's evaluation of pay in terms of what he/she things it should be, determined by a broad range of cognitive comparison referents. For instance, people tend to compare their pay to pay in past situations, the amount of effort they put forth, the pay of others, and/or their financial needs and lifestyle standards.

Pay satisfaction represents an individual's overall attitude toward their pay. It is typically viewed as a facet of job satisfaction. Pay equity perceptions predict pay satisfaction.

Perceived income adequacy to meet needs refers to evaluations of individuals' ability to afford life's basic necessities (e.g., food, shelter, basic clothing). From an equity theory perspective, it can also be viewed as a referent-specific type of pay equity comparison in which individuals compare their income to their wants.

Perceived income adequacy to meet wants refers to evaluations of individuals' ability to maintain a desired lifestyle and afford the things they want. From an equity theory perspective, it can also be viewed as a referent-specific type of pay equity comparison in which individuals compare their income to their wants.

Poverty is defined as when household income does not exceed a household-specific poverty threshold computed based on family composition and ages of family members (U.S. Census Bureau, 2007).

Underemployment as any one of the following conditions: when a person has a more formal education or skills than required by their job; when they are 
Financial Stress xii

involuntarily employed outside of their specialty area; when they are

involuntarily employed at part-time or temporary status; or when they are

earning $20 \%$ less than a referent with similar training, experience, etc.

(Feldman, 1996).

Unemployment is the condition where a person is a) without employment, b) eligible and available for employment, and c) currently seeking employment (Bureau of Labor Statistics, 2001).

The working poor represent individuals who are employed but whose household income is below their poverty threshold. 
Financial Stress 1

\section{CHAPTER 1: INTRODUCTION}

"Money is a headache, and money is the cure." (Mámor, n.d.)

“Get a good job with good pay and you're okay." (Waters, 1973)

"My mind on my money, and my money on my mind" (Casey, Young, Finch, \& Broadus, 1993)

With the onset of globalization, the economic contexts and working conditions within many countries are shifting, presenting new challenges for governments, organizations, and workers. The United States, for instance, has the largest economy in the world, but has lost many jobs to countries offering cheaper labor to organizations (Bureau of Labor Statistics, 2000, 2008). With jobs in high demand and the ever-present drive for companies to compete for lower costs and higher profits, many American workers have been forced to accept lower wages and fewer benefits (Heymann, 2006). The lack of paid leave and other protections for working individuals and families in need exacerbates this issue, with the result being that many Americans cannot adequately support themselves and their families (Heymann \& Barrera, 2008).

People in developing countries like the People's Republic of China (PRC) face similar financial problems, but for different reasons. While many of these countries' economies benefit from the influx of new jobs, they must keep labor costs low and productivity high to attract companies. As a result, these countries may lack the resources or incentives to enforce minimum wage regulations, work hour limits, and health and safety standards for workers (e.g., Barboza, 2008; Chossudovsky, 2003). In 
the PRC, specifically, average income levels have risen over the past few decades, however, income disparities have also risen (Zhao, 2006). In light of recent recordbreaking inflation levels, many lower-income workers (whose incomes have not risen at the same rate as middle- and upper-level income workers) are unable to afford basic necessities, like food and fuel (e.g., Bradsher, 2007).

The economic and regulatory contexts in the US and China have negative implications for many workers' ability to ensure stable employment and earn a decent wage, both of which are necessary for meeting survival needs and supporting a family. Income and employment, however, may mean different things to different people depending on their level of need and personal characteristics. Employment, for example, can offer workers a wage and benefits, but also a sense of purpose and identity, information about status and self-worth, and an opportunity to socialize (Jahoda, 1984). Income, aside from meeting basic needs, affects workers' ability to achieve a desired lifestyle (cf. Hobfoll, Freedy, Green \& Solomon, 1996; Peirce, Frone, Russell, \& Cooper, 1996), feelings of self-worth (McKee-Ryan, Song, Wanberg, \& Kinicki, 2005), and perceptions about how much their organization values their contribution (Rousseau, \& Ho, 2000). With money and work being so central to people's lives, worry about finances and employment can be a significant source of stress (Pearlin, Lieberman, Menaghan, \& Mullan, 1981; Probst, 2004; Voydanoff, 1990). The economic conditions in the US and PRC, therefore, present an opportunity for organizational researchers to understand how these financial concerns influence workers. 
The concept of economic stress, which encompasses both employment- and income-related stressors (Voyadanoff, 1990), has been addressed by researchers in psychology, sociology, and economics. Some of the more extensively-studied employment-related stressors are thoroughly reviewed in a chapter by Probst (2004); they include unemployment, underemployment, and job insecurity. Unemployment is the condition where a person is a) without employment, b) eligible and available for employment, and c) currently seeking employment (Bureau of Labor Statistics, 2001). Feldman (1996) identifies underemployment as any one of the following conditions: when a person has more formal education or skills than required by their job; when they are involuntarily employed outside of their specialty area; when they are involuntarily employed at part-time or temporary status; or when they are earning $20 \%$ less than a referent with similar training, experience, etc. Finally, job insecurity represents an individual's subjective assessment of "prospects for the future regarding onset of, duration of and recovery from unemployment" (Voydanoff, 1990, p.1103).

Some of the more commonly studied income-related stressors, hereafter referred to as financial stressors, include objective poverty and the working poor, evaluations of financial adequacy, and financial concerns or worries. According to the U.S. Census Bureau, poverty is defined as when household income does not exceed a household-specific poverty threshold computed based on family composition and ages (U.S. Census Bureau, 2007). The working poor represent individuals who are employed but whose household income is below the poverty threshold. Studies of income adequacy and financial worries differ drastically in their definitions of these 
constructs, which will be addressed further in Chapter 2. Moreover, these concepts have yet to be systematically explored in the organizational literature.

Although organizational psychologists have paid less attention to income and income perceptions as sources of stress, the negative impact of financial stress on individuals and families is actively discussed in several other academic disciplines, including developmental psychology (e.g., Aranda, \& Chi, 2007), economics (e.g., Lyons \& Yilmazer, 2005), public health (e.g., Olivius, Ostergren, Hanson, \& Lyttkens, 2004), and sociology (e.g., Whelan, 2001). It seems that this omission in the organizational literature can be attributed to a lack of interdisciplinary research that integrates work stress research with other research related to personal finances. Financial stressors are unique from other types of stressors typically studied in organizational research in that they do not necessarily originate in the work environment, and are not necessarily considered role stressors. Financial stressors can be thought of as chronic life stressors which occur over time and affect many aspects of an individual's life.

Because money is, first and foremost, an instrumental resource, Conservation of Resources Theory (COR; Hobfoll, 1989) would suggest that a threat, loss, or failure to regain money causes stress. Other research has used COR Theory to explain how stress itself, through a drain psychological resources, has the potential to affect performance and satisfaction across multiple roles (e.g., Edwards, Guppy, \& Cockerton, 2007; Frone, 2003; Hammer, Cullen, Neal, Sinclair, \& Shafiro, 2005). This 
thesis will advance the current literature by examining the effects of financial stress on employees in organizations.

\section{Linking Financial Stress to Work}

Most of the organizational research on financial stress to date has focused on unemployed populations (e.g., McKee-Ryan, et al., 2005); however, people experience financial stress regardless of their employment status (Creed \& Evans, 2002). It is important to examine this type of stress in an organizational context because it is prevalent among employees (Garman, Junk, Kim, O’Neill, Prochaska-Cue, Prawitz et al., 2005) and has negative implications for many other aspects of employees' lives, including their physical health (Olivius et al., 2004), psychological well-being (Mills, Grasmick, Morgan, \& Wenk, 1992), and marriage quality (Conger et al., 1994). In addition, organizations are in the position to offer instrumental support, training, opportunities for advancement, and policies which are likely to reduce employee financial stress.

\section{Prevalence of Employee Poverty and Financial Stress}

Objective poverty is prevalent among employees, in the US and world-wide (Bian, 2002; U.S. Census Bureau, 2006). Recent polls and labor statistics classify 36.5 million Americans as falling at or below the poverty line (12.3\%; U.S. Census Bureau, 2006 ) and about 6.8 million Americans as unemployed (4.5\%; Bureau of Labor Statistics, 2007). The Bureau of Labor Statistics (BLS; 2003) also classified $8.4 \%$ of employable Americans as being "underutilized," accounting for individuals who are unemployed, marginally attached, and employed part-time. The most recent estimate 
from the BLS (2003) categorized 7.4 million Americans, as working poor, representing 4.2 million families.

In the developing world, estimates from 2001 suggest that approximately 790 million people (about $13.2 \%$ of the world population) are chronically undernourished, almost two-thirds of whom reside in Asia and the Pacific (Wood, Seastian, \& Scherr, 2001). Again, poverty in developing nations is not limited to the unemployed. For example, the three poorest working social classes in rural People's Republic of China (PRC) make up $80 \%-85 \%$ of that rural population, including the Peasant Laborers (16\%-18\%), the New Working Class (16\%-17\%), and the Peasants (48\%-50\%; Bian, 2002).

While estimates of objective poverty rates are informative, other research has found that the psychological experience of economic stress is also prevalent among American employees. Belton (1999) estimated that 37\% of Americans experienced stress and worried about job loss during a time when the U.S. economy was doing well. A meta-analysis of business-sponsored surveys and academic studies found that an estimated 30 million working Americans, accounting for about $25 \%$ of the workforce, experience high levels of reported financial distress (Garman et al., 2005). While a meta-analysis of this scope does not yet exist for workers in other countries, several studies suggest that financial stress is a significant problem among individuals in both Eastern and Western cultures (e.g., Chou \& Chi, 2002; Krause, Liang, \& Gu, 1998; Olivius et al., 2004). Further, the large percentage of working poor in the PRC 
suggests that financial stress resulting from poverty is prevalent, especially among those who are earning low wages (Bian, 2002).

Pervasiveness of Poverty and Financial Stress

Another reason it is important to study the effects of financial stress among workers is because of its pervasive effects on employees' lives. Not only does financial stress account for a vast proportion of the overall reported stress an individual experiences (i.e., approximately 49\%; Bailey et al., 1998), but it is also associated with diminished marriage quality (Conger, Ge, Elder Jr, Lorenz, \& Simons, 1994; Vinokur, Price, \& Caplan, 1996), physical health (Olivius et al., 2004), psychological well-being (Mills, Grasmick, Morgan, \& Wenk, 1992), and life satisfaction (Bailey et al., 1998). There are a number of pathways through which objective poverty, perceptions about finances, and worry about finances can negatively affect employee health, well-being, and functioning. This should be of interest to organizations since health and well-being have implications for how well employees are able to perform their jobs.

First, money is critical for meeting basic survival needs. Without a decent household income, people are unable to afford basic necessities like food, shelter, utilities, and medicine. Moreover, money is necessary to obtain things that enable people to work, like basic clothing, child care, and transportation. In addition, a lack of financial resources might restrict people from engaging in social activities, acquiring wanted possessions, achieving their financial and/or life goals, or simply living the lifestyle they desire (Pearlin \& Radabaugh, 1976; Peirce et al., 1996). In all of these 
cases, the physical health, psychological well-being, and life satisfaction of workers and their families are likely to suffer.

Second, money serves as a symbol to many people. Money is often linked to some of the most basic symbolic qualities that people strive for, such as achievement, status, control, and power (Mitchell \& Mickel, 1999). Money is often used as a reward for achievements (Tang, 1992), creates respect from others (Goldberg \& Lewis, 1978), and gives people the power to change some things in life (e.g., where to live, education). Studies show that people who perceive their income to be inadequate also feel a low sense of self-worth and feel they have little control over their environment (Pearlin et al., 1981; Price, et al. 2002). Further, these studies found that perceived control and self-esteem mediate the effects of income adequacy on individual wellbeing.

Third, the financial situation itself can be a significant source of stress because it is so closely linked to all of these important aspects of an individual's life. Spending time and energy worrying about finances may become draining, leaving individuals with fewer psychological resources to allocate toward coping with other life demands. Not surprisingly then, the literature strongly supports the link between financial stress and important individual outcomes like physical health (Olivius et al., 2004), psychological well-being (Mills, Grasmick, Morgan, \& Wenk, 1992), and life satisfaction (Bailey et al., 1998). Proponents of COR Theory suggest that stress from various sources (e.g., work-family conflict, emotional labor) depletes one's resources (e.g., emotional energy), resulting in reduced performance and withdrawal from other 
roles including work (e.g., Gorgievski-Duijvesteijn, Bakker, Schaufeli, \& van der Heijden, 2005; Grandey, 2000; Grandey \& Cropanzano, 1999; Hobfoll \& Shirom, 1993).

Finally, financial stress can be damaging to family systems. It has been linked to partner conflict (Conger, Ge, Elder, Lorenz, \& Simons, 1994), withdrawal of social support from one's partner, increased social undermining of one's partner (Vinokur et al., 1996), and emotional and behavioral problems in adolescent children (Felner, Brand, DuBois, Adan, Mulhall, \& Evans, 1995). Having a strained family life can spillover and inhibit performance in other roles, such as performance at work (Frone, Yardley, \& Markel, 1997).

Taken as a whole, the problems associated with low-income and financial stress among workers are clearly insidious, carry important implications for organizations, and should be examined. In response to these concerns, the present thesis focuses on the ways in which financial stress directly affects working individuals.

The Organization as a Venue for Intervention

There are several ways in which changes within organizations could substantially reduce financial stress. Specifically, companies are in a prime position to offer instrumental support, financial education, opportunities for advancement, and protective policies to help workers with their financial difficulties and resulting stress. In addition to reducing financial stress, organizational interventions may possibly increase employee organizational commitment and enhance public perceptions of 
corporate social responsibility. While there are many approaches to preventing and remedying financial stress, more research is needed to make a business case for targeting financial stress in organizations. Then, further research can identify, implement, and test such interventions. First and foremost, if key stakeholders in organizations are made aware of the effects of financial stress on their organizational outcomes, they may be more motivated to invest in financial stress interventions.

\section{Gaps in Previous Research}

The prevalence and pervasiveness of financial stress among employees and corresponding opportunities for workplace intervention illustrate the need to study how financial stress affects worker and organizational outcomes. While literature on pay perceptions and attitudes is abundant (e.g., Shaw \& Gutpa, 2001), research in the specific area of financial stress lacks clear constructs, well-validated measures, and a comprehensive theoretical framework to capture the financial stress process. These gaps have hindered advancement of knowledge in this area. Further, while pay satisfaction and perceptions of pay equity have been linked to performance (e.g., Brett, Cron, \& Slocum Jr., 1995; Lawler, 1971; Staw, 1984), to my knowledge no research has examined the effects of financial stress on employee performance at work. Theory of Financial Stress

Studies from several disciplines (i.e., social psychology, community psychology, economics, and financial literacy) have established that income and income perceptions are linked to stress processes. Moreover, work stress researchers have drawn from Lazarus' cognition-based model of stress (Lazarus, 1966), and 
Conservation of Resources Theory (Hobfoll, 1989), to understand the resourceretaining mechanisms that produce stress and drive many of its outcomes. To my knowledge, researchers have yet to synthesize these models. Studying financial stress within such a theoretical framework allows for a better understanding of the underlying mechanisms and provides a structure for systematic research in the future. Operationalizations of Financial Stress

In addition to theoretical advances, conceptual and methodological work is needed to identify and operationalize the constructs involved in the financial stress process. The literature lacks a consistent operational definition of financial stress (or related concepts) as a construct. No studies that I know of have systematically explored the content domain of financial stress. Further, I have yet to find a validated scale for financial stress and its potential subdimensions. Many studies use proxy indicators such as income level, single-item indicators of income adequacy, and short strain-like scales for which I cannot find validation evidence. Without systematic validation studies, there is no way to assess the accuracy of these measures. Such research represents a necessary first step in establishing the need for and likely benefits of financial stress intervention.

\section{Lack of Organizational Research}

Although I/O psychological studies have examined how pay satisfaction and equity perceptions predict outcomes related to job performance and life satisfaction (e.g., George \& Brief, 1990; Lawler, 1971; Shaw \& Gutpa, 2001; Staw, 1984), very few I/O studies have directly examined financial stressors and strain. In fact, Table 1 
provides a frequency count of how many top I/O and OHP journal articles over the past 10 years mention key terms associated with financial stress and explicitly examine financial constructs. Out of 20 total journal articles that mention any one of the financial key words, only 12 of these studies explicitly measured a financial concept. This lack of attention is surprising considering the overwhelming evidence from other fields about the detrimental effects of financial stress on individual health and well-being.

Of the empirical work that has been done on issues related to financial stress, the majority of studies examine unemployed populations. While financial stress is a significant predictor of psychological well-being in these populations (McKee-Ryan et al., 2005), research by Jahoda (1984) and others suggest that losing the latent benefits of employment (e.g., time structure, social contact, common goals, status or identity, enforced activity) also contributes to poor psychological outcomes. Thus, the relationship between financial stress and individual outcomes should be tested in employed populations to completely rule out these alternative explanations. Also, studies of the unemployed, by definition, cannot consider the potential effects of financial stress on organizationally-valued outcomes, such as job performance and turnover.

\section{Summary and Purpose}

There is a need for research on financial stress as it relates to employee outcomes because of its prevalence in working populations, pervasive effects on employee health, well-being, and families, and promise for workplace interventions. 
The lack of comprehensive measures of financial stress and the absence of a theoretical framework, however, have made it difficult to understand how financial stressors and strain affect employees. Therefore, the purposes of this thesis are to a) systematically explore the construct of financial stress (Chapter 3), b) propose and test a theoretical model linking financial stress to worker life satisfaction and job performance (Chapter 4), and c) examine differences in the financial stress process across American and Chinese workers (Chapters 5 \& 6). 


\section{CHAPTER 2: STRESS AND RESOURCES}

This chapter begins with a general discussion of the stress process with regard to Lazarus' Transactional model (1966). Then, I provide an overview of Conservation of Resource (COR) Theory (Hobfoll, 1989) and describe how it has been used to understand the affective, cognitive, and behavioral outcomes of stress. Finally, I show how resource-based models like COR apply to the study of financial stress.

\section{Stress as a Process}

Stress models have been categorized into stimulus, response, and stimulusresponse models (Sulsky \& Smith, 2005). Stimulus definitions consider stress to be a threatening stimulus in the environment, usually described as a stressor. Response definitions of stress focus on individual reactions to stressors, typically described as strain. For instance, early physiological stress research by Cannon (1929) and Selye (1956) defined stress in terms of the biological responses elicited by a.stimulus (e.g., fight or flight response). Later definitions, which focused on psychological aspects of the stress response, define it as a dynamic process reflecting the relationship between environmental stimuli and responses to those stimuli (Beehr \& Franz, 1987; Lazarus \& Folkman, 1984).

Researchers today typically describe stress as a process by which an environmental stimulus is perceived as threatening, referred to as a stressor, and leads to a short-term affective, cognitive, and/or physiological response known as strain (e.g., feelings of worry or concern, trouble concentrating, elevated blood pressure, respectively). Psychological strain represents the impairment of cognitive functioning 
and/or disturbed affect after a stressor occurs, while physiological strain represents a stress response in which there is a change in the body (Gross, 1970). Over time, chronic exposure to strain leads to long-term consequences for health (Karasek \& Theorell, 1990), psychological well-being (van der Doef \& Maes, 1999), job attitudes (Netemeyer, Johnston, \& Burthon, 1990), job performance (Jex, 1998), and retention (Schaubroeck, Cotton, \& Jennings, 1989). This stressor-strain-outcome framework is commonly utilized in modern conceptualizations of stress (e.g., Bliese \& Castro, 2002; Sulsky \& Smith, 2005; Tetrick, Slack, Da Silva, \& Sinclair, 2000).

\section{Lazarus' Transactional Model}

An important aspect of the stress process introduced by Lazarus and colleagues (1966) is the idea of cognitive appraisal. Lazarus and Folkman (1984) emphasize that stress occurs when an environmental stimulus is "appraised by the person as taxing or exceeding his or her resources and endangering his or her well-being" (p. 19). This assumes that an environmental stimulus is not in fact a stressor unless it is perceived as such, and is therefore best referred to as a potential stressor (Sulsky \& Smith, 2005). For example, among sales employees who are paid based on their performance, some people perceive that situation to be threatening to their financial resources and endangering their financial well-being, while others see it as a challenge.

Lazarus posits that individuals first determine if the situation is stressful or threatening (primary appraisal), then select a coping response (secondary appraisal), and potentially reassess the situation to determine if the response was sufficient and determine other ways to respond if necessary (reappraisal). During primary appraisal, 
the extent to which an individual appraises an environmental stimulus as negative or threatening depends on personal, group, and situational characteristics. It is, therefore, important to measure perceived stressors, not potential stressors (Lazarus, 1966; Sulsky \& Smith, 2005). For instance, two individuals in the same financial situation could evaluate and respond to that situation quite differently depending on how much they value material possessions. A materialistic individual who values the acquisition of possessions might perceive their income as particularly inadequate for affording their lifestyle (i.e., wants; Richins \& Dawson, 1992), while a less materialistic person with the same financial demands and resources might view their income as adequate for affording wants. By measuring the extent to which an individual perceives a stressor instead of relying on objective measures, researchers can account for these individual, group, and situational differences that might moderate the potential stressor-perceived stressor relationship.

While not central to the present study, it is important to note that Lazarus' (1991) notion of secondary appraisal deals with decisions regarding reaction and coping processes. He argues that there are three considerations people make during secondary appraisal: the attribution of blame or credit to oneself or others, the potential for coping to influence the situation for the better, and the extent to which one expects positive or negative change in the future. Research suggests that positive expectations about the future buffer the negative effects of stress (Chang, 1998; Fryer \& McKenna, 1987). For instance, the expectation that stressful conditions will improve in the future mitigates the negative effects of stress. 
While Lazarus' model is useful in understanding how the stress process occurs, there is also a need to understand the theoretical mechanisms which lead to strain responses and outcomes. For this, COR Theory has been used as a resource-based explanatory model to better understand the mechanisms causing stress and subsequent reactions.

\section{Conservation of Resources Theory}

COR theory operates on the basic assumption that individuals "strive to obtain, retain, protect, and foster those things that they value" Hobfoll, 2001, p. 341). These valued things are called resources and include objects, personal characteristics, conditions, or energies or means for attaining these things (Grandey, 1999; Hobfoll, 1989). Whenever resources are threatened, lost, inadequate for meeting demands, or not regained after a significant investment, psychological stress will occur (Hobfoll, 2001; Treadway, Ferris, Hochwarter, Perrewe, Witt, \& Goodman, 2005).

COR theory suggests that when employees face a situation where resources are threatened or lost, they might withdraw or withhold effort to preserve their resources and prevent further resource loss (Leiter, 1991). Employee withdrawal can manifest through employee attitudes or behaviors. Attitudinal withdrawal might include lower engagement, commitment, or satisfaction. Behavioral withdrawal could take the form of reduced performance, discontinued citizenship behaviors, increased counterproductive work behaviors, lateness, absenteeism, and quitting. An example of this exists in research on work-family balance, which argues that stressful processes like juggling work and family roles result in a loss of resources (e.g., Cullen \& 
Hammer, 2007; Grandey \& Cropanzano, 1999; Hammer, Bauer, \& Grandey, 2003; Witt \& Carlson, 2006). When resources approach threateningly low levels, individuals withdraw in order to conserve personal resources and avoid further resource loss (Grandey \& Cropanzano, 1999).

\section{Financial Stress and Resources}

COR theory is applicable to this study in two ways. First of all, money itself is a resource. According to the theory, the extent to which an event or situation is stressful depends on one's perception that it threatens resources or is inadequate to meet demands. Thus, COR would suggest that a perceived loss of or insufficient financial resources will lead to strain. This analysis supports the proposition that perceived income adequacy mediates the relationship between one's objective financial situation and financial strain.

Secondly, when viewed from a COR perspective, psychological strain is conceptualized as a drain in psychological resources. These emotional, cognitive, and physical energies might be drained from the strain of one's financial situation. Wright and Cropanzano (1998) argued that emotional energy, specifically, is a resource which is instrumental in overcoming daily stressors in the workplace and maintaining acceptable performance levels. When employees are emotionally exhausted, not only are they less capable of dealing with work-related stressors, but they lack the energy to perform their job tasks well. As financial strain depletes emotional resources, COR suggests that individuals will attempt to protect and retain their remaining resources and may do so by withdrawing energy from their job. 


\section{Summary}

Cognitive appraisal models of stress like Lazarus' transactional model are useful in conceptualizing the stress process. An environmental stimulus, when perceived to be threatening, is considered a stressor which causes psychological and physiological responses known as strain. Overtime, prolonged exposure to strain can leads to adverse psychological, physical, and behavioral outcomes. COR theory explains the resource-based mechanisms influence strain and behavioral responses to stress. In the case of financial stress, the perception of threatened, lost, or insufficient financial resources causes strain, viewed from this perspective as a drain in psychological resources or energies. In an effort to protect and avoid further loss of resources, workers may withdraw these psychological resources from their work, family, or other life roles. 


\section{CHAPTER 3: FINANCIAL STRESS}

With an understanding of how potential stressors may be perceived as stressors and lead to strain, I now turn the discussion toward economic stress. Past research has offered many different definitions of economic stress and related variables such as financial/economic stress, economic/financial strain, financial/economic hardship, and financial/economic deprivation. In this chapter, I provide an overview of economic stress followed by a more focused review of financial stress and its components. Finally, I propose an integrative definition of the financial stress process within a stressor-strain-outcome framework.

\section{Economic Stress}

Voydanoff (1990) was the first to propose a comprehensive taxonomy of economic stressors (Figure 1). According to her model, economic distress encompasses both employment-related and income-related stressors. This is an important distinction; my paper focuses primarily on income-related economic stress, in part because job insecurity has been heavily studied (cf. Probst, 2003). Each of these categories then consists of both objective and subjective dimensions. This proposed two-by-two matrix results in four categories of economic stressors. Regarding the employment-related economic stressors, employment instability is defined as the objective extent and duration of current and past unemployment, underemployment, and extent of downward mobility. Employment uncertainty represents an individual's subjective assessment of "prospects for the future regarding onset of, duration of and recovery from unemployment" (Voydanoff, 1990, pp.1103). 
Employment uncertainty is commonly referred to as job (in)security in the $\mathrm{I} / \mathrm{O}$ literature (e.g., Probst, 2003).

According to Voydanoff (1990), income-related, or financial stress includes economic deprivation, defined as the objective inability to meet current financial needs and a loss of income and financial resources. The subjective counterpart to deprivation is economic strain, which she defined as "an evaluation of current financial status such as perceived financial adequacy, financial concerns and worries, adjustments to changes in one's financial situation, and one's projected financial situation" (Voydanoff, 1990, p. 1104). The proposed concept of economic strain includes several underlying dimensions that this paper will clarify. I propose that Voydanoff's "income-related stress" be referred to as "financial stress", because the word "financial" includes unemployed or other individuals who may be without income altogether yet who still may experience this type of stress. The word "financial" also accounts for issues related to debt, assets, and expenses, not just income (see Figure 2 for conceptual map of terminology).

Probst (2004) expanded this line of research by proposing a model which integrated the predictors and outcomes of economic stress. Probst's model, however, dealt only with commonly-studied, employment-related stressors (i.e., unemployment, underemployment, and job insecurity). She did not propose links to Voydanoff's (1990) income-related stressors (i.e., economic deprivation and economic strain), nor has such a model been developed to my knowledge. 


\section{Financial Stress}

Research shows that financial stress can span the spectrum of wealth and is not only specific to low-income and unemployed populations (Whelan, 1992). Imagine a single father with two children. He works two part-time jobs, neither of which offer benefits, and is still rarely able to pay all of the bills on time. Now imagine a high-rate lawyer who, with her husband, supports three children. They just bought an expensive beach house, which has overextended their budget. Now, the couple must struggle to make payments on both their home and beach house. In both of these scenarios, individuals experience financial stress but for different reasons. While the specific reasons and actual wealth of the individuals differ across these scenarios, the psychological experience of financial stress may be similar. It is important to note, however, that the working poor population is likely to be more susceptible to financial stress than middle- or upper-class employees due to low hourly wages, less resources to afford help with care-giving responsibilities, and lack of financially-related job benefits like healthcare coverage, paid leave, and employer-provided financial assistance to purchase child care services (Heymann, Boynton-Jarrett, Carter, Bond, \& Gallinsky, 2002). Nevertheless, the purpose of this thesis is not to argue the conditions under which well-being and behavior is more significantly influenced by financial stress, but just to establish evidence that financial stress generally influences these outcomes.

Although there has been much discussion in the I/O literature regarding definitions of employment-related economic stress components (e.g., unemployment, 
underemployment, job insecurity; Feldman, 1996; McKee-Ryan et al., 2005; Probst, 2003), relatively few papers have differentiated financial stress constructs. In fact, there are almost as many operationalizations of financial stress as there are papers that examine them, and so there is a need to systematically identify this content domain. To do this, I scanned the relevant literatures (i.e., psychology, sociology, and economics) and collected existing operationalizations of financial stress and related constructs. Then I reviewed all these constructs for common themes.

Three definitional components were consistent throughout these operationalizations. First, some conceptualizations include the idea of objectively calculating financial demands and/or resources. Second, many conceptions of financial stress involve the extent to which people perceive or evaluate their income as being adequate or able to meet their financial demands. Finally, financial stress is often defined in terms of the affective reaction to one's financial situation, including feelings of worry, concern, pressure, or stress. Table 2 lists these constructs, provides their definitions from the literature, and specifies which themes are present in each definition. For each of these three components, I discuss existing operationalizations in the literature and propose a definition, operationalization, and title that appropriately represent each construct.

\section{Objective Financial Situation}

Many studies partly or wholly define financial stress as an objective phenomenon in which individuals or households have low income, high demands, or do not have sufficient resources to accommodate financial demands. Voydanoff 
(1990) called this objective aspect of financial stress economic deprivation, while others have called it economic hardship (e.g., Simons, Lorenz, Conger, \& Wu, 1992), financial need (e.g., George \& Brief, 1990) and more generally, economic stress and economic pressure (e.g., Conger, Elder Jr., Lorenz, Conger, Simons, \& Whitbeck, et al., 1990; Takeuchi, Williams, \& Adair, 1991).

Some of the operationalizations for this construct include calculations of household income (e.g., Sinclair \& Martin, 2006), changes in income (e.g., Elder Jr \& Caspi, 1988), income as it relates to other people's income within the sample or within a population (e.g., Fox, Benson, DeMaris, \& Wyk, 2002), financial resources as they relate to financial demands (e.g., Conger, et al., 1990), debt-to-asset ratios (e.g., Simons, Lorenz, Conger, \& Wu, 1992), and calculations of household factors that represent financial demands. In the I/O literature, George and Brief (1990) developed a scoring procedure to measure financial need/requirements based on one's marital status, the employment status of one's marital partner (should he/she exist), number of dependents, and number of working dependants (should they exist). This measure has been used in a number of other studies in the organizational literature as well (i.e., Brett et al., 1995; Doran et al., 1991; Shaw \& Gupta, 2001).

While informative and sometimes quite innovative, some objective measures may be better at capturing differences in financial stress than others. For instance, measuring household income alone or relative to a sample or population is insufficient because it does not account for a family's financial demands. A single person with no dependants has the same household income as a married person with two children, but 
they have very different levels demands and potentially experience quite different levels of financial stress. Similarly, it is inappropriate to measure only financial demands because it does not account for financial resources. A working married couple with 2 children could have a substantially different income than another working married couple with 2 children. Although they have the same demands, differences in their financial resources are likely to result in different levels of financial stress.

Whelan (1992) supports the need for a relative definition of poverty, suggesting that objective measures should focus on household income and the demands of that household. He and other researchers have further emphasized that deprivation, or not having enough income to fulfill financial obligations, can occur at any income level (e.g., Halleröd, Larsson, Gordon, \& Ritakallio, 2006; Whelan, 1992). Using measures of relative deprivation alone (e.g., subtracting demands from resources), however, may make it more difficult to identify households that are truly impoverished (Whelan, 2001). This is because discrepancy measures provide no information about income levels. To understand how income and expense levels affect outcomes, researchers need to use distinct measures of income and expenses.

\section{Perceived Income Adequacy}

While income and expenses are good objective indicators of financial stress, objective measures do not capture employees' subjective experience of financial stress. Subjective constructs most likely mediate the relationship between objective demands/resources and outcomes. As suggested in several stress models (e.g., Lazarus 
\& Folkman, 1984), objective financial measures should be distinguished from the more subjective evaluative and affective responses they elicit because accounting for both enhances understanding of the process leading to outcomes (cf. Whelan, 1992).

Perhaps the most popular definitional component of financial stress is the evaluation that one's income is capable of fulfilling demands, which includes affording both general and specific things that are needed and wanted. Like the previous objective financial stress construct, there are many names for this component of stress: economic/ financial strain (e.g., Pearlin et al., 1981; Voydanoff, 1990), economic/ financial/ lifestyle deprivation (e.g., Voydanoff, 1990; Waters \& Moore, 2002; Whelan, 1992), financial stress (e.g., Kim \& Garman, 2003), income adequacy (e.g., Ackerman \& Paolucci, 1983), and income sufficiency (e.g., Witt \& Wilson, 1990).

The idea that people evaluate an outcome like pay in comparison to some kind of cognitive standard or referent has its roots in equity theory (Adams, 1963; Lawler, 1971). According to this perspective, appraisals of a person's situation are influenced by their actual situation and what he or she thinks it should be (Lawler, 1971). To determine what the situation should be, research on pay equity has found that people tend to compare their pay to pay in past situations, the amount of effort they put forth, or the pay of others (Adams, 1963). Taylor and Vest (1992) examined several of these comparison referents including an economic referent that involved comparisons of pay level to the cost of living and the cost of meeting one's own needs. Similarly, Williams (1995), when developing a model explaining benefit satisfaction, included 
need-related antecedents such as family composition and health of family members. Taken together, this research suggests that employees do evaluate their pay relative to their level of economic need and possibly lifestyle standards. The concept of pay equity represents comparisons made with what a person thinks they fairly deserve, while income adequacy refers to a comparison with what a person needs and/or wants.

Similar to this idea are the even broader concepts of pay and financial satisfaction. Financial satisfaction is typically viewed as a facet of life satisfaction (Diener \& Diener, 1995), while pay satisfaction is more specific to the work context, and usually defined as a facet of job satisfaction (Michell \& Mickel, 1999). Pay equity evaluations are important predictors of both pay and financial satisfaction (e.g., Diener \& Diener, 1995; Scholl, Cooper, \& McKenna, 1987). Therefore, income adequacy, when viewed as the comparison between a person's actual situation and their needs and wants, would also be related to more global constructs of pay and income satisfaction.

Researchers have captured the idea of income adequacy in terms of one's perceived ability to meet demands. Some indicators include the ability to making ends meet (e.g., Pearlin, et al., 1981; Whelan, 1992), ability to meet financial needs (e.g., Voydanoff, 1990), ability to meet current expenses (e.g., Lyons \& Yilmazer, 2005), having difficulty paying bills (e.g., Gorgievski-Duijvesteijn et al., 2005), and having financial setbacks (e.g., Peirce et al., 1996). Some studies rely on a single item indicator similar to the item developed by Stewart and Archbold (1996) asking participants "Which of the following four statements describes your ability to get 
along on your income?" Response options include: "we can't make ends meet"; "we have just enough, no more"; "we have enough, with a little extra sometimes"; and "we always have money left over". Some more specific indicators include being able to replace worn out tools (e.g., Gorgievski-Duijvesteijn et al., 2005), save and invest for retirement (e.g., Kim \& Garman, 2003), and afford specific items (e.g., housing, food, healthcare, clothing, household items; Pearlin et al., 1981; Whelan, 1992). Among these specific demands, researchers have distinguished between the ability to afford basic needs (e.g., food, shelter, medicine, needed transportation) and affording wants (e.g., entertainment, unnecessary clothing or household items, leisure travel; Waters \& Moore, 2002; Whelan, 1992).

Needs and wants. Pearlin and colleagues (1981) defined economic strain as "the difficulty people have in acquiring both the necessities of life.... and some of its more optional accoutrements" (p. 344). In his work exploring the measurement and effects of poverty, Whelan (1992) asserted that there are indeed two types of deprivation: primary deprivation, referring to the inability to afford things deemed as necessities by society, and secondary deprivation, or lifestyle deprivation, defined as the inability to afford things that are desired but deemed as non-necessities by society. $\mathrm{He}$ argues that measuring both of these dimensions is essential in that they both lead to the experience of financial strain and psychological distress.

Current and future. In her definition of economic strain, Voydanoff (1990) includes the idea of expectations about "one's projected financial situation" (p. 1104). Shek (2003) similarly defines the construct of perceived economic stress in terms of 
current economic hardship and future economic worry. Some stress research suggests that the consideration of future expectations influences how stress response and coping decisions are made (Lazarus, 1991; Perrewe \& Zellars, 1999). Thus, a distinction should be made between the extent to which current financial resources are able to meet financial demands and the extent to which expected future financial resources will be able to meet future demands. Most conceptualizations of income adequacy frame items in terms of one's current situation, but Lazarus's transactional model (1991) suggests that individuals consider future expectations when deciding how to respond to a potential stressor. Given the case of financial stress, expectations that one's financial situation will improve in the future may help individuals cope during the financial stress process.

Some studies have supported this notion, showing that future expectations regarding one's financial situation influence psychological outcomes. Fryer and McKenna (1987), for example, conducted a study of unemployed adults and found that those who were only temporarily laid off had significantly better psychological well-being during unemployment than those who were permanently laid off. These results, however, could have been due to the anticipated return of the latent benefits of working expected by the temporarily laid-off workers (i.e., social interaction, time structure, common goals), and not the manifest advantages (i.e., income and benefits; Jahoda, 1984). Although expectations about one's future financial situation are theorized to play a role in financial stress processes, coping mechanisms are beyond 
the scope of this study but will be considered for future research. For the purposes of this study, I will focus on perceptions of current income adequacy.

Taken together, this research suggests a two-dimensional content domain of perceived income adequacy, as depicted in Figure 3. This domain distinguishes perceptions about basic needs from perceptions about lifestyle wants, and distinguishes current perceptions from future-oriented expectations, leading to four types of perceived income adequacy: meeting current needs, current wants, future needs, and future wants. One goal of this study is to develop a measure that reflects this proposed framework. Specific perceptions of wants and needs are expected to vary depending on cultural values and societal expectations (Whelan, 1992). In addition, Chiu and Kosinski (1995) note that stress processes may be similar across cultures but perceptions of specific stressors are likely to differ depending on cultural orientations and values. Therefore, because the concept of perceived income adequacy represents perceived stressors, culturally-sensitive scales are required to capture this construct.

Since the perceived adequacy of one's income is evaluative in nature, terms identifying it as a type of strain response to financial stressors is inappropriate. Further, labels indicating poverty, such as financial deprivation, are inappropriate because judgments of income adequacy do not necessarily indicate poverty or deprivation. Consider a wealthy individual who is financially overextended; that person may evaluate his or her financial resources as being inadequate, but the individual is by no means destitute. As it is an evaluative perception of the sufficiency 
or adequacy of one's income, this construct is appropriately termed perceived income adequacy.

\section{Financial Strain}

Financial stress has also been defined in terms of one's experience of worry, concern, pressure, or stress. The experience of worry or concern in response to a stressor is a type of affective disturbance which would constitute a type of psychological strain (Beehr \& Glazer, 2005). Unlike general conceptualizations of affective strain, this affective response of worry and concern is specific to one target, namely one's financial situation. Asking about domain-specific strain is justifiable in the case of financial stress because this type of stress, unlike others, is widespread, cuts across multiple roles and life domains, and can affect anyone. Researchers have referred to this response to financial stressors as financial stress (e.g., Bailey et al., 1998), financial strain (e.g., Vinokur et al., 1996), and economic stress (e.g., Elder \& Caspi, 1988). Since it is typically conceptualized as an affective stress response to one's financial situation, the term financial strain most appropriately captures this idea.

It is important to distinguish perceived income adequacy from the physical, affective, or cognitive strain responses it may elicit (e.g., elevated blood pressure, feelings of worry or concern, distraction). Many of the existing definitions of financial stress conceptualize one's perception of financial adequacy and one's affective reaction to these perceptions as being one construct. For instance, Vinokur and colleagues (1996) characterize financial stress as "perceived economic pressure" (p. 
166) suggesting that the construct encompasses both one's cognitive perception as well as one's affective feelings of pressure. This is problematic in that the concepts represent two fundamentally different psychological processes.

Probst (2003), when distinguishing between job security and job security satisfaction, argued that separating cognitive elements of perceived stressors from their resulting affective elements allows researchers to examine potential moderators to the perceived stressor-strain relationship. Further, this partition allows researchers to hypothesize both cognition-based and affect-based pathways leading to outcomes, providing a clearer understanding of theoretical mechanisms at play. For instance, a direct relationship between perceived income adequacy and performance might implicate an equity-based theoretical explanation. On the other hand, a direct relationship between an affective strain response and performance would suggest a resource-based explanation.

\section{Summary}

Stress is defined as the process by which an environmental stimulus is perceived as threatening (perceived stressor) and leads to a short-term affective, cognitive, and/or physiological response known as strain. Economic stress is comprised of employment-related stress, which includes employment instability and job insecurity, and financial stress. The concept of financial stress contains three key ideas: the objective financial situation, perceived income adequacy, and financial strain. One's objective financial situation can be appropriately represented by measures household income, household expenses. Perceived income adequacy to 
afford needs refers to individuals' evaluations of their ability to afford life's basic necessities (e.g., food, shelter, basic clothing). Perceived income adequacy to afford wants refers to individuals' evaluations of their ability to maintain a desired lifestyle and afford the things they want. These income adequacy perceptions can be considered in terms of both current and future income, though this study deals only with perceptions of current income. Financial strain represents the affective response of worry or concern about one's financial situation. Financial stress, therefore, is defined as the process by which individuals perceive their financial situation (household income and expenses) to be inadequate for affording their needs and wants (perceived income adequacy), leading to an affective strain response (financial strain). Appendix A provides a glossary of these and other relevant terms. In the following section, I explain how these aspects of financial stress interrelate.

\section{The Financial Stress Process}

While many researchers have proposed models containing one or more of the aforementioned components in financial stress models (e.g., Conger et al., 1994; Voydanoff, 1990), no framework links these elements into a single comprehensive model. Integrating the definitional components of financial stress using Lazarus' framework, one's objective financial situation (i.e., income-expense discrepancy) would be considered a potential stressor. Perceived income adequacy reflects the cognitive evaluation of one's objective financial situation, specifically regarding ability to afford needs and wants, and thus represents a perceived stressor. Financial strain is the affective reaction to perceived financial stressors and therefore represents 
the strain dimension. Following this framework, I propose that financial stress is the process by which individuals perceive their objective financial situation to be inadequate (perceived income adequacy) which then leads to a negative affective response (financial strain). Figure 4 presents a model of this stress process. Prolonged exposure to such strain is likely to lead to negative long-term consequences for employees and their organizations (more fully discussed in Chapter 3).

\section{A Mediation Model of Financial Stress}

Based on the stressor-strain-outcome model and Lazarus' argument for the cognitive appraisal of potential stressors, income adequacy perceptions should mediate the relationship between household level finances (income and expenses) and financial strain. Empirical evidence supports the relationship between objective measures of one's financial situation and appraisal of the financial situation (Conger et al., 1990; Pearlin et al., 1981; Simons et al., 1992). Pearlin and colleagues' (1981) paper on the stress process found that changes in income were negatively related to income adequacy perceptions. Although income changes indeed elicit an evaluative response, income alone as an indicator fails to account for the possibility of changing financial demands. Individuals might differ in their financial obligations or in how they evaluate the situation (cf. McKee-Ryan, et al., 2005). In their work on marital quality and stability, Conger and colleagues (1990) found a significant negative relationship between household income-to-needs ratio and perceptions of income adequacy. While it accounts for both financial needs and resources, a more straightforward way to 
capture financial troubles would be to directly account for both household expenses and household income as predictors of adequacy perceptions.

Finally, objectively-calculated family income per capita predicted perceptions of sufficient income among mothers and fathers (Simons et al., 1992). A per capita measure of income is a progressive step toward accounting for financial need; however, some household members may take up more financial resources than others. For instance, an elderly relative living in a household may require significantly more financial resources than a toddler. Given that the differences between household members may confound per capita measures, I propose to measure an individual's financial resources and needs at the household level.

To my knowledge, no studies have examined the relationship between perceived income adequacy and financial strain because few studies have distinguished the two constructs. Nevertheless, the stress literature supports that perceived stressors precede strain reactions (Lazarus, 1966; Lazarus \& Folkman, 1984). I propose that an individual's objective financial situation, best captured in terms of household income and household expenses, predict his/her perceptions of income adequacy to afford needs and wants. These income adequacy perceptions, in turn, predict financial strain. A visual representation of this mediation model is presented in Figure 4.

Hypothesis 1a: Perceived income adequacy to afford needs mediates the relationship between income and financial strain. 
Hypothesis 1b: Perceived income adequacy to afford wants mediates the relationship between income and financial strain.

Hypothesis 2a: Perceived income adequacy to afford needs mediates the relationship between expenses and financial strain.

Hypothesis 2b: Perceived income adequacy to afford wants mediates the relationship between expenses and financial strain. 


\section{CHAPTER 4: OUTCOMES OF FINANCIAL STRESS}

Financial stress leads to negative outcomes for individuals, families, and organizations. It has been linked to psychological outcomes such as psychological well-being, life satisfaction, and clinical depression (e.g., Bailey et al., 1998; Hu, et al., 2007; McKee-Ryan et al., 2005). Financial stress is also associated with poor physical health and alcohol use (McKee-Ryan et al., 2005; Olivius et al., 2004; Peirce et al., 1994). Regarding familes, research has linked financial stress to marital problems (Conger et al., 1994; Vinokur et al., 1996) and the health and well-being of children (Conger et al., 1994; Felner et al., 1995; Heymann et al., 2002). Finally, research examining financial stress and organizational outcomes has discovered relationships between financial stress and job satisfaction (Bailey et al., 1998), organizational commitment, absenteeism (Kim \& Garman, 2003), and productivity (Kim, Sorhaindo, \& Garman, 2004).

In this thesis, I focus on two important outcomes, namely life satisfaction and job performance. By linking financial stress to a psychological health outcome such as life satisfaction, I am able to confirm prior research and establish criterion-related validity evidence for new financial stress scales. Another aim of this study is to extend prior research and theory by linking financial stress to job performance, specifically task performance and organizational citizenship behavior.

\section{Life Satisfaction}

I selected the psychological health outcome, life satisfaction, for several reasons. First, life satisfaction is an "indispensible component of positive 
psychological well-being”' (Diener, Sapyta, \& Suh, 1998; p. 33). Diener et al. (1998) also remarked that the great philosopher, Aristotle, thought of happiness as "the final and sufficient goal for which all other goals were sought" (p. 34). Thus, it is a central health outcome to examine. Second, financial stress is conceptualized in this study as a psychological phenomenon and so linking it to psychological health outcomes is a logical first step in a systematic exploration of the construct's predictive validity. Third, life satisfaction has theoretical linkages to financial strain and is, therefore, a reasonable outcome. For instance, financial strain can affect people's psychological resources (Hobfoll, 1989), affective states (Warr, 2005), and other negative health and family outcomes (Conger et al., 1994; Peirce et al., 1994), which, in turn, can influence attitudes about one's life (Atchley, 1991; Palmer, Donaldson, \& Stough, 2002). Lastly, life satisfaction is a relevant outcome to organizations. Employees who are happy tend to be more creative (Isen, Daubman, \& Nowicki, 1987), be more resilient to adversity (Folkman \& Moskowitz, 2000), and have better health than those who are unhappy (Fredrickson \& Losada, 2005; Fredrickson, Mancuso, Branigan, \& Tugade, 2000). By linking financial stress to life satisfaction and highlighting these benefits to organizations, researchers and practitioners can make a business case for potential financial stress interventions.

The general concept of psychological health consists of six dimensions: subjective well-being, positive self-regard, competence, aspiration, autonomy, and integrated functioning (Warr, 2005). Subjective well-being, generally thought of as happiness or life satisfaction, reflects the feelings and judgments regarding one's life 
(Andrews \& Withev, 1976; Diener \& Emmons, 1984). Life satisfaction, therefore, contains both a cognitive component (a set of beliefs or evaluations about one's life) and an affective component (feelings or emotions elicited by one's life; Baron \& Byrne, 1981), though researchers differ in the extent to which they emphasize each dimension in life satisfaction research (Warr, 2005).

Life satisfaction theory proposes that predictors such as perceptions of mastery, progress toward goals, participation in enjoyable activities, positive interpersonal relationships, and dispositional attributes influence one's life satisfaction (Diener et al., 1998). Bottom-up theories tend to view life satisfaction as the result of positive and negative experiences. According to this perspective, life satisfaction is conceptualized as the result of satisfaction in more specific life domains (e.g. job satisfaction, marital satisfaction; Brief, Butcher, George, \& Link, 1993; Diener, 1984). On the other hand, top down explanations attribute life satisfaction to dispositional characteristics of the individual, assuming people are inclined to react positively or negatively to life events (Brief et al., 1993). While both perspectives are valid and interesting to examine, this thesis takes a bottom-up approach, focusing on the ways in which financial strain affects life satisfaction.

\section{Financial Stress and Life Satisfaction}

There is considerable evidence to suggest that financial strain is an important predictor of life satisfaction (e.g., Bailey et al., 1998; McKee-Ryan et al., 2005). Moreover, greater financial strain leads to decreased life satisfaction among members of both individualistic and collectivist cultures (e.g., Chou, Chi, \& Chow, 2004; Creed 
\& Evans, 2002; Creed \& Muller, 2006; Shek, 2003). There are several theoretical explanations for this relationship. First of all, COR Theory suggests that affective strain drains emotional resources leaving individuals with fewer resources to cope with daily stressors and to allocate toward performance in various roles (Hobfoll \& Shirom, 1993; Wright \& Cropanzano, 1998). Drained emotional resources may inhibit an individual's ability or desire to engage in enjoyable activities, interact with others, and seek social support, all of which are positively associated with life satisfaction (Diener et al., 1998; Warr, 1999). Some evidence suggests that social support has direct effects on stress outcomes and buffering effects on the stress-health outcome relationship. Specifically, when social support is present, the positive relationship between stress and negative health outcomes is weaker than when social support is absent (e.g., Cohen \& Willis, 1985).

Secondly, financial strain could affect life satisfaction through negative affective states. Psychological experiences of financial strain, defined as a negativelyoriented affective state of arousal, are likely to accumulate and lead to other negative moods or emotions. Research shows that positive and negative affective states, and more severe mood disorders, such as anxiety and depression, are related to life satisfaction (Emmons \& Diener, 1985; Lehman, 1988; Palmer et al., 2002).

Furthermore, the bottom-up theories confirm the idea that life satisfaction is the result of positive and negative experiences in one's life (cf. Brief et al., 1993). Therefore, an individual with high levels of financial strain experiences frequent or intense levels of that negative affective state, which would lead to lower life satisfaction. In sum, 
affective processes could serve as the linking mechanism between financial strain and life satisfaction.

Finally, financial strain could negatively influence life satisfaction through physical health or family problems. As the bottom-up perspective of life satisfaction suggests, the evaluations and feelings about a person's life are constructed from satisfaction with specific life domains, such as work, school, family, or health (cf. Brief et al., 1993). Research has established that financial strain leads to poor physical health and marital dissatisfaction (Olivius et al., 2004; Conger et al., 1994). Thus, financial strain reduces a person's satisfaction as it relates to health and family. Research and theory suggest that these health and marital quality ratings affect a person's overall life satisfaction (Brief et al., 1993; Glen, 1990).

In addition to these theoretical linkages, there is strong empirical support to suggest that financial strain is negatively related to life satisfaction. In their metaanalysis on unemployment, McKee-Ryan and colleagues (2005) found that financial resources and financial stress were significantly related to life satisfaction. Also, Pittman and Lloyd (1988) collected telephone interviews from a random sample of Americans living in Utah. They found that stress about finances significantly predicted life satisfaction when controlling for demographics, income, social support, faith, and other sources of stress.

Some cross-cultural and international research supports the link between financial stress and life satisfaction as well. In a study of Chinese elderly, $\mathrm{Li}$, Aranda, and Chi (2007) found that financial strain was significantly associated with life 
satisfaction and physical health outcomes. In a 3-year longitudinal study conducted by Chou and Chi (1999), financial strain was a significant predictor of life satisfaction for men and women controlling for other demographics, physical health, healthy lifestyle, and depression.

Financial strain has the potential to affect life satisfaction by way of reduced emotional resources, the experience of negative affective states, and decreased health and family outcomes. Furthermore, research has demonstrated that measures of financial stress are better predictors of well-being than more commonly used objective financial indicators (McKee-Ryan et al., 2007; Ullah, 1990). Therefore, I propose that financial strain will negatively predict life satisfaction and mediate the relationship between financial stressors and life satisfaction (See Figure 5 for a model of Hypotheses 3-6).

Hypothesis 3a: Financial strain will mediate the relationship between perceived income adequacy to afford needs and life satisfaction.

Hypothesis 3b: Financial strain will mediate the relationship between perceived income adequacy to afford wants and life satisfaction.

That being said, there is a possibility that income adequacy perceptions have a direct effect on life satisfaction. A common explanation for this relationship is that money is related to many of life's basic needs, activities, and chances to succeed (Pearlin \& Radabaugh, 1976; Peirce et al., 1996). Perceptions about financial adequacy should therefore be associated with feelings and evaluations of one's life. In addition, some studies have shown that perceived income adequacy may affect life 
satisfaction through negative self-evaluations and perceptions of control. For example, Pearlin and colleagues (1981) found that feelings of mastery and self-esteem mediated the relationship between financial adequacy and depression. In another study, Price, Choi, and Vinokur (2002) discovered that perceived personal control mediates the effects of financial strain on daily functioning and health. Thus, it is plausible that income adequacy perceptions affect life satisfaction through cognitively-rooted mechanisms like perceived control and self-esteem and so I will also test for partial mediation effects in the model.

\section{Job Performance}

While it is important to reconfirm the effects of financial strain on established outcomes such as life satisfaction, it is also important to consider organizationally valued outcomes such as performance. I selected individual job performance for two reasons. First of all, job performance is linked to organizational effectiveness (e.g., profits, productivity). Since most organizations are interested in learning how to maximize job performance, this research can inform organizations as to the pragmatic value of potential financial stress interventions. Hart and Cooper (2001) argue for more studies which examine the strain-performance relationship, as establishing a link to performance demonstrates the usefulness of stress research to organizations. Further, research and theory suggest that psychological resource levels influence job performance (e.g., Cullen \& Hammer, 2007; Wright \& Cropanzano, 1998). Thus, job performance is a theoretically appropriate outcome of financial strain, which is theorized to lead to a drain in emotional resources. Therefore, in this section, I define 
job performance, discuss some of the relationships between stress and job performance, and explain the financial stress-performance link.

Job performance consists of the behaviors employees engage in at work which contribute to organizational goals (Campbell, 1990; Jex, 1998). Campbell, McCloy, Oppler, and Sager (1993) make three fundamental arguments about job performance: that it is behavior, not the outcomes of behavior; that there are specific determinants of performance; and that performance is multidimensional. They note that performance has been operationalized inconsistently and propose that job performance only entails actual behaviors, not the outcomes or evaluations of behaviors like effectiveness, productivity, utility.

Campbell and colleagues (1993) also posit that job performance is influenced by three key determinants: declarative knowledge, which is knowledge about facts and things; procedural knowledge and skill, which is the knowledge of how to do something; and motivation. Motivation, they argued, is the combined effect from three choices the employee makes: the choice to expend effort, the choice of level of effort to expend, and the choice to persist in the expenditure of that level of effort. There is much research on the processes and antecedents related to motivation which are beyond the scope of this paper. In any case, declarative knowledge, procedural knowledge, and motivation are all needed for job performance to occur.

Finally, Campbell and colleagues (1993) argue that job performance is not unidimensional but is comprised of eight higher-order performance dimensions, some of which are universal to all jobs. One of these universal dimensions included the idea 
of extra-role behavior, or taking on duties that were beyond an employee's prescribed role. Organ $(1977,1988)$ was actually one of the first to talk about organizational citizenship behavior (OCB) as a type of performance that supports the context which sustains the technical core operations of organizations. Research has demonstrated that task performance and $\mathrm{OCB}$ each contribute unique variance to overall performance ratings and should, therefore, each be measured (Motowidlo \& Van Scotter, 1994). Knowledge, skills, and abilities are good predictors of task performance while personality and job attitudes generally predict OCB (Borman \& Motowidlo, 1993; Hoffman, Blair, Meriac, \& Woehr, 2007).

Borman and Motowidlo (1993) conceptualize contextual performance as a more broadly defined form of $\mathrm{OCB}$, though they share subdimensions with most conceptualizations of OCB (Borman \& Motowidlo, 1993; Organ, 1988; Williams \& Anderson, 1991). They explain that contextual performance differs from task performance in four important ways. First, contextual performance is more discretionary, while task performance is a mandatory part of one's job. Second, contextual performance behaviors are also not explicitly stated on one's job description, whereas task performance expectations typically are. Third, contextual performance is applicable to all types of jobs, while task performance is typically jobspecific. Finally, in most circumstances, contextual performance is not formally rewarded, while task performance generally is.

Many studies have explored the dimensionality of OCB. Organ's (1988) original taxonomy identifies five core dimensions of OCB: altruism, courtesy, 
sportsmanship, civic virtue, and conscientiousness. Altruism represents helping another coworker with an organizationally-relevant task. Courtesy involves behavior directed toward preventing work-related problems with other employees. Sportsmanship is the extent to which an employee tolerates less than ideal circumstances without complaining. Civic virtue involves participating in nonmandatory company events and activities. Finally, conscientiousness represents performance that goes above and beyond the defined job tasks. Largely based on Organ's (1988) five-factor taxonomy, Williams and Anderson (1991) provide the distinction that some citizenship behaviors are directed toward individuals (OCB-I) and other helping behaviors are directed toward the organization (OCB-O). Many studies have further explored the dimensionality of $\mathrm{OCB}$ and proposed more detailed taxonomies (for comprehensive reviews, see Hoffman et al., 2007; Podsakoff, MacKenzie, Paine, \& Bachrach, 2000).

Although less research has investigated OCB in Chinese populations, one study found that Chinese employees exhibited 5 dimensions of OCB that have not been found in Western populations (i.e., self-training, social welfare participation, protecting and saving company resources, keeping the workplace clean, and maintaining interpersonal harmony; Farh, Zhong, \& Organ, 2004). While these were argued to be distinct from Western-developed scales, some dimensions are conceptually embedded in the Western scales. For instance, social welfare participation is similar to altruism, and self-training could be clustered under conscientiousness. Ultimately, the individual-organizational distinction is the most 
straightforward conceptualization of OCB. Therefore, I will first examine the OCB-I and OCB-O model (Williams \& Anderson, 1991).

\section{Theories of Stress and Performance}

Research examining the effects of stress on performance has produced several theories of how stress relates to performance, including negative linear, positive linear, inverted-U, and appraisal-based theories such as the Challenge-Hindrance stress model (cf. Lepine, Podsakoff \& Lepine, 2005; Muse, Harris, \& Field, 2003). The negative linear theory argues that stress takes up individual resources (time, energy, attention) detracting from one's ability to perform on the job (Jamal, 1985). In this case, poor performance could be the result of cognitive failures, intrusive physiological responses (Vroom, 1964), or low energy due to stress, all of which are manifestations of strain. Positive linear theory suggests that performance improves as stress increases and that low levels of stress lead to boredom and therefore, poor performance (Meglino, 1977). The inverted-U theory of stress posits that there is an optimal level of stress at which maximum performance can be achieved; any more stress will reflect the negative linear stress theory and any less stress will reflect the positive linear theory (McGrath, 1976; Seyle, 1975).

Finally, in theories like the Challenge-Hindrance model, the effects of stressors on performance depend on whether the stressor is perceived as a challenge or a threat (Boswell, Olson-Buchanan, \& LePine, 2004; Lepine, Podsakoff \& Lepine, 2005).

Challenge-stressors are perceived to have the potential to promote mastery or personal growth and, therefore, trigger positive emotions. Hindrance-stressors, on the other 
hand, are perceived to potentially harm personal growth or gain, and therefore trigger negative emotions (Lepine et al., 2005). According to this perspective, the linear relationship between stress and performance will be positive if stressors ore viewed as a challenge and negative if stressors are viewed as a threat.

Although the positive linear and inverted-U theories of the stress-performance relationship have received a small amount of support in the literature, most studies have confirmed the negative linear theory (cf. Muse, et al., 2003). For example, Jamal (2007) recently found that $90 \%$ of the stress-performance comparisons in his study supported the negative linear relationship, whereas only $10 \%$ of cases supported a Ushaped/curvilinear relationship. Muse and colleagues (2003) note that these results could be due to a bias in the types of stressors and populations typically studied in stress research. Nevertheless, the negative relationship between stress and performance has received the most support and is consistent with other widely-held theories (e.g., Conservation of Resources Theory).

While organizational stress research has found that various work stressors and role conflict stressors lead to decrements in performance (e.g., Frone et al., 1997; Jex, 1998), there is less research on the link between non-work-related stress and performance. Some studies from the work-family balance literature use Conservation of Resources (COR) Theory (Hobfoll, 1989) to explain how stress depletes employees' personal resources leading to declines in job performance. I make a similar argument that financial strain leaves individuals with fewer emotional resources with which to perform their jobs. 
Financial Stress and Job Performance

Wright and Cropanzano (1998) discussed the importance of emotional energy in overcoming daily stressors and maintaining acceptable performance levels. When people worry about their financial situation, it drains these emotional resources, leaving them less capable of dealing with work-related stressors and lacking the energy to perform their job tasks well. COR theory suggests that when employees face a situation where resources are threatened or lost, they may withdraw or withhold effort to preserve their resources and avoid further resource loss (Grandey \& Cropanzano, 1999; Leiter, 1991). I argue that financial strain, brought on by perceptions of low income adequacy, will lead to a drain in emotional resources, which in turn leads to decreased task performance. Given that OCB is discretionary and requires additional motivational resources, financial stress should also lead to decreased OCB.

Although no specific studies have examined how financial stress affects job performance, some research has successfully linked non-work stressors and role conflict stressors to job performance using this resource argument. The work-family literature supports the claim work-family conflict leads to a depletion of psychological resources, which in turn affects job performance (e.g., Cullen \& Hammer, 2007). More specifically, some studies have demonstrated that family-to-work conflict, or the interference of one's family role with one's work role, negatively affects job performance (Aryee, 1992; Frone et al., 1997; Witt \& Carlson, 2006). It stands to reason that financial stress, which affects people in many aspects of their lives, has the 
potential to interfere with job performance in some of the same ways as family-towork conflict (e.g., interfering thoughts about family/financial issues, time spent handling family/financial issues). In fact, Kim and colleagues (2004) have extended this idea by developing the concept of finance-to-work conflict, which refers to incidents where personal finances interfere with work, affecting things like getting to work on time and concentrating on daily tasks.

A meta-analysis by Kossek and Ozeki (1999) found a negative relationship between work-family conflict and performance across studies. Outside of the workfamily literature, two peer-reviewed studies have looked at how stressors from home affect job performance. Van Dyne, Jehn, and Cummings (2002) found that interpersonal conflict at home was negatively related to employee creativity at work. Another recent longitudinal study by Edwards, et al. (2007) discovered that workload and interpersonal conflict at home significantly predicted self-ratings of performance. These studies suggest that resource depletion from non-work areas of people's lives, such as financial strain, can affect their performance.

Finally, the relationship between financial stress and performance may depend on how financial stress and performance are measured. For instance, Brett and colleagues (1995) found that their objective measure of financial need was in fact positively related to sales volume. Shaw and Gutpa (2001) found no correlation between the same objective measure of financial need and supervisor-rated job performance. Because they measured need objectively, their construct does not 
provide a direct account of the underlying cognitive and affective processes that reflect people's financial situation and concerns.

Although no studies to my knowledge have examined financial strain and job performance in collectivist cultures, Hobfoll (2001) asserted that resource-based models such as COR Theory hold up cross-culturally. Further, the phenomenon of financial strain has been documented in several studies looking at Chinese elderly and adolescents (i.e., Chou \& Chi, 2000; Krause, Liang \& Gu, 1998; Shek, 2003). Together, this information suggests that the process by which financial strain drains emotional resources and leads to decreased job performance is generally similar across people. Therefore, I predict that financial strain will mediate the relationship between perceived income adequacy and task performance, and will have a negative linear relationship with task performance (see Figure 4).

Hypothesis 4a: Financial strain will mediate the relationship between perceived income adequacy to afford needs and self-rated task performance.

Hypothesis 4b: Financial strain will mediate the relationship between perceived income adequacy to afford wants and self-rated task performance.

Unlike task performance, $\mathrm{OCB}$ represents discretionary, extra-role behavior, and so I argue that when financial strain is high and emotional resources are depleted, workers will opt not to engage in OCBs, as they require further resource expenditure. Because OCBs are not explicitly part of a worker's prescribed role, supervisors may not be in the best position to judge this aspect of job performance (cf. Werner, 2000). Nevertheless, OCB-I and OCB-O require energy and resources, so I predict that 
financial strain will negatively predict OCB-I and OCB-O, through a drain in emotional resources.

Hypothesis 5a: Financial strain will mediate the relationship between perceived income adequacy to afford needs and self-rated self-rated organizational citizenship behavior directed toward individuals.

Hypothesis 5b: Financial strain will mediate the relationship between perceived income adequacy to afford wants and self-rated self-rated organizational citizenship behavior directed toward individuals.

Hypothesis 6a: Financial strain will mediate the relationship between perceived income adequacy to afford needs and self-rated self-rated organizational citizenship behavior directed toward the organization.

Hypothesis 6a: Financial strain will mediate the relationship between perceived income adequacy to afford wants and self-rated self-rated organizational citizenship behavior directed toward the organization.

Beyond examining the mediating effects of financial strain on these work and individual outcomes, there is a possibility that perceived income adequacy directly influences job performance. From an equity theory perspective, perceptions of income adequacy represent the judgment that pay is fair relative to one's personal needs and wants (see Chapter 3; Adams, 1963; Taylor \& Vest; 1992; Williams, 1995). The pay equity literature suggests that employees may intentionally withdraw effort from their tasks and even retaliate against the organization if pay is perceived to be inequitable or insufficient (e.g., Cowherd \& Levine, 1992; Greenburg, 1990). Thus, it is plausible 
that income adequacy perceptions affect job performance through a cognitive mechanism such as equity appraisals and so I will also test for partial mediation effects in the model.

\section{Correlates of Financial Stress}

Some research has demonstrated that age and gender are significantly related to financial stress. For instance, age was significantly correlated with financial stress in a study of Chinese elderly (Chou \& Chi, 2000) and in a random sample of Americans (Frone et al., 1996). Gender was significantly related to financial strain in a convenience sample of unemployed individuals (Creed et al., 2001) and chronic financial stress in a random sample of Americans living in New York (Peirce et al., 1996). Moreover, Fox and Chancey (1998) found that age was significantly, positively related to financial well-being in women, but this relationship was not significant in men. In order to account for these other sources of variance that might explain the relationships of interest in this study, I will determine if each variable correlates significantly with my outcomes of interest and control for them if necessary.

\section{Summary}

I predict that financial strain will mediate the effects of perceived income adequacy on life satisfaction, task performance, and OCB. I argue that financial strain will negatively affect life satisfaction by potentially inhibiting participation in healthy, enjoyable behaviors, increasing negative affective states, harming physical health, and decreasing marriage and family satisfaction. I also argue that financial strain leaves individuals with fewer emotional resources to allocate toward successfully performing 
Financial Stress 54

their jobs and participating in discretionary citizenship behaviors for other individuals and the organization. 


\section{CHAPTER 5: STUDY 1}

Examining the financial stress process is theoretically and practically important for understanding how it affects individuals and organizations, but there is also a need for better measurement of income adequacy and financial strain. This project presented the opportunity to examine the financial stress process in two data sets, one working American sample and one working Chinese sample. I used the first sample (Study 1, American workers) to examine new scales of income adequacy and financial strain and test the financial stress process model (H1, H2). In Study 2 (Chapter 6), I used a second sample of Chinese workers to develop Chinese scales for income adequacy and financial strain, and to longitudinally explore the mediation model linking the financial stress process to life satisfaction and job performance (H3-H6). Each study concludes with a discussion of the findings and the strengths and limitations specific to that study. Chapter 7 provides a general discussion of the theoretical and practical implications of this work, and directions for future research.

Method

\section{Participants}

The original sample consisted of 696 undergraduates attending a public university in the Northwestern United States. To enhance the external validity of the study, I selected only students who were employed in paying jobs and paying for $75 \%$ or more of their own expenses. In addition, two cases were omitted from analyses because of extreme responses to income and expense questions (greater than 3 standard deviations). This left a sample size of 285 working students. The majority of 
participants were female (68.8\%), Caucasian (78.2\%), not living with parents (89.4\%), single or not living with a partner $(59.0 \%)$, and without dependants $(88.0 \%$ without children; $85.9 \%$ without other dependants). The mean age was $25.6(S D=6.1$ years). About $74.0 \%$ of the sample paid for all of their own living expenses, while $8.5 \%$ were paying between $90 \%-99 \%$ of their own expenses, and $17.5 \%$ were paying between $75 \%-89 \%$. With $92.6 \%$ of students working for hourly pay, $52.6 \%$ were working parttime at one job, $28.8 \%$ were working full time at one job, and $18.6 \%$ were working multiple jobs. The mean annual take-home income (after taxes) was $\$ 19,498.64(S D=$ $\$ 13,073.52)$ and participants were spending an average of $\$ 16,929.36$ annually $(S D=$ $\$ 13,268.48)$.

\section{Procedure}

Students were recruited to participate in this study from psychology courses and given the opportunity to receive extra credit for their participation. Professors who agreed to provide extra credit to their students distributed a web link to an online survey. When students entered the link, they were asked to give their informed consent and also had the option to complete an alternate scale development assignment for the same extra credit. After completing the survey or alternate assignment, students were sent to a separate online survey which asked them to provide identifying information and request the courses for which they wanted extra credit.

\section{Measures}

Demographics. Participants were asked to indicate their gender. Men were coded as 1 and women were coded as 2 . They were also asked to indicate their age. 
Actual household income and expenses. Participants were instructed to indicate the dollar amount of their typical monthly household income and expenses. They were asked, "How much money do you typically receive each month (from all sources including work, gifts, loans, interest on savings, family, etc.)?". Then they were given the item, "How much money do you typically spend each month (rent, food, utilities, transportation, healthcare, education, entertainment, child/elderly care, etc)?". I computed annual household income and annual household expenses by multiplying the monthly values by 12 . For all analyses reported below, I scaled household income and expenses into increments of $\$ 10,000$ so the results could be more easily interpreted.

Current income adequacy. To generate income adequacy items, I conducted an extensive literature review (described in Chapter 3) and conducted several student interviews, as suggested by Stanton and colleagues (2001; see Table 3). I also brainstormed item targets that would be specific to affording current needs and current wants. Some items, such as food and clothing could be perceived as needs or wants. In these cases, I differentiated these items by specifying "the clothes I need" and "the clothes I want". For each item, I used a similar stem such as "I can/cannot afford...". Half of the items were negatively worded.

Participants were asked to respond to 24 of these items designed to tap individuals' perceived ability to afford current needs and current wants. Ten items were written to measure current needs and 14 items were written for current wants. Participants were asked to "please answer the following questions for yourself and 
your household/family (i.e., spouses, dependent children, and/or relatives). Note: Your income may include all sources (e.g., spouse, parents, loans, job, etc.)." Participants rated each statement along a 5-point agreement scale ranging from strongly disagree (1) to strongly agree (5). An example of a current need item is, "I can afford to pay my utilities."

To develop scales for current income adequacy, I followed the guidelines and suggestions put forth by Fabrigar, MacCallum, Wegener, and Strahan, (1999). First, I converted each item to a Z-score so that differences in variance would not affect the results. Then, I used exploratory factor analysis (EFA) using the principal axis factoring method with oblique rotation since I expected perceived income adequacy dimensions to be correlated (EFA; Fabrigar et al., 1999; Finch \& West, 1997; Russell, 2002).

Without specifying the number of factors, the scree plot and eigenvalues suggested a 2, 3, 4, or 5 factor solution and so I evaluated each solution based on its interpretability, parsimony, and consistency with theory. The five factor solution accounted for $49.54 \%$ of the variance in the item responses and contained the following factors: wants (savings, extra money, lifestyle), daily expenses (clothes, transportation, food), paying bills, healthcare (insurance, child/elder care), and housing. Because the housing factor contained only two items, I examined a four factor solution. The four factor solution accounted for $47.02 \%$ of the variance in the item responses and contained the following factors: wants (savings, extra money, lifestyle), daily expenses and needs (clothes, food, transportation, housing), paying 
bills, and healthcare (insurance, child/elder care). Unlike factors 1, 2, and 4, the paying bills factor is less interpretable because it is more conceptually vague than the other factors. Therefore, I examined a three factor solution, which accounted for $43.78 \%$ of the variance in the item responses and contained the following factors: wants (savings, extra money, lifestyle), needs and financial obligations (clothes, food, transportation, housing, paying bills), and healthcare (insurance, child/elder care). Because health care is considered to be a basic need, I decided to also explore a two factor solution.

The two factor solution accounted for $39.90 \%$ of the variance in the item responses and contained the following factors: wants (savings, extra money, lifestyle) and needs (clothes, food, transportation, housing, paying bills, healthcare). After deleting crossloading items and items that were theoretically inconsistent with their factor (cf. Linden \& Maslyn, 1998), the 2-factor solution accounted for $39.00 \%$ of the variance in item responses. Although it accounts for slightly less variance than other models with more factors, I decided to keep the two factor solution as it is interpretable, parsimonious, and consistent with the literature. Moreover, I decided to keep some of the lower-loading items in the 2-factor model (e.g., insurance, child/elder care) because they may have more variance and load higher in other populations. Means and standard deviations for a list of original and deleted income adequacy items can be found in Table 4 . The final factor loadings can be found in Table 5. The final income adequacy needs scale contained 10 items and had an alpha of .89. The final income adequacy wants scale contained 11 items and had an alpha of 
83. Higher scores represent perceptions that income is adequate for the specific target, while lower scores represent inadequacy.

Financial strain. To generate item content for financial strain, I adapted 13 affectively-oriented stress adjectives developed by Stanton and colleagues (2001) for the Stress in General scale. I wrote 4 additional items based on other affectivelyoriented words and incorporated all of these adjectives into the item stem referring to one's financial situation. For instance, the adjective, "demanding", was used in the item, "My financial situation is demanding". Participants responded to 17 items and were asked to "Please indicate your level of agreement with each of the following statements about your financial situation." Participants rated each statement along a 5point agreement scale ranging from strongly disagree (1) to strongly agree (5).

The scree plot and eigenvalues from an EFA of the financial strain items suggested a 1- or 2-factor solution. Using oblique rotation, the two-factor solution produced a high arousal factor (e.g., pressured, hectic, irritating), and a low arousal factor (e.g., unhappy, drained, exhausted) and accounted for $67.43 \%$ of the item variance. I selected only the nine items loading on the first high arousal dimension because the literature on financial strain characterizes it as a negatively valent, high arousal affective state (e.g., worry, concern, and stress). In an EFA, these items loaded on to a single factor, accounting for $63.74 \%$ of the item variance. Item means and standard deviations of the original and deleted financial strain item can be found in Table 4. Factor loadings can be found in Table 6. The final financial strain scale contained 9 items and had an alpha of .93. Higher scores represent high arousal and 
negative affect about one's finances, while lower scores represent an absence of high arousal and negative affect (i.e., not low arousal and positive affect).

Analyses

Descriptive Statistics. I computed mean scores for the income adequacy for wants, income adequacy for needs, and financial strain scales if participants had responded to at least $60 \%$ of the items in each scale. I computed means, standard deviations, and scale reliabilities, and computed correlations between the scales, indicators, and demographic variables.

Financial Stress Mediation Model. I tested a structural equation model where individual items are loaded onto their corresponding latent factors. The observed variables of income and expenses each predict the latent factors of perceived income adequacy to afford needs and wants, which in turn, predict the latent factor representing financial strain (see Figure 4). With regard to model fit, I reported the chi square significance test and fit indices. I reported the standardized structural path coefficients in Figure 6.

I tested the mediation hypotheses $(\mathrm{H} 1$ and $\mathrm{H} 2)$ in two ways: by examining full versus partial mediation, and by examining direct and indirect effects. First, I compared a full mediation model (i.e., where income adequacy mediates the relationship between income/expenses and financial strain) to a partial mediation model (i.e., where direct paths between income/expenses and financial strain are added). In addition to these model comparisons, I asked for modification indices to identify paths or correlations that are detracting from the model fit. When new paths 
suggested by modification indices were theoretically appropriate, I explored alternative post-hoc models including these paths (Muthén \& Muthén, 2006). To compare nested models and determine the most appropriate representation of the data, I calculated a delta chi-square significance test. I selected the most parsimonious model that fit the data significantly better than other models or as well as the bestfitting model.

In the most appropriate model, I tested for indirect effects of income and expense indicators on the outcomes. An indirect effect, also referred to as a mediated effect, represents the extent to which the predictor affects the outcome variable through the mediator (Pearl, 2001). Indirect effects, in this study, were statistically tested by computing the product of the relationship between the predictor and mediator and the relationship between the mediator and the outcome. A bootstrap analysis, which randomly samples observations repeatedly with replacement, was used to generate an approximate sampling distribution with which significance of these coefficient product estimates could be determined (Shrout \& Bolger, 2002). I also conducted a bias-corrected bootstrap analysis of indirect effects, which accounts for the typical non-normality of indirect effect distributions and the imbalance of confidence limits for indirect effect estimates (MacKinnon, Lockwood, \& Williams, 2004). If zero is within the $95 \%$ confidence intervals presented by these analyses, indirect effects are not significantly different from zero with at the $p<.05$ level. 


\section{Results}

\section{Descriptive Statistics}

Means, standard deviations, and correlations of Study 1 variables are presented in Table 7. Gender, where men were coded as 1 and women were coded as 2, was significantly correlated with expenses $(r=-.12, p<.05)$, income adequacy to afford wants $(r=-.14, p<.05)$, and financial strain $(r=.19, p<.01)$ and so it was controlled for in the following model. Age was significantly correlated with gender $(r=-.14, p<$ $.05)$, income $(r=.35, p<.01)$, and expenses $(r=.31, p<.01)$, but because these variables are not outcomes in the model, they were not controlled.

Income was positively related to perceived income adequacy for needs $(r=$ $.27, p<.001)$ and perceived income adequacy for wants $(r=.24, p<.01)$, and negatively related to financial strain $(r=-.14, p<.05)$. This provides some construct validity evidence in that income should theoretically be related to these constructs. Interestingly, expenses were not significantly related to any of these outcomes.

The dimensions of perceived income adequacy for needs and wants were positively correlated $(r=.62, p<.01)$. Further, financial strain was significantly related to both perceived income adequacy for needs $(r=-.47, p<.01)$ and wants $(r=$ $-.71, p<.01)$, as the financial stress model would suggest.

\section{Financial Stress Mediation Model}

A mediation model of financial stress, where the effects of income and expenses on financial strain were mediated by income adequacy for wants and needs demonstrated adequate fit to the data $\left(\chi^{2}=1128.84, d f=485 ; \mathrm{CFI}=.86 ; \mathrm{SRMR}=.06\right.$; 
RMSEA $=.07$ ). While the Root Mean Square Error of Approximation (RMSEA) indicated close-to-acceptable model fit (i.e., less than .06; Hu \& Bentler, 1999), and the Standardized Root Mean Squared Residual (SRMR) indicated acceptable fit (less than .08; Hu \& Bentler, 1999), the Confirmatory Fit Index (CFI) indicated poor fit (i.e., greater than .95; Hu \& Bentler, 1999). The modification indices did not suggest any additional paths that would improve model fit.

I compared this model to a partial mediation model as a way to determine the best-fitting, most parsimonious solution. The partial mediation model included two additional paths linking income and expenses to financial strain directly. Table 8 presents this model comparison. The partial mediation model also demonstrated adequate fit $\left(\chi^{2}=1127.27, d f=483 ; \mathrm{CFI}=.86 ;\right.$ SRMR $\left.=.06 ; \mathrm{RMSEA}=.07\right)$. However, the model fit did not significantly differ in fit from the full mediation model $\left(\Delta \chi^{2}=1.57, d f=2\right.$, n.s. $)$. Because the full mediation model is more parsimonious and fits as well as a partial mediation model, I conclude that the full mediation model is the best representation of the data. This lends some support to the mediation hypotheses ( $\mathrm{H} 1$ and $\mathrm{H} 2)$.

Figure 6 presents the standardized structural path coefficients of the full mediation model. Income was positively related to perceived income adequacy for needs and wants, while expenses were negatively associated with only perceived income adequacy for needs. In turn, perceived income adequacy for wants was negatively related to financial strain, while perceived income adequacy for needs was 
not. Nevertheless, these two variables and gender accounted for $60 \%$ of the variance in financial strain ratings.

Hypothesis 1 predicted that perceived income adequacy for needs ( $\mathrm{H} 1 \mathrm{a})$ and wants $(\mathrm{H} 1 \mathrm{~b})$ would mediate the relationship between income and financial strain. Table 9 presents the results of a test of indirect effects using bootstrapped samples and bias-corrected bootstrap samples. Results provide partial support for Hypothesis 1. Specifically, income was not indirectly related to financial strain through income adequacy for needs $(\mathrm{H} 2 \mathrm{a})$, but there was a negative indirect effect through income adequacy for wants $(\mathrm{H} 2 \mathrm{~b}$; bootstrap $\mathrm{CI}=-.041,-.006, p<.05$; bias-corrected bootstrap $\mathrm{CI}=-.037,-.004, p<.05)$. Moreover, the sum indirect effect of income on financial strain was significant such that higher income was indirectly associated with lower financial strain (bootstrap CI $=-.037,-.005, p<.05$; bias-corrected bootstrap $\mathrm{CI}=-$ $.034,-.004, p<.05)$. Hypothesis 2 , which predicted that perceived income adequacy for needs ( $\mathrm{H} 2 \mathrm{a})$ and wants $(\mathrm{H} 2 \mathrm{~b})$ would mediate the relationship between expenses and financial strain, was not supported.

\section{Discussion}

In Study 1, I tested an appraisal-based model of financial stress whereby actual income and expenses relate to perceptions of income adequacy, viewed as a perceived stressor, in this case. I predicted that these perceived stressors lead to financial strain, represented as negative affective state regarding one's financial situation. I developed scales to capture these constructs and tested this model. 


\section{Findings}

The results provide general support for the process model of financial stress. The mediation model solution is consistent with Lazarus' (1966) idea that stressor appraisals mediate the potential stressor-strain relationship. Further, these findings are in accordance with COR Theory (Hobfoll, 1989). Under this perspective, money is viewed as a resource and perceived income adequacy is an indicator of potentially insufficient resources. Insufficient resources should theoretically lead to strain as these results have supported.

These findings also establish some evidence of construct validity for new measures of perceived income adequacy and financial strain in that most of the variables that theoretically should be related, did in fact correlate. Actual income, income adequacy, and financial strain variables were related to each other, as their constructs would suggest. Actual annual expense, however, was not correlated with these variables, but was highly related to annual income. Further, according to the mediation model, actual expense had a weak relationship with income adequacy for needs, no relationship with income adequacy for wants, and no indirect relationship with financial strain. These findings suggest that annual expense is less relevant potential stressor in the financial stress process than annual income. It is possible that expenses are a function of income such that people only spend as much as they earn. Thus, people may have more control over their expenses than over their income in this sample, which would explain the low or null effects of expenses in the perception of financial stressors and the experience of financial strain. 
Perceptions of income adequacy to afford wants and needs were strongly correlated with financial strain, but the effect for income adequacy to afford needs became insignificant when controlling for income adequacy to afford wants in the mediation model. This presents the possibility that income adequacy to afford wants mediates the relationship between adequacy to afford needs and financial strain. For instance, if people perceive their income to be inadequate for affording needs (e.g., "I cannot afford to pay my bills on time"), they are less likely to perceived their income as adequate for affording wants (e.g., "I cannot afford the lifestyle I want"), which is then related to financial strain (e.g., "I feel pressured by my financial situation"). Future research should consider income adequacy to afford needs as a predictor of income adequacy to afford wants, since fulfilling needs is a more fundamental goal than obtaining wants.

The differences in relationships of the income adequacy dimensions with financial strain suggest that income adequacy for wants and needs are conceptually distinct constructs. Thus, they may also relate to different outcomes. While income adequacy to afford wants is related to financial strain, which represents a high arousal, negative affective state, perhaps income adequacy to afford needs is associated with a different outcome, such as a low arousal negative affective state or other emotions like guilt, disappointment, fear, or anger. Clearly, more research is needed to clarify these issues. 
Strengths and Limitations

Although the results of this study are generally consistent with previous literature and theory, they should be interpreted with caution as the data are crosssectional, are obtained by means of self-report, and represent only working college students. With a cross-sectional, correlational design, I could not infer causality from the relationships between variables. In Study 2, however, I employ a longitudinal design to allow me to make a somewhat stronger causal inference.

Self-report data can be problematic in that response tendencies may tend to inflate correlations between constructs measured in the same way (i.e., common method bias). On the other hand, self-report may be a good way to capture the subjectivity of financial stress. In an effort to enhance respondent accuracy and vigilance, I negatively-worded half of the financial stress items. Nevertheless, objective indicators of strain would compliment self-report measures in future studies of financial stress.

Finally, while the participants in this study work in different jobs, it is important to note that the working student sample is not representative of employees in the US and may influence the data in several ways. College students are more likely to live at home, receive financial assistance from parents, receive student loans, have enough financial resources to afford tuition and fees, and are less likely to have dependents (children or other family). On the other hand, college students may be more likely to be work part-time, work for hourly pay, have less job experience, and acquire and carry student loan debt than non-students. These sample characteristics 
could have influenced my findings by restricting the range of incomes and expenses, inflating income adequacy scores, underestimating financial strain, and underestimating the relationship between perceived income adequacy to afford needs and financial strain.

To address some of these generalizability concerns, I selected only students who were employed in paying jobs and responsible for paying at least $75 \%$ of their own expenses. Nevertheless, the selected sample was predominantly single, without other financial providers in the household, and without dependants to care for. Such characteristics may cause these individuals to experience more financial strain because there are fewer resources, less financial strain because there are fewer demands, or both depending on any particular person's situation. All in all, these sample characteristics raise some concerns for generalizabilty. There is a clear need to investigate the model in other samples. Study 2 was designed for that purpose. 


\section{CHAPTER 6: STUDY 2}

Several of the design and sample limitations in Study 1 are addressed in Study 2, as I was able to analyze multi-wave data from full-time employees. The purpose of Study 2 was to confirm the financial stress mediation model and link financial stress to worker and organizational outcomes in a Chinese sample. Specifically, I a) validated Chinese scales of income adequacy and financial strain, and longitudinally explored the model linking the financial stress process to life satisfaction and job performance (H3-H6). I employed a prospective design to test the predictive power of financial stress at Time 1 in relation to life satisfaction and job performance at Time 2 (Figure $5)$.

\section{Method}

\section{Participants}

The survey was distributed to 385 machine operators, technicians, and managers working in an automotive parts manufacturing plant in the People's Republic of China. Of the employees who were given the survey, 316 responded (82.1\%) at Wave 1. The majority of participants were male (89\%), married or partnered $(69.3 \%)$, and had dependants $(65 \%$ with children; $80 \%$ with other dependants). The average age was $31.19(S D=8.96)$. Most employees worked 40 hours per week (44\%), while $30.8 \%$ worked $41-49$ hours per week, and $23.6 \%$ worked 50-60 hours per week. Most of the participants’ annual income ranged from $¥ 12,000$ $¥ 17,999$ (29.4\%) and $¥ 18,000$ - 30,000 (44.7\%). Most of participants’ spending ranged from $¥ 12,000$ - $¥ 17,999$ per year $(38.8 \%)$ and $¥ 18,000$ - $¥ 30,000$ per year 
(35.5\%). The Chinese Yuan to US Dollars exchange ratio was around 7.5:1, so one Chinese Yuan was equal to approximately $\$ .13$ at the time of data collection in March 2007. The Wave 2 survey was given to the 316 employees who responded to the Wave 1 survey. Of these employees, 159 (50.3\%) employees responded.

\section{Procedure}

Translation. To translate the scales from English into Chinese, three bilingual translators completed a process of back-translation (Brislin, 1970). Back translation is an iterative process where a judge translates the English scales to Chinese. Then, a second translator, blind to the original English items, translated the Chinese items back into English. The newly back-translated English items were then compared to the original English items and any necessary changes were made to ensure item accuracy.

Design. Two waves of surveys were given to employees. In the first wave, employees were asked about their demographics, monthly income and expenses, perceived income adequacy, and financial strain. Wave 2 asked employees about monthly income and expenses, perceived income adequacy, financial strain, satisfaction with life, task performance, and OCB.

\section{Measures}

Demographics. Participants were asked to indicate their gender. Men were coded as 1 and women were coded as 2 . They were also asked to indicate their age.

Perceived income adequacy. Participants were asked to respond to a 15-item culturally-bounded subset of the original pool of items generated to tap individuals' perceived ability to afford current needs and current wants. The items were selected by 
a Chinese judge based on how culturally applicable they would be in a Chinese sample. For instance, insurance and healthcare items were omitted because many employees receive health care assistance from their company or the government.

For current needs and wants, participants were asked to "please answer the following questions for yourself and your household/family (i.e., spouses, dependent children, and/or relatives). Note: Your income may include all sources (e.g., spouse, parents, loans, job, etc.)." Participants rated each statement along a 5-point agreement scale ranging from strongly disagree (1) to strongly agree (5). An example of a current want item is, "I can afford the type of recreation/entertainment I like."

Following the same procedure from Study 1, I first converted each item to a Zscore so that differences in variance would not affect the results. Then, I conducted an EFA with principal axis factoring and oblique rotation without the number of factors specified. Eigenvalues and the scree plot suggest a 2 or 3 factor solution. The 3 factor solution accounted for $38.30 \%$ of the item variance and produced a positively-worded wants factor (e.g., lifestyle, savings, recreation), a needs factor (e.g., bills, food, transportation), and a negatively-worded wants factor (e.g., clothes, retirement, household items). Because the third factor appeared to reflect response effects to the negatively worded items, I examined a 2 factor solution. The 2 factor solution accounted for $32.93 \%$ of the item variance and produced a wants factor (e.g., lifestyle, savings, desired housing) and a needs factor (e.g., food, bills, transportation), which confirms the structure identified Study 1 and is consistent with much of the literature. After deleting 5 items that were factorially complex or that had low factor loadings, 
the 2 factor model accounted for $44.31 \%$ of the item variance. Table 10 contains item descriptive statistics for the original income adequacy items. Table 11 presents the final EFA factor loadings. The final scale for perceived income adequacy to afford needs had 4 items and an alpha of .75. The final scale for perceived income adequacy to afford needs had 6 items and an alpha of .80 . Higher scores represent perceptions that income is more adequate for affording wants or needs, while lower scores represent inadequacy.

Financial strain. Participants responded to 9-items designed to tap the high arousal, negative affective state brought on by one's financial situation (i.e., financial strain). They were asked to "Please indicate your level of agreement with each of the following statements about your financial situation." Participants rated each statement along a 5-point agreement scale ranging from strongly disagree (1) to strongly agree (5). An example item is "I feel pushed by my financial situation."

The results of an initial EFA with an unspecified number of factors suggested a 1 or 2 factor solution. The 2 factor solution accounted for $56.56 \%$ of the item variance and produced a positive factor (e.g., calm, relaxed, comfortable), and a negative factor (e.g., stressful, irritating, hectic). Because the second factor appeared to reflect response effects to the positively-worded items, I examined a single factor solution. The single factor solution accounted for $43.55 \%$ of the item variance. After deleting low loading items, the 1 factor model accounted for $49.45 \%$ of the item variance. Table 10 contains item descriptive statistics for the original financial strain items. Table 12 presents the final EFA factor loadings. The final financial strain scale 
contained 7 items and had an alpha of .87. Higher scores represent high arousal and negative affect about one's finances, while low scores represent an absence of high arousal and negative affect (i.e., not low arousal or positive affect).

Life Satisfaction. Participants were given the Satisfaction With Life Scale (SWLS; Diener, Emmons, Larson, \& Griffin, 1985). They were asked to rate their agreement with 5 attitudinal statements about their life. Ratings were made on a 7point agreement scale (strongly agree- strongly disagree). An example item is, "In most ways, my life is close to ideal". The initial alpha of this scale was .76, but "alpha if item deleted" analyses revealed that deleting one item would improve internal consistency and so I omitted the item, "If I could live my life over, I would change almost nothing". The final scale had 4 items and an alpha of .79. Higher scores on this scale indicate greater life satisfaction, while lower scores represent dissatisfaction with life.

Self-rated Task Performance. Participants were asked to rate their own task performance using Jenson and Van Yperen's (2004) 5-item measure. The items were designed to capture in-role, expected performance on the job. Employees made ratings on a 5-point frequency scale ( 5 = Always, $1=$ Never $)$. A sample item is, "I fulfill all responsibilities required by my job". The initial alpha of this scale was .69 , but "alpha if item deleted" analyses revealed that deleting one item would substantially increase the internal consistency and so I omitted the item, "I never neglect aspects of the job that I am obligated to perform". The final scale had 4 items and an alpha of .74. 
Higher scores on this scale indicate better task performance, while lower scores represent poorer task performance.

Organizational Citizenship Behavior. Employees rated themselves in the extent to which they participate in OCB. I used the short form of a scale developed by MacKenzie and colleagues (1993) to capture OCB-I and OCB-O (Williams \& Anderson, 1991). Employees were asked to rate their agreement on a 5-point scale. OCB-I was measured using the 3-item subscale for altruism, which represents the extent to which an employee helps another individual with a work-related task. A sample item is, "I help others with heavy workloads". OCB-O was measured using 3item subscales for conscientiousness. Conscientiousness represents behaviors that extend beyond one's prescribed work role. An example item is, "I complete work earlier than expected".

To confirm the 2 factor structure of OCB-I and OCB-O, I conducted a confirmatory factor analysis in which I loaded the altruism items on an OCB-I factor, and the conscientiousness items on an OCB-O factor. The analysis indicated acceptable fit $\left(\chi^{2}=12.92, d f=8 ; \mathrm{CFI}=.97 ; \mathrm{SRMR}=.04 ; \mathrm{RMSEA}=.06\right)$. I compared the 2 factor model of these items to a single factor model and found no significant differences in fit $\left(\Delta \chi^{2}=1.29, d f=1\right.$, n.s. $)$. Thus, a single factor model of OCB is the best fitting, most parsimonious representation of the data. This is consistent with a recent meta-analysis finding support for a single-factor model of OCB (Hoffman et al., 2007). Together, the 6 OCB items had an alpha of .72. Higher scores on this scale 
indicate more participation in citizenship behaviors, while lower scores represent a less participation in citizenship behaviors.

Analyses

Descriptive Statistics. I computed mean scores for the income adequacy for wants, income adequacy for needs, financial strain, life satisfaction, task performance, and OCB scales if participants responded to at least $60 \%$ of the items in each scale. I computed means, standard deviations, and scale reliabilities, and caluclated correlations between the scales, indicators, and demographic variables.

Financial Stress and Outcomes Model. For Hypotheses 3-5, I used a structural equation modeling to test the mediation hypotheses (H3-H5) in two ways: by examining full versus partial mediation, and by examining direct and indirect effects of the predictors. In this study, financial strain measured at Time 1 was modeled as the mediator between perceived income adequacy predictors at Time 1 and life satisfaction (H3), task performance (H4), and OCB (H5), all measured at Time 2. To identify the best fitting model to the data, I first estimated the confirmatory measurement model by loading all of the items on their respective factors, and correlating all of the factors. Once adequate fit was achieved, I estimated a saturated model, systematically removed paths from subsequent nested models, and compared them to the saturated model. Specifically, I compared the a) Saturated Model, in which financial strain partially mediates the relationships between income adequacy and each outcome such that income adequacy dimensions directly predict all of the outcomes; b) Partial Mediation Model 1, in which financial strain fully mediates 
income adequacy and life satisfaction, but partially mediates job performance; c) Partial Mediation Model 2, in which financial strain fully mediates income adequacy and job performance, but partially mediates life satisfaction; and d) Full Mediation Model, which is the hypothesized model and described previously. To compare models and determine the most appropriate representation of the data, I calculated a delta chi-square significance test for each comparison. I selected the most parsimonious model that fit the data significantly better than other models.

In the best-fitting model, I tested for the indirect effects of perceived income adequacy for wants and needs in predicting life satisfaction, task performance, and OCB. Following the same procedure described in Study 1, I conducted bootstrap and bias-corrected bootstrap analyses to create a sampling distribution against which indirect effect estimates could be tested.

\section{Results}

\section{Descriptive Statistics}

Means, standard deviations, and correlations of Study 2 variables are presented in Table 13. Neither gender nor age was significantly correlated with variables in this study, and so they were not controlled for in this study.

The dimensions of perceived income adequacy for needs and wants were positively correlated $(r=.13, p<.05)$. Further, financial strain was significantly related to both perceived income adequacy for needs $(r=-.29, p<.01)$ and wants $(r=$ $-.47, p<.01)$, as the financial stress model would suggest. 
The correlations also supported relationships between predictors at Time 1 with outcomes at Time 2. Perceived income adequacy for wants and financial strain at Time 1 were related to life satisfaction at Time $2(r=.19, p<.05 ; r=-.16, p<.05$, respectively). Contrary to expectations, perceived income adequacy to afford wants measured at Time 1 was negatively related to task performance and OCB measured at Time $2(r=-.18, p<.05 ; r=-.18, p<.05$, respectively), while financial strain correlated with neither of these outcomes.

\section{Financial Stress and Outcomes Model.}

I found that the measurement model, in which each item was loaded on to its respective factor and all factors were correlated, fit the data poorly $\left(\chi^{2}=671.69, d f=\right.$ $419 ; \mathrm{CFI}=.81 ; \mathrm{SRMR}=.09 ; \mathrm{RMSEA}=.07)$. Moreover, the sample size for Time 2 probably does not provide enough power to estimate an adequately fitting model (MacCallum, Browne, \& Sugawara, 1996). Therefore, I decided to average the items to create scales and test a manifest path model instead of a structural equation model.

Table 14 presents the fit indices and delta chi square tests for each of the four models I compared. Of the four models, only the Partial Mediation Model 1 and the Saturated Model had acceptable fit. Furthermore, only Partial Mediation Model 1 where financial strain fully mediated income adequacy and life satisfaction, but partially mediated job performance - did not differ significantly from the Measurement Model $\left(\Delta \chi^{2}=3.26, d f=2, p=.20\right)$. Partial Mediation Model 2 and the Full Mediation Model fit the data significantly worse than the Measurement Model $\left(\Delta \chi^{2}=11.53, d f=4, p<.05 ; \Delta \chi^{2}=14.72, d f=6, p<.05\right.$, respectively). Because 
Partial Mediation Model 1 was more parsimonious than the Measurement Model, I concluded that it was the best representation of the data. This provides support for Hypothesis 3, which predicted that financial strain would mediate the relationship between perceived income adequacy and life satisfaction. Hypotheses 4 and 5 predicted financial strain as a mediator between task performance (H4) and OCB (H5). These hypotheses were not supported, as the best fitting model supports partial mediation to these outcomes.

The standardized structural path coefficients for Partial Mediation Model 1 are presented in Figure 7. Both dimensions of perceived income adequacy were negatively related to financial strain and accounted for $22 \%$ of its variance, lending support to the financial stress model. In looking at Time 2 outcomes, financial strain negatively predicted life satisfaction and accounted for $3 \%$ of the variance in life satisfaction ratings. Financial strain did not, however, predict job performance outcomes as predicted.

Perceived income adequacy to afford wants at Time 1 negatively predicted both task performance and $\mathrm{OCB}$ at Time 2 such that the less adequate a person perceives their income for buying wants (e.g., "I cannot have the lifestyle I want."), the more likely they will be to have higher job perform and engage in OCB. Interestingly, perceived income adequacy to afford needs at Time 1 positively predicted OCB at Time 2 such that people who perceive their income to be inadequate for affording needs (e.g., "I cannot afford the food I need to survive."), will be less 
likely to engage in OCB. Taken together, the financial stress variables accounted for $4 \%$ of the variance in task performance ratings and $6 \%$ of the variance in OCB ratings.

Tests of indirect effects are presented in Table 15. Hypothesis 3, predicting that financial strain mediates the relationship between perceived income adequacy for needs (H3a) and wants (H3b) and life satisfaction, was fully supported. Income adequacy for needs and wants at Time 1 both positively and indirectly predicted life satisfaction at Time 2 through financial strain. There were no significant indirect effects of income adequacy on task performance or OCB, and so Hypotheses 4 and 5 were not supported.

\section{Discussion}

In Study 2, I tested a financial stress-outcomes model in which perceptions of income adequacy lead to financial strain. In turn, financial strain, through a drain in resources, leads to decreased life satisfaction, poorer task performance, and less participation in organizational citizenship behaviors. I developed Chinese scales to capture these constructs and tested this model longitudinally in a sample of full-time Chinese factory workers.

\section{Findings}

Overall, I found full support for Hypothesis 3 in that financial strain fully mediated the relationship between perceived income adequacy and life satisfaction. However, I only found partial support for Hypotheses 4 and 5, which predicted financial strain mediates the relationship between task performance and $\mathrm{OCB}$, 
respectively. The best fitting model actually suggested a partially mediated relationship between these variables.

The results provide general support for the model of financial stress in that income adequacy perceptions were linked to financial strain. This is consistent with the idea that perceived stressors lead to affective strain responses (Gross, 1970). This finding also supports COR Theory (Hobfoll, 1989) in that perceptions of income adequacy, serving as a proxy for insufficient resources, lead to strain as we are naturally motivated to protect, acquire and avoid the loss of resources like money.

Perceived income adequacy for wants, adequacy for needs, and financial strain were all significantly related to each other in the expected directions, which establishes some evidence of construct validity for these new measures. Perceived income adequacy for wants and financial strain were both correlated with life satisfaction. The structural equation model, however, revealed that financial strain fully mediates the relationship between both types of income adequacy and life satisfaction, supporting Hypothesis 3. Specifically, lower perceptions of income adequacy were associated with higher levels of financial strain, which in turn, negatively predicted life satisfaction. This is consistent with the proposition that financial strain, through a drain in emotional resources, may limit a person's capacity to socially interact, seek out social support, and participate in enjoyable activities, all of which have been previously linked to life satisfaction. Financial strain might also influence life satisfaction through negative affective states or through other established predictors of life satisfaction, like physical health or marriage satisfaction. 
While there was support for the link between financial strain and life satisfaction, financial strain did not correlate with or predict either indicator of job performance. There are several possible explanations for this null finding. First of all, there may be a non-linear relationship between financial strain and job performance. The inverted-U theory of stress and performance would argue that there is some optimal level of financial strain that motivates workers (e.g. McGrath, 1976; Seyle, 1975). Meanwhile, financial strain levels below this optimal range would lead to poor performance due to a lack of motivation, and financial strain levels above the optimal range would also lead to poor performance due to a drain in psychological resources. Another possibility is that there is no relationship between financial strain and job performance below a certain threshold of financial strain. For instance, financial strain may have no effect on performance among employees experiencing middle-to-low levels of financial strain; performance might only be disrupted when employees are under high levels of financial strain.

Second, financial strain may not have predicted job performance because of unspecified situational or individual differences that influence how emotional resources are acquired, allocated, and retained, possibly moderating this relationship. Job attitudes might play a role in determining the allocation of scarce emotional resources toward or away from the job tasks. For example, an employee high in affective organizational commitment may be more inclined to devote emotional resources to their job, even if these resources are scarce as a result of financial strain. In this way, positive job attitudes may buffer the negative relationship between 
financial strain and performance. Social support from various sources (e.g., family, friends, coworkers, supervisors, the organization) may also buffer the negative effects of financial strain on performance. Emotional support from others might contribute emotional resources to an individual potentially deficient in these resources due to financial strain. There are also a number of individual differences which could moderate the relationship between financial strain and performance. The stress literature suggests that characteristics like self-efficacy and resilience have been linked to job performance (Luthans, Avolio, Walumbwa, \& Li, 2005). These tendencies might help individuals retain psychological resources, thus buffering against the resource drain brought on by financial strain.

Lastly, financial strain, as it was conceptualized here, should theoretically lead to a drain in emotional resources, but perhaps emotional resources may not be necessary for successful performance in the job I examined. Cognitive resources are probably more indicative of performance in a factory worker sample such as this one, while emotional resources might be better predictors of performance in peopleoriented, service jobs such as customer service, teaching, or nursing jobs. Taken together, the null linear relationship between financial strain and job performance could be explained in several different ways, all of which should be considered in future research.

Interestingly, perceived income adequacy to afford wants negatively and directly predicted both task performance and OCB. Specifically, the more inadequate a person perceives their income to be for affording wants (e.g., "I cannot afford the 
lifestyle I want"), the higher their subsequent task performance and participation in OCB. When interpreted the other way, the more adequate a person perceives their income to be for affording wants, the lower their subsequent task performance and OCB. These findings may be interpreted from a goal-setting theory perspective. Goal striving is the process by which people try to reduce discrepancies between their reality and their desired states, or goals (Locke \& Latham, 1990; Sheldon \& Elliot, 1999). Income inadequacy can be viewed as an indicator of goal discrepancy because adequacy refers to the difference between an actual amount of something and a person's expectation, ideal, or goal amount. When income is perceived to be inadequate for affording wants, there is a high discrepancy between the actual state of affairs (i.e., income that cannot meet wants) and the goal (i.e., income that can meet wants). Therefore, individuals with unmet wants will increase their task performance and OCB participation to hopefully make a good impression and earn a promotion or pay raise (Locke \& Latham, 1990). Conversely, people with high income adequacy have little to no discrepancy between their current state and their desired state and so will not be motivated to increase their job performance.

Unlike income adequacy to afford wants, employees' perceived income adequacy to afford needs positively predicted OCB, but not task performance. In other words, the less adequate people perceived their income to be for affording life's basic needs (e.g., "I cannot afford the food I need to survive."), the less they engaged in OCBs. Alternatively, the more adequate income was perceived to be for affording needs, the more likely people were to engage in OCBs. This finding seems consistent 
with the reciprocity motive, which serves as the foundation of Social Exchange Theory (SET; Blau, 1964; Gouldner, 1960). Basically, SET states that people are naturally motivated to reciprocate what they are given or how they are treated (Gouldner, 1960). In this case, if people are given wages that they perceive to be insufficient for meeting their basic survival needs, they will not motivated to perform citizenship behaviors for the organization. This finding also confirms some of the pay equity literature. An equity theory perspective would suggest that these employees evaluate how fairly they are being treated by comparing their pay in relation to their basic needs (Adams, 1963; Taylor \& Vest; 1992; Williams, 1995). When pay is perceived to be inequitable or insufficient to meet these needs, employees will refrain from engaging in OCB (e.g., Cowherd \& Levine, 1992; Greenburg, 1990).

While the connection between income adequacy and job performance is generally supported in the literature, perceived income adequacy to afford needs did not predict task performance. Because $\mathrm{OCB}$ is, by definition, not explicitly required for a job, employees have more latitude in their choices to perform these helping behaviors than they do for task performance. In this way, situational influences to perform may be weaker for OCB than for task performance. Workers may not be willing to risk a pay cut or job loss that may result from withdrawing from task performance, and so it stands to reason that income adequacy for needs did not predict task performance. Clearly, these financial stressors have interesting implications for motivation, and so there is a need for better integration of stress and motivation theory in this area. 
Strengths and Limitations

Although there were many strengths of this study and the results are generally consistent with theory, there are several limitations that should be considered when interpreting these findings. This study involved a sample of full-time employees working in an automotive manufacturing factory in China. This full-time, non-student factory sample enhances the likelihood that these results will generalize to full-time employees working in other factories in China. In addition, because the sample was Chinese, I had the opportunity to develop scales in a second language and confirm the financial stress model in a different culture. On the other hand, the results of study 2 could have been influenced by characteristics of the sample. For instance, Chinese employees may have fewer dependants living at home than American employees because of the one-child policy in China. On the other hand, working American students aren't likely to have any dependents at home. In addition, Chinese factories often provide their employees with meals and housing, though recent press has highlighted the adverse working conditions and low wages still exist in many factories (e.g., Barboza, 2008). More studies are needed to better understand these moderators establish the generalizability of these results beyond similar populations working in similar jobs. For instance, researchers might not find the same results in a sample of white collar workers in the US. In addition, these results may not generalize to jobs requiring more interpersonal interactions and emotional resources, such as customer service or nursing jobs. 
Another strength of this study was its prospective design. The longitudinal nature of the data allowed me to infer causality between predictors at Time 1 and outcomes at Time 2 . While this strengthens the implications of my findings, all data was collected by means of self-report, which can produce a common method bias that has the potential to inflate correlations. Supervisor ratings or objective performance data could account for this potential problem with relation to performance measures in future studies.

Lastly, I was able to replicate the financial stress process (income adequacy leading to financial strain) in two cultures using scales in two languages. The Chinese scales, however, were developed using only a subset of the original item pool. Further, scale reliabilities and model fit indices were rather low, suggesting that the Chinese measures can be improved. Future studies should consider adding items to these measures based on qualitative data from Chinese employees, as extensive research in this area is lacking. 


\section{CHAPTER 7: GENERAL DISCUSSION}

The following general discussion highlights important findings from each of the studies in terms of their implications for theory and practice. The chapter closes with several meaningful directions for future research and a brief conclusion.

In light of globalization and changing work contexts, employee concerns about personal finances are prevalent and detrimental to workers' health, well-being, and families. The overarching objective of this thesis was to learn more about the ways in which financial stress affects employees and organizations. Specifically, the goals of this thesis were to explore the construct of financial stress, examine the financial stress process among working American and Chinese samples, and test a theoretical model linking the financial stress to employee life satisfaction and job performance. To accomplish this, I developed scales for perceived income adequacy to afford needs, perceived income adequacy to afford wants, and financial strain in two languages.

The present thesis confirms and extends prior research in showing how financial stress can be harmful to individual and organizational well-being. Further, I think this thesis suggests a useful and meaningful way that researchers can acknowledge, measure, and study financial stress among workers. To my knowledge, no research to date has conceptually and empirically examined the financial stress process, nor has any research incorporated the concept financial stress into the organizational science literature. 


\section{Implications}

\section{Implications for Theory and Research}

This thesis clarified many of the conceptual inconsistencies embedded in prior research on financial stress. With a clearer definition of financial stress and its components, progress can be made in examining the ways in which they affect individuals and organizations. The findings support a mediation model of financial stress as a process by which actual income is evaluated in terms of its adequacy to afford things people need to survive and non-necessary things they want. These adequacy perceptions, in turn, relate to financial strain. This supports Lazarus' (1966) idea that stressor appraisals mediate the potential stressor-strain relationship. These results also support COR Theory (Hobfoll, 1989) in that when people judge themselves to be lacking sufficient financial resources, these perceptions lead to strain.

This research also contributes to the understanding of how income perceptions and financial strain might influence emotional resources and work motivation. With regard to worker well-being, financial strain completely mediated the relationship between adequacy perceptions and life satisfaction, and perceived income adequacy indirectly affected life satisfaction through financial strain. Essentially, this financial stress process predicted life satisfaction among Chinese employees such that higher levels of financial strain decreased how satisfied people were with their lives. Further, Life satisfaction is one the most fundamental human outcomes; thus, these findings highlight the detrimental effects of financial stress on employee well-being. While these results do not provide insight into the longstanding debate as to whether or not 
money leads to happiness, the results suggest that financial stress, resulting from insufficient money, does predict happiness.

Both studies provided strong evidence that perceived income adequacy to afford needs and wants are distinct and possibly operate on outcomes by way of different theoretical mechanisms. These constructs predicted different outcomes and in fact, oppositely predicted OCB. In general, the findings from both studies suggest that achieving wants, though not necessary, is quite salient to people in predicting financial strain and job performance. On the other hand, adequacy to afford needs was rated higher in both samples (meaning people found income more adequate for needs than wants) and was less significant in how it related to financial strain and performance. This may not be the case, however, in lower income populations and so future research should account for actual income. This evidence together suggests that income adequacy to afford needs may be a precondition for perceived income adequacy to afford wants.

According to the findings, it appears as though people's perceptions that they can afford wants acts as a motivational status, negatively affecting task performance and OCB through what appears to be a process of goal striving. Meanwhile, perceived adequacy to afford needs positively affects OCB through what appears to be an equitybased mechanism. This is an interesting finding suggesting that people's reactions to circumstances affecting their basic needs are fundamentally different than the way they react to circumstances involving the attainment of less necessary things. 
Finally, I have developed perceived income adequacy and financial strain scale in two languages so that researchers can continue to examine these issues. Many studies related to this research area have relied on measures of income and/or pay perceptions alone, but research from multiple disciplines suggest that a person's financial situation can be a stressor worthy of its own study. The work put forth in this thesis establishes preliminary evidence of validity for measures of financial stress constructs, making it possible for researchers to explicitly account for financial stress. Implications for Practice

This research has important implications for how organizations manage employees who are experiencing low income adequacy and high financial strain. The positive relationship between perceived income adequacy to afford needs and OCB suggests that organizations should be concerned for their employees who are unable to afford basic needs.

The negative relationship between financial strain and life satisfaction can have negative consequences for the organization, in that employees experiencing financial strain are likely to have poorer health (Brief et al., 1993; Olivius et al., 2004), which can cause employees to miss work or work fewer hours. Employees with high financial strain and low life satisfaction are also likely to have higher negative affect (Emmons \& Diener, 1985; Lehman, 1988; Palmer et al., 2002), which could lead to less cooperation, lower energy levels, and less creativity (Fredrickson \& Losada, 2005; Fredrickson, Mancuso, Branigan, \& Tugade, 2000; Isen, Daubman, \& Nowicki, 1987). 
At the national level, government policy and wage laws could be changed to address the needs of working individuals and families experiencing high financial strain. For instance, there are reports of low wage workers in China whose income does not increase at even close to the rate of inflation. That leaves poorer workers with an increasingly less valuable wage to purchase increasingly expensive goods. Wage regulations could be enforced to ensure that the minimum wage is comparable to the cost of living in a country.

Organizations that deem financial stress interventions to be a sound investment have many options to prevent or at least decrease employee financial stress. First, instrumental support can be targeted to increase workers' financial resources or reduce their financial demands. To target economic resources, organizations can increase wages, increase benefits, make full-time employment status available, offer a paid overtime option, and provide short-term, low-interest loan assistance for financial emergencies. To directly alleviate employees' financial demands, companies can provide free uniforms and/or work supplies, provide a discounted or emergency transportation program, and offer assistance with childcare.

Second, some research from the financial consulting literature suggests that financial education may be related to financial stress (Kim \& Garman, 2003; Kim, Sorhaindo, \& Garman, 2004). Companies can provide financial education which teaches employees how to most effectively handle their income, manage debt, learn about savings and investment options, and plan for retirement. Organizations can also 
select Employee Assistance Programs that offer financial counseling for employees who need one-on-one advice.

Third, organizations can reduce financial stress by designing jobs so that all employees have equal and realistic opportunities for promotions and advancements to higher levels within the company. Helping employees develop valuable skills, experience, and education to be competitive for these positions benefits employees while enhancing the human capital and value of employees for the organization. One way to accomplish this would be to allow employees to rotate jobs and offer employee training and development targeted toward developing a variety of skills. To promote employee education, companies could provide scholarships, tuition reimbursements, and/or incentive programs for students seeking a diploma or other degree.

Finally, there are a number of policy changes organizations can make that help working individuals and caretakers, such as offering paid family, paid medical leave, and guaranteeing job security while on leave. In addition to policy changes, organizations can institute practices and procedures which protect workers in these situations from discriminatory or unfair treatment on the job. While these preventative strategies are intended to reduce employee financial stress, many of these programs and benefits have the potential to also increase employee commitment to the organization. Moreover, organizations may find that acting in these socially responsible ways enhances the public's image of the company, which could serve to improve business outcomes (McGuire, Sundgren, \& Schneeweis, 1988). 


\section{Future Directions}

Several directions for future research have already been suggested based on the results of Study 1 and 2. Here, I highlight some of these meaningful opportunities for future research.

With regard to the financial stress process itself, there are opportunities to examine other operationalizations of a household's actual financial situation, as well as the financial stress process that individuals undergo. Future studies could examine the discrepancy between income and expenses, perhaps weighted by income level to account for the extent the household is impoverished. Also, other indicators of wealth such as debt and assets should be explored as potential predictors. Regarding the psychological aspects of financial stress, the findings suggested that perceived income adequacy to afford needs could be a precondition or predictor of perceived income adequacy to afford wants, and so future research should examine this relationship. In addition, research is needed to better understand the ways in which perceived income adequacy for needs and wants relate to financial strain. Lazarus' (1991) conceptualization of secondary appraisal suggests that expectations about future income probably play a role in the psychological experience of stress; future research should also examine the potential buffering effects of perceived future income adequacy.

I conceptualized financial strain as a high arousal, negative affective state based on definitions and operationalizations that came out of the financial stress literature. Research on emotions and affective states, however, suggest that there are 
other types of affective reactions that people could have to their financial situations. For instance, people may also react to their stressful situation with low arousal, negative affective feelings or other emotions such as guilt or shame (e.g., Johnson, Danko, Huang, Park, Johnson, \& Nagoshi, 1987; Watson, Clarke, \& Tellegen, 1988). In addition to affective responses, the psychological stress literature suggests that there are physiological and cognitive types of strain reactions that future research should also consider. Physiological strain in response to financial troubles would most likely predict physical health outcomes, while cognitive strain is likely to predict outcomes requiring cognitive resources, such as cognitive failures, safety performance, and task performance (De Jonge \& Dorman, 2006). It would be interesting for researchers to theoretically address the ways in which perceived income adequacy to afford needs and wants differentially predict these various stress responses.

In terms of other outcomes, researchers should, first and foremost, consider physical health outcomes to confirm prior research. Building a link between financial stress and health could explain some public health findings connecting low socioeconomic status to physical health. To my knowledge, no researchers have taken a financial stress-response approach in examining this relationship. Such research could have profound implications for public policy.

Study 2 found that financial strain predicts life satisfaction and fully mediates the indirect effects of income adequacy. Life satisfaction, however, represents only one dimension of overall mental health. It would be interesting to examine other 
psychological outcomes such as affective well-being, positive self-regard, competence, aspiration, autonomy, and integrated functioning to fully capture the ways in which financial stress affects employee well-being (Warr, 2005).

In these studies, I looked at self-rated job performance as an outcome of financial strain. Future studies could improve the internal validity of their findings by collecting multi-source data, such as objective performance indicators or supervisor ratings of performance. In addition, future studies could consider other organizational outcomes of financial stress such as absenteeism, job satisfaction, organizational commitment, and turnover.

The relationship between financial strain and performance was non-significant. There are several possible explanations for this null result, which should be considered for future research. First, other studies linking financial stress to performance should examine non-linear relationships such as the inverted-U relationship. Studies could also test for relationships above particular thresholds of financial strain. Second, future research should consider social support, job attitudes, and individual differences as moderators to the financial strain-job performance relationship as they are likely to affect the extent to which emotional resources are acquired, allocated, and retained. Finally, future studies should examine the financial strain-job performance relationship in jobs where emotional resources are more necessary for performance, such as customer service, teaching, or nursing.

The dimensions of perceived income adequacy had different effects on different aspects of performance, presenting an opportunity for subsequent research to 
explore these different theoretical mechanisms. Perceived income adequacy to afford needs seems to operate on equity-driven mechanisms, while income adequacy to afford wants is associated with goal-directed mechanisms. It would be interesting for researchers to propose and test a model that integrates these two dimensions and the mechanisms that connect them with job performance. More research, however, is needed to confirm these findings in different occupations and samples to establish the generalizability of these results.

Not only should future studies consider different types of jobs, but research should investigate workers who vary in their level of income and economic demands as well. The relationships between financial stress and outcomes may differ depending on an individual's or families' absolute income level or poverty status (Whelan, 1992; 2001). Further, research by Heymann (e.g., Heymann \& Barrera, 2008) and Swanberg (e.g., Swanberg, 2005) highlight the ways in which family responsibilities, such as caring for children or caring for elderly, exacerbate the challenges of poverty for working families in the U.S. and worldwide. Thus, future research should consider these populations, specifically.

Regarding measurement, future research should examine the nomological network of other constructs associated with perceived income adequacy and financial strain. My fit indices and reliability estimates suggest that the Chinese measures of these constructs can be improved and so future research should attempt to better capture this content domain. Finally, it remains a question as to whether or not financial stress constructs and relationships with other variables are structurally 
similar across cultures. These studies revealed different degrees of relationships between perceived income adequacy to afford wants and needs, which signifies that there are potentially fundamental differences in these constructs across cultures. This is another interesting area for future research.

\section{Conclusion}

As the world changes and evolves, so do national economies, organizations, and the nature of work itself. It is the duty of organizational researchers to anticipate and identify these changes in order to understand how they will affect worker and organizational well-being. The increase of global competition represents one multifaceted way in which the world, economies, etc. are shifting and leaving many individuals around the world concerned about their financial well-being. The overarching objective of this thesis has been to anticipate and identify financial stress as an existing and potentially growing problem among employees worthy of its own study within the organizational literature. I hope that this thesis has provided a sufficient theoretical foundation and empirical base to encourage future studies of financial stress and work. A better understanding of how these issues affect workers is the first step in helping prevent and alleviate the detrimental effects of financial stress on employees. 
Financial Stress 99

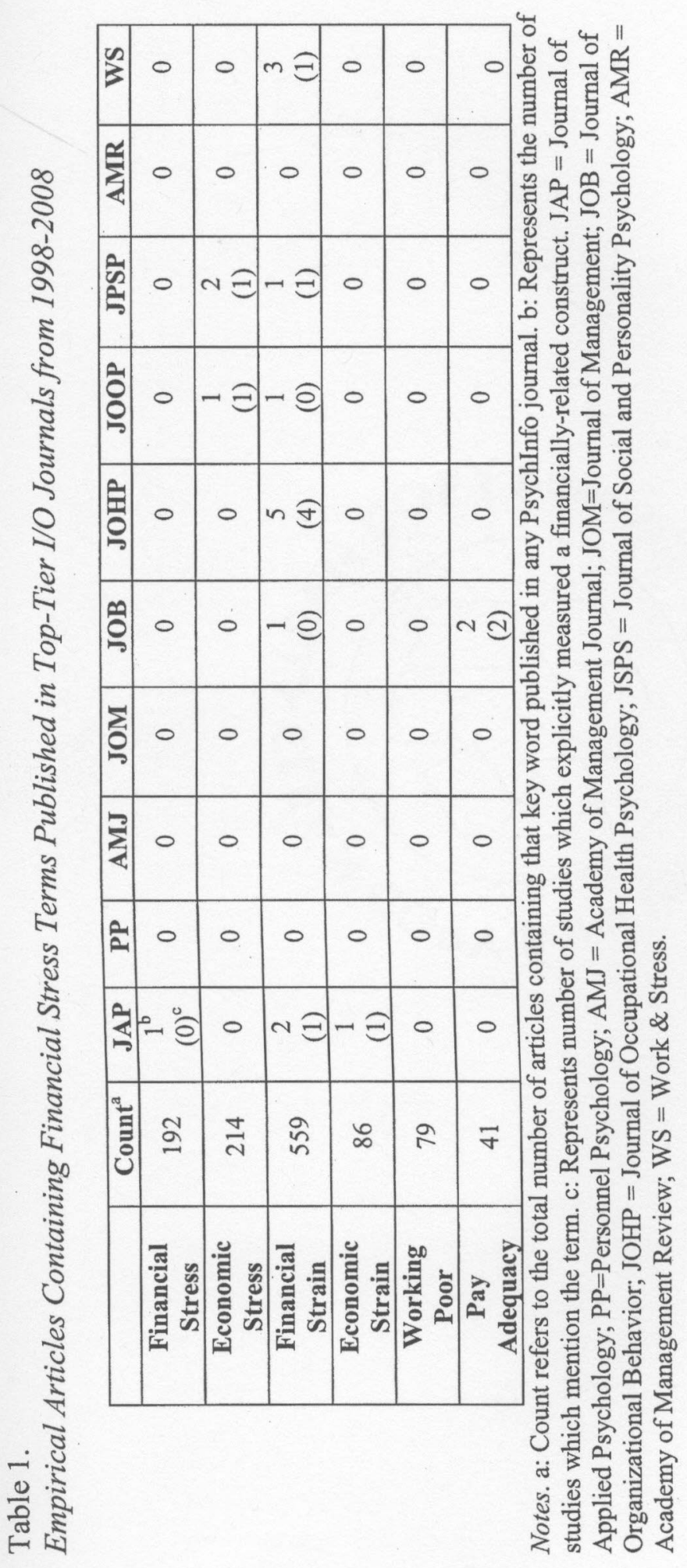


Table 2.

Sample of Operational Components of Financial Stress from Literature

\begin{tabular}{|c|c|c|c|c|c|}
\hline \multirow[b]{2}{*}{ Source } & \multirow[b]{2}{*}{ Construct } & \multirow[b]{2}{*}{ Operationalization } & \multicolumn{3}{|c|}{ Component } \\
\hline & & & $\begin{array}{c}\text { Objective } \\
\text { Calculation }\end{array}$ & \begin{tabular}{|c|} 
Perceived \\
Income \\
Adequacy \\
\end{tabular} & $\begin{array}{c}\text { Perceived } \\
\text { Financial } \\
\text { Strain }\end{array}$ \\
\hline $\begin{array}{l}\text { Conger et } \\
\text { al. }(1990)\end{array}$ & $\begin{array}{l}\text { Economic } \\
\text { Pressure }\end{array}$ & $\begin{array}{l}\text { Changes in family } \\
\text { resources (income) that are } \\
\text { inadequate to keep up with } \\
\text { family demands and } \\
\text { inflation }\end{array}$ & $\mathbf{X}$ & & \\
\hline $\begin{array}{c}\text { George \& } \\
\text { Brief } \\
(1990)\end{array}$ & $\begin{array}{c}\text { Financial } \\
\text { Need }\end{array}$ & $\begin{array}{l}\text { Marital status, spouse } \\
\text { employment status, and } \\
\text { number of dependants }\end{array}$ & $\mathbf{X}$ & & \\
\hline $\begin{array}{l}\text { Simons et } \\
\text { al. (1992) }\end{array}$ & $\begin{array}{l}\text { Economic } \\
\text { Hardship }\end{array}$ & Adverse economic event. & $\mathbf{X}$ & & \\
\hline $\begin{array}{c}\text { Fox \& } \\
\text { Chancey } \\
(1998)\end{array}$ & $\begin{array}{l}\text { Economic } \\
\text { Sufficiency }\end{array}$ & $\begin{array}{l}\text { Extent of economic } \\
\text { deprivation; total } \\
\text { household income }\end{array}$ & $\mathbf{X}$ & & \\
\hline $\begin{array}{l}\text { Sinclair \& } \\
\text { Martin } \\
(2006)\end{array}$ & $\begin{array}{c}\text { Economic } \\
\text { Stress }\end{array}$ & Total family income level. & $\mathbf{X}$ & & \\
\hline $\begin{array}{l}\text { Voydanoff } \\
\text { (1990) }\end{array}$ & $\begin{array}{l}\text { Economic } \\
\text { Deprivation }\end{array}$ & $\begin{array}{l}\text { The inability to meet } \\
\text { current financial needs; the } \\
\text { loss of financial resources } \\
\text { and income over a period } \\
\text { of time. }\end{array}$ & $\mathbf{X}$ & $\mathbf{X}$ & \\
\hline $\begin{array}{l}\text { Hoard } \\
(2004)\end{array}$ & $\begin{array}{c}\text { Economic } \\
\text { Strain }\end{array}$ & $\begin{array}{l}\text { Perceived and actual } \\
\text { economic hardships. }\end{array}$ & $\mathbf{X}$ & $\mathbf{X}$ & \\
\hline $\begin{array}{c}\text { Elder \& } \\
\text { Caspi } \\
(1988)\end{array}$ & $\begin{array}{l}\text { Economic } \\
\text { Stress }\end{array}$ & $\begin{array}{l}\text { Pressures and strains that } \\
\text { arise from a substantial } \\
\text { income loss. }\end{array}$ & $\mathbf{X}$ & & $\mathbf{X}$ \\
\hline $\begin{array}{c}\text { Pearlin \& } \\
\text { Radabaugh } \\
\text { (1976) }\end{array}$ & $\begin{array}{l}\text { Economic } \\
\text { Strain }\end{array}$ & $\begin{array}{l}\text { Not being able to afford } \\
\text { the things you "should } \\
\text { have" }\end{array}$ & & $\mathbf{X}$ & \\
\hline $\begin{array}{l}\text { Conger et } \\
\text { al. (1990) }\end{array}$ & $\begin{array}{l}\text { Economic } \\
\text { Strain }\end{array}$ & $\begin{array}{l}\text { Difficulty paying bills, } \\
\text { making ends meet, and } \\
\text { adapting behavior to } \\
\text { acknowledge hardship. }\end{array}$ & . & $\mathbf{X}$ & \\
\hline $\begin{array}{l}\text { Takeuchi et } \\
\text { al. (1991) }\end{array}$ & $\begin{array}{l}\text { Economic } \\
\text { Stress }\end{array}$ & $\begin{array}{l}\text { Perceived ability to meet } \\
\text { financial obligations }\end{array}$ & & $\mathbf{X}$ & \\
\hline $\begin{array}{l}\text { Simons et } \\
\text { al. (1992) }\end{array}$ & $\begin{array}{c}\text { Economic } \\
\text { Strain }\end{array}$ & $\begin{array}{l}\text { Judgment that family } \\
\text { resources are not adequate } \\
\text { to meet family needs }\end{array}$ & & $\mathbf{X}$ & \\
\hline
\end{tabular}


Table 2. (Continued)

Sample of Operational Components of Financial Stress from Literature

\begin{tabular}{|c|c|c|c|c|c|}
\hline \multirow[b]{2}{*}{ Source } & \multirow[b]{2}{*}{ Construct } & \multirow[b]{2}{*}{ Operationalization } & \multicolumn{3}{|c|}{ Component } \\
\hline & & & $\begin{array}{c}\text { Objective } \\
\text { Calculation }\end{array}$ & $\begin{array}{l}\text { Perceived } \\
\text { Income } \\
\text { Adequacy }\end{array}$ & $\begin{array}{c}\text { Perceived } \\
\text { Financial } \\
\text { Strain }\end{array}$ \\
\hline $\begin{array}{l}\text { Whelan } \\
\text { (1992) }\end{array}$ & $\begin{array}{l}\text { Primary } \\
\text { Deprivation }\end{array}$ & $\begin{array}{l}\text { Inability to afford things } \\
\text { deemed as necessities by } \\
\text { society. }\end{array}$ & & $\mathbf{X}$ & \\
\hline $\begin{array}{l}\text { Whelan } \\
\text { (1992) }\end{array}$ & $\begin{array}{l}\text { Secondary } \\
\text { Deprivation }\end{array}$ & $\begin{array}{l}\text { Inability to afford things } \\
\text { not deemed as necessities } \\
\text { by society. }\end{array}$ & & $\mathbf{X}$ & \\
\hline $\begin{array}{l}\text { Whelan } \\
\text { (1992) }\end{array}$ & $\begin{array}{c}\text { Economic } \\
\text { Strain }\end{array}$ & $\begin{array}{l}\text { Perceived ability to make } \\
\text { ends meet }\end{array}$ & & $\mathbf{X}$ & \\
\hline $\begin{array}{l}\text { Peirce et al. } \\
\text { (1996) }\end{array}$ & $\begin{array}{c}\text { Financial } \\
\text { Stress } \\
\text { (Acute) }\end{array}$ & $\begin{array}{l}\text { Discrete financial setbacks } \\
\text { that may or may not lead } \\
\text { to chronic stress. }\end{array}$ & & $\mathbf{X}$ & \\
\hline $\begin{array}{l}\text { Peirce et al. } \\
\qquad(1996)\end{array}$ & $\begin{array}{l}\text { Financial } \\
\text { Stress } \\
\text { (Chronic) } \\
\end{array}$ & $\begin{array}{l}\text { The persistent inability to } \\
\text { afford the basic necessities } \\
\text { of life. }\end{array}$ & & $\mathbf{X}$ & \\
\hline $\begin{array}{l}\text { Fox \& } \\
\text { Chancey } \\
(1998)\end{array}$ & $\begin{array}{l}\text { Perceived } \\
\text { Economic } \\
\text { Well-being }\end{array}$ & $\begin{array}{l}\text { Subjective perception of } \\
\text { one's economic situation } \\
\text { or relative economic well- } \\
\text { being }\end{array}$ & & $\mathbf{X}$ & \\
\hline $\begin{array}{l}\text { Gorgievski } \\
\text { Duijvesteijn } \\
\text { et al. (2000) }\end{array}$ & $\begin{array}{l}\text { Perceived } \\
\text { Financial } \\
\text { Problems }\end{array}$ & $\begin{array}{l}\text { Frequency with which } \\
\text { people had trouble making } \\
\text { ends meet, paying bills on } \\
\text { time, or replacing worn } \\
\text { out tools. }\end{array}$ & & $\mathbf{X}$ & \\
\hline $\begin{array}{l}\text { Waters \& } \\
\text { Moore } \\
(2002)\end{array}$ & $\begin{array}{l}\text { Financial } \\
\text { Deprivation }\end{array}$ & $\begin{array}{l}\text { The extent to which } \\
\text { spending is curtailed for } \\
\text { necessary things and non- } \\
\text { necessary things }\end{array}$ & & $\mathbf{X}$ & \\
\hline $\begin{array}{l}\text { Kim \& } \\
\text { Garman } \\
(2003)\end{array}$ & $\begin{array}{l}\text { Financial } \\
\text { Stress }\end{array}$ & $\begin{array}{l}\text { The subjective perception } \\
\text { of one's personal finances; } \\
\text { perceived economic well- } \\
\text { being. }\end{array}$ & & $\mathbf{X}$ & \\
\hline $\begin{array}{l}\text { Lyons } \\
(2005)\end{array}$ & $\begin{array}{l}\text { Economic } \\
\text { Strain }\end{array}$ & $\begin{array}{l}\text { Inability to meet current } \\
\text { expenses. }\end{array}$ & & $\mathbf{X}$ & \\
\hline $\begin{array}{l}\text { Warr \& } \\
\text { Jackson } \\
(1987)\end{array}$ & $\begin{array}{l}\text { Financial } \\
\text { Strain }\end{array}$ & $\begin{array}{l}\text { Serious financial worries, } \\
\text { inability to do things } \\
\text { because of money, \& } \\
\text { inability to manage money }\end{array}$ & & $\mathbf{X}$ & $\mathbf{X}$ \\
\hline
\end{tabular}


Table 2. (Continued)

Sample of Operational Components of Financial Stress from Literature

\begin{tabular}{|c|c|c|c|c|c|}
\hline \multirow[b]{2}{*}{ Source } & \multirow[b]{2}{*}{ Construct } & \multirow[b]{2}{*}{ Operationalization } & \multicolumn{3}{|c|}{ Component } \\
\hline & & & $\begin{array}{c}\text { Objective } \\
\text { Calculation }\end{array}$ & $\begin{array}{l}\text { Perceived } \\
\text { Income } \\
\text { Adequacy }\end{array}$ & $\begin{array}{c}\text { Perceived } \\
\text { Financial } \\
\text { Strain }\end{array}$ \\
\hline $\begin{array}{l}\text { Voydanoff } \\
\text { (1990) }\end{array}$ & $\begin{array}{l}\text { Economic } \\
\text { Strain }\end{array}$ & $\begin{array}{l}\text { An evaluation of current } \\
\text { financial status such as } \\
\text { perceived financial } \\
\text { adequacy, } \\
\text { concerns/worries, } \\
\text { adjustments to changes in } \\
\text { one's financial situation, } \\
\text { and one's projected } \\
\text { financial situation. }\end{array}$ & & $\mathbf{X}$ & $\mathbf{X}$ \\
\hline $\begin{array}{l}\text { Vinokur et } \\
\text { al. (1996) }\end{array}$ & $\begin{array}{c}\text { Financial } \\
\text { Strain }\end{array}$ & $\begin{array}{l}\text { Perceived economic } \\
\text { pressure }\end{array}$ & & $\mathbf{x}$ & $\mathbf{X}$ \\
\hline $\begin{array}{c}\text { Mauno \& } \\
\text { Kinnunen } \\
(2002)\end{array}$ & $\begin{array}{l}\text { Economic } \\
\text { Stress }\end{array}$ & $\begin{array}{l}\text { Worry that finances can't } \\
\text { pay bills; trouble meeting } \\
\text { expenses }\end{array}$ & & $\mathbf{X}$ & $\mathbf{x}$ \\
\hline $\begin{array}{l}\text { McKee- } \\
\text { Ryan et al. } \\
(2005)\end{array}$ & $\begin{array}{c}\text { Perceived } \\
\text { Financial } \\
\text { Strain }\end{array}$ & $\begin{array}{l}\text { Worry about finances and } \\
\text { difficulty paying bills }\end{array}$ & & $\mathbf{X}$ & $\mathbf{X}$ \\
\hline $\begin{array}{c}\text { Warr \& } \\
\text { Jackson } \\
(1987)\end{array}$ & $\begin{array}{l}\text { Financial } \\
\text { Strain }\end{array}$ & $\begin{array}{l}\text { Serious financial worries, } \\
\text { inability to do things, and } \\
\text { inability to manage money }\end{array}$ & & $\mathbf{X}$ & $\mathbf{X}$ \\
\hline $\begin{array}{l}\text { Bailey et al. } \\
\text { (1998) }\end{array}$ & $\begin{array}{l}\text { Financial } \\
\text { stress }\end{array}$ & $\begin{array}{l}\text { Personal stress caused by } \\
\text { concerns over financial } \\
\text { well-being }\end{array}$ & & & $\mathbf{X}$ \\
\hline
\end{tabular}


Table 3.

Operational Components of Financial Stress from Graduate Students

\begin{tabular}{|c|c|c|c|}
\hline \multirow[b]{2}{*}{ Operationalization } & \multicolumn{3}{|c|}{ Component } \\
\hline & $\begin{array}{c}\text { Objective } \\
\text { Calculation }\end{array}$ & $\begin{array}{c}\text { Perceived } \\
\text { Income } \\
\text { Adequacy }\end{array}$ & $\begin{array}{l}\text { Perceived } \\
\text { Financial } \\
\text { Strain }\end{array}$ \\
\hline $\begin{array}{l}\text { Environmental demands (rent, gas, car, etc.) exceeds or } \\
\text { comes close to a person's resources. }\end{array}$ & $\mathbf{X}$ & & \\
\hline Not being able to cover all of your expenses. & $\mathbf{X}$ & & \\
\hline Not having enough money to pay my bills. & $\mathbf{X}$ & & \\
\hline $\begin{array}{l}\text { Excessive strain I think is exemplified by unpaid bills, } \\
\text { going without food, turning off utilities, and excessive } \\
\text { borrowing from friends or family. I guess I started by } \\
\text { focusing on concrete examples of what might indicate } \\
\text { economic hardship...this may be different than "strain". I } \\
\text { am guessing that people of all monetary levels may } \\
\text { experience "strain". } \\
\text { So maybe strain would deal with emotional aspects, such } \\
\text { as excessive worry over finances, rumination over } \\
\text { financial matters, or even physical symptoms that might } \\
\text { be associated with the worrying (headaches, stomach } \\
\text { issues). }\end{array}$ & $\mathbf{X}$ & & $\mathbf{X}$ \\
\hline $\begin{array}{l}\text { Deficiency of income in relation to amount of debt and } \\
\text { obligation resulting in a stressor triggered by any further } \\
\text { need of money. }\end{array}$ & $\mathbf{X}$ & & $\mathbf{X}$ \\
\hline $\begin{array}{l}\text { Inability to afford basic necessities. A person feels } \\
\text { economic strain when one is unable to afford something } \\
\text { that is needed like food, rent, etc. }\end{array}$ & & $\mathbf{X}$ & \\
\hline Lack of money. & & $\mathbf{X}$ & \\
\hline $\begin{array}{l}\text { My first thought is that economic strain is going to be } \\
\text { very relative based upon lifestyle demands. Many folks } \\
\text { are deeply in debt and struggle to make ends meet because } \\
\text { they live beyond their means. } \\
\text { So, economic strain could be: "a struggle to financially } \\
\text { meet lifestyle demands and essential needs." }\end{array}$ & & $\mathbf{X}$ & \\
\hline $\begin{array}{l}\text { Stress or strain that arises due to lack of money, or not } \\
\text { being able to make ends meet }\end{array}$ & & $\mathbf{X}$ & $\mathbf{X}$ \\
\hline Stress created by financial situation. & & $\mathbf{X}$ & $\mathbf{X}$ \\
\hline $\begin{array}{l}\text { Worry about money, finding the money for the } \\
\text { 'necessities' of life. }\end{array}$ & & $\mathbf{X}$ & $\mathbf{X}$ \\
\hline $\begin{array}{l}\text { Financial concerns in a persons life that push them toward } \\
\text { a breaking point }\end{array}$ & & & $\mathbf{X}$ \\
\hline $\begin{array}{l}\text { People under economic strain that is severe or prolonged } \\
\text { spend more time worrying about money }\end{array}$ & & & $\mathbf{X}$ \\
\hline
\end{tabular}


Table 4.

Means and Standard Deviations for All Financial Stress Items in Study 1

\begin{tabular}{|c|c|c|}
\hline Dimension $^{\mathrm{a}}$ and Items & Mean & SD \\
\hline \multicolumn{3}{|l|}{ Income Adequacy for Current Needs } \\
\hline I can afford the health care I need.* & 2.74 & 1.43 \\
\hline I do not need to borrow money in order to pay my bills. & 3.19 & 1.33 \\
\hline I cannot pay my bills on time. $(\mathrm{R})$ & 4.00 & 1.04 \\
\hline I can afford to pay my utilities (heat, water, gas, etc). & 3.93 & 1.03 \\
\hline I can afford the child care/elder care my family needs. & 3.09 & .89 \\
\hline $\begin{array}{l}\text { I am able to pay my expenses without overdrawing my bank } \\
\text { account. }\end{array}$ & 3.86 & .98 \\
\hline I cannot pay for the clothes I need. $(R)$ & 3.54 & 1.16 \\
\hline I cannot afford the basic transportation I need. (R) & 3.93 & .99 \\
\hline $\begin{array}{l}\text { I can afford the basic housing (e.g. rent, mortgage) I need to } \\
\text { survive. }\end{array}$ & 3.89 & 1.00 \\
\hline I cannot afford the food I need to survive. (R) & 4.04 & .95 \\
\hline I can afford the insurance I need. & 3.10 & 1.33 \\
\hline \multicolumn{3}{|l|}{ Income Adequacy for Current Wants } \\
\hline I cannot pay for the clothes I want. (R) & 2.82 & 1.37 \\
\hline I cannot afford the kind of transportation I want. (R) & 3.07 & 1.38 \\
\hline I can afford the type of housing I want. & 2.57 & 1.24 \\
\hline I cannot pay for the type of food I like to eat. (R)* & 3.31 & 1.21 \\
\hline I cannot afford the household items I want. (R) & 2.93 & 1.20 \\
\hline I cannot afford to replace broken or worn out things. (R)* & 3.22 & 1.17 \\
\hline I can afford the recreation/ entertainment I like. & 2.91 & 1.17 \\
\hline I can afford to save as much money as I want to be saving. & 1.79 & .98 \\
\hline My current income allows me to have the lifestyle I want. & 2.16 & 1.08 \\
\hline I have extra money for unexpected expenses. & 2.38 & 1.26 \\
\hline I cannot save for retirement at the rate I want to save. (R) & 2.04 & 1.15 \\
\hline I am currently unable to meet my financial goals. (R) & 2.56 & 1.22 \\
\hline I can afford to travel where I want.* & 1.87 & 1.04 \\
\hline I cannot afford to eat at the kind of restaurant I like. (R) & 2.98 & 1.21 \\
\hline I can afford the insurance I want.* & 2.72 & 1.37 \\
\hline \multicolumn{3}{|l|}{ Financial Stress } \\
\hline My financial situation is demanding. & 3.97 & .93 \\
\hline I feel pressured by my financial situation. & 3.99 & 1.04 \\
\hline My financial situation is hectic. & 3.53 & 1.16 \\
\hline I feel calm about my financial situation. (R) & 3.60 & 1.15 \\
\hline I am relaxed regarding my financial situation. (R) & 3.69 & 1.13 \\
\hline I feel pushed by my financial situation. & 3.70 & 1.12 \\
\hline My financial situation is irritating. & 3.74 & 1.11 \\
\hline I have my financial situation under control. $(\mathrm{R})^{*}$ & 3.05 & 1.17 \\
\hline My financial situation is nerve-wracking.* & 3.32 & 1.25 \\
\hline I feel hassled by my financial situation.* & 3.47 & 1.20 \\
\hline I am comfortable with my financial situation. (R) & 3.47 & 1.17 \\
\hline My financial situation is more stressful than I'd like. & 3.85 & 1.07 \\
\hline My financial situation is overwhelming.* & 3.06 & $1.25^{\circ}$ \\
\hline My financial situation makes me nervous/ anxious.* & 3.47 & 1.19 \\
\hline My financial situation makes me feel emotionally drained.* & 3.10 & 1.30 \\
\hline My financial situation makes me feel unhappy.* & 3.15 & 1.24 \\
\hline My financial situation makes me feel depressed.* & 2.90 & 1.30 \\
\hline
\end{tabular}


Financial Stress 105

Notes. a: Dimensions represent the intended category for each item. $(\mathrm{R})=$ items that have been reverse coded; $*=$ items that were omitted from final scales due to crossed factor loadings or theoretical inconsistencies with the factor. 
Table 5.

Exploratory Factor Analysis for Current Income Adequacy Scales in Study 1

\begin{tabular}{lll}
\multicolumn{1}{c}{ Item } & \multicolumn{2}{c}{ Factor $^{\mathrm{a}}$} \\
\cline { 2 - 3 } My current income allows me to have the lifestyle I want. & $1^{\mathrm{b}}$ & $2^{\mathrm{c}}$ \\
\hline I cannot afford the household items I want. (R) & .80 \\
I cannot pay for the clothes I want. (R) & .69 \\
I cannot afford to eat at the kind of restaurant I like. (R) & .66 \\
I am currently unable to meet my financial goals. (R) & .66 \\
I can afford the type of housing I want. & .65 \\
I cannot save for retirement at the rate I want to save. (R) & .64 \\
I can afford to save as much money as I want to be saving. & .61 \\
I have extra money for unexpected expenses. & .58 \\
I cannot afford the kind of transportation I want. (R) & .55 \\
I can afford the recreation/ entertainment I like. & .46 \\
I cannot afford the basic transportation I need. (R) & .46 \\
I cannot pay my bills on time. (R) & \\
I can afford to pay my utilities (heat, water, gas, etc). & .73 \\
I am able to pay my expenses without overdrawing my bank account. & .72 \\
I cannot afford the food I need to survive. (R) & .70 \\
I cannot pay for the clothes I need. (R) & .66 \\
I do not need to borrow money in order to pay my bills. & .65 \\
I can afford the basic housing (e.g. rent, mortgage) I need to survive. & .54 \\
I can afford the child care/elder care my family needs. & .46 \\
I can afford the insurance I need. & .45 \\
\hline
\end{tabular}

Notes. a: Principal Axis Factoring, Promax rotation with Kaiser Normalization. b: Current perceived income adequacy to afford wants. c: Current perceived income adequacy to afford needs. $(R)=$ items that have been reverse coded. 
Table 6.

Exploratory Factor Analysis for Financial Strain in Study 1

\begin{tabular}{lc}
\hline \multicolumn{1}{c}{ Item } & Factor $^{\mathrm{a}}$ \\
\hline I feel pressured by my financial situation. & .88 \\
R- I am relaxed regarding my financial situation. (R) & .84 \\
R- I feel calm about my financial situation. (R) & .83 \\
My financial situation is hectic. & .83 \\
My financial situation is more stressful than I'd like. & .79 \\
I feel pushed by my financial situation. & .78 \\
I am comfortable with my financial situation. (R) & .76 \\
My financial situation is irritating. & .76 \\
My financial situation is demanding. & .72 \\
\hline
\end{tabular}

Notes. a: Principal Axis Factoring, Promax rotation with Kaiser Normalization. $(\mathrm{R})=$ items that have been reverse coded. 
Table 7.

Descriptive Statistics, Alpha Coefficients, and Bivariate Correlations for Study 1 Variables

\begin{tabular}{lrrrrrrrr}
\hline & Mean & SD & 1 & 2 & 3 & 4 & 5 & 6 \\
\hline 1. Gender & 1.69 & .46 & & & & & & \\
2. Age & 25.61 & 6.14 & $-.14^{*}$ & & & & & \\
3. Annual & 19.50 & 13.07 & -.08 & $.35^{* *}$ & & & & \\
$\quad$ Income & & & & & & & & \\
4. Annual & 16.93 & 13.27 & $-.12^{*}$ & $.31^{* *}$ & $.63^{* *}$ & & & \\
$\quad$ Expenses & & & & & & & & \\
5. PIA Needs & 3.72 & .68 & -.05 & -.04 & $.27^{* *}$ & .09 & $(.89)$ & \\
6. PIA Wants & 2.57 & .83 & $-.14^{*}$ & -.10 & $.24^{* *}$ & .08 & $.62^{* *}$ & $(.83)$ \\
7. Financial & 3.73 & .90 & $.19^{* *}$ & .06 & $-.14^{*}$ & -.07 & $-.47^{* *}$ & $-.71^{* *}(.93)$ \\
$\quad$ Strain & & & & & & & & \\
\hline
\end{tabular}

Notes. Gender was coded as 1 for male, 2 for female. Annual income and expenses were scaled in units of $\$ 1,000$. Responses to PIA Needs, PIA wants, and Financial Strain were rated on a scale ranging from 1 (strongly disagree) to 5 (strongly agree). Sample sizes ranged from 283 to 285 . Values in parentheses are alpha coefficients. PIA $=$ Perceived Income Adequacy.

${ }^{*} p<.05,{ }^{* *} p<.01$, two-tailed. 
Financial Stress 109

Table 8

Model comparison results for Study 1

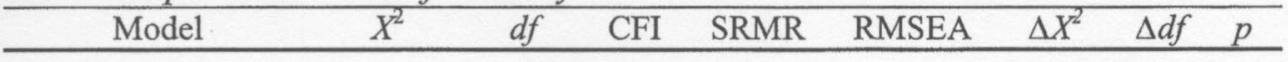

$\begin{array}{llllll}\begin{array}{l}\text { Full Mediation } \\ \text { Model }\end{array} & 1128.84 & 485 & .86 & .06 & .07\end{array}$

$\begin{array}{lllllllll}\text { Partial Mediation } & 1127.27 & 483 & .86 & .06 & .07 & 1.57 & 2 & .46 \\ \text { Model } & 112 & \end{array}$

Notes. CFI $=$ comparative fit index; SRMR $=$ standardized root mean square residual; RMSEA $=$ Root mean square error of approximation 
Financial Stress 110

Table 9.

Tests of Indirect Effects of Income and Expenses on Financial Strain for Study 1

\begin{tabular}{lcc}
\hline Antecedent and Mediator & $95 \%$ CI (PB) & $95 \%$ CI (BCB) \\
\hline Income & $-0.02,0.08$ & $-0.03,0.08$ \\
Income Adequacy for Needs & $-0.41,-0.06^{*}$ & $-0.37,-0.04^{*}$ \\
Income Adequacy for Wants & $-0.37,-0.05^{*}$ & $-0.34,-0.04^{*}$ \\
Sum of Indirect Effect & &
\end{tabular}

Expenses

Income Adequacy for Needs

$-0.07,0.02 \quad-0.08,0.01$

Income Adequacy for Wants

$-0.01,0.44$

$-0.02,0.42$

Sum of Indirect Effect

$-0.01,0.41$

$-0.02,0.39$

Notes: Unstandardized estimates are reported. $\mathrm{CI}=$ Confidence Interval; PB = Percentile bootstrap; $\mathrm{BCB}=$ Bias-corrected bootstrap.

$* p<.05$ 
Table 10

Means and Standard Deviations for All Financial Stress Items in Study 2

\begin{tabular}{|c|c|c|}
\hline Item & Mean & $\begin{array}{c}\text { Std. } \\
\text { Deviation }\end{array}$ \\
\hline Income Adequacy for Current Wants & . & \\
\hline My current income allows me to have the lifestyle I want. & 2.03 & .96 \\
\hline I am currently unable to meet my financial goals. (R)* & 2.43 & 1.14 \\
\hline I can afford to save as much money as I want to be saving. & 2.10 & 1.04 \\
\hline I have extra money for unexpected expenses. & 2.41 & 1.09 \\
\hline I can afford to travel where I want. & 2.04 & 1.01 \\
\hline I can afford the type of housing I want. & 2.10 & 1.13 \\
\hline I cannot afford the household items I want. (R)* & 2.88 & 1.19 \\
\hline I cannot pay for the clothes I need. $(R)$ & 3.13 & 1.08 \\
\hline I cannot save for retirement at the rate I want to save. (R)* & 2.65 & 1.03 \\
\hline I can afford the recreation/ entertainment I like. & 2.51 & 1.14 \\
\hline \multicolumn{3}{|l|}{ Income Adequacy for Current Needs } \\
\hline I cannot afford the food I need to survive. (R) & 3.72 & .96 \\
\hline I cannot afford the basic transportation I need. (R) & 3.55 & 1.07 \\
\hline I can afford to pay my utilities (heat, water, gas, etc).* & 3.75 & .87 \\
\hline I cannot pay my bills on time. (R) & 3.67 & .94 \\
\hline $\begin{array}{l}\text { I can afford the basic housing (e.g. rent, mortgage) I need } \\
\text { to survive.* }\end{array}$ & 3.54 & .88 \\
\hline \multicolumn{3}{|l|}{ Financial Strain } \\
\hline I feel pressured by my financial situation. & 3.85 & .99 \\
\hline My financial situation is demanding. & 3.17 & 1.20 \\
\hline I am relaxed regarding my financial situation. (R) & 3.90 & .97 \\
\hline I feel calm about my financial situation. $(\mathrm{R})^{*}$ & 3.97 & 1.06 \\
\hline I feel pushed by my financial situation. & 3.71 & 1.04 \\
\hline My financial situation is irritating. & 2.93 & 1.12 \\
\hline My financial situation is hectic. & 3.19 & 1.16 \\
\hline My financial situation is more stressful than I'd like. & 3.30 & 1.05 \\
\hline I am comfortable with my financial situation. (R)* & 3.75 & .95 \\
\hline
\end{tabular}

Notes. a: Dimensions represent the intended category for each item. $(\mathrm{R})=$ items that have been reverse coded; $*=$ items that were omitted from final scales due to crossed factor loadings or theoretical inconsistencies with the factor. 


\section{Table 11}

Exploratory Factor Analysis for Current Income Adequacy Scales in Study 2

\begin{tabular}{lll}
\hline \multicolumn{1}{c}{ Item } & \multicolumn{2}{c}{ Factor $^{\mathrm{a}}$} \\
\cline { 2 - 3 } & $1^{\mathrm{b}}$ & $2^{\mathrm{c}}$ \\
\hline I can afford to travel where I want. & .82 & \\
I have extra money for unexpected expenses. & .70 & \\
I can afford to save as much money as I want to be saving. & .69 & \\
I cannot afford the household items I want. (R)* & .59 & \\
My current income allows me to have the lifestyle I want. & .57 & .83 \\
I can afford the recreation/ entertainment I like. & .42 & .71 \\
I cannot afford the food I need to survive. (R) & & .63 \\
I cannot pay my bills on time. (R) & & .49 \\
I cannot afford the basic transportation I need. (R) & & \\
I cannot pay for the clothes I need. (R) & & \\
Notes. a: Principal Axis Factoring, Promax rotation with Kaiser Normalization. b: Current \\
perceived income adequacy to afford wants. c: Current perceived income adequacy to afford \\
needs. (R) = items that have been reverse coded.
\end{tabular}




\section{Financial Stress 113}

\section{Table 12}

Exploratory Factor Analysis for Financial Strain in Study 2

\begin{tabular}{lc}
\hline \multicolumn{1}{c}{ Item } & Factor $^{\mathrm{a}}$ \\
\hline My financial situation is hectic. & .79 \\
My financial situation is demanding. & .76 \\
I feel pressured by my financial situation. & .75 \\
My financial situation is irritating. & .72 \\
I feel pushed by my financial situation. & .70 \\
My financial situation is more stressful than I'd like. & .65 \\
I am relaxed regarding my financial situation. (R) & .54 \\
\hline
\end{tabular}

Notes. a: Principal Axis Factoring, Promax rotation with Kaiser Normalization. $(\mathrm{R})=$ items that have been reverse coded. 
Financial Stress 114

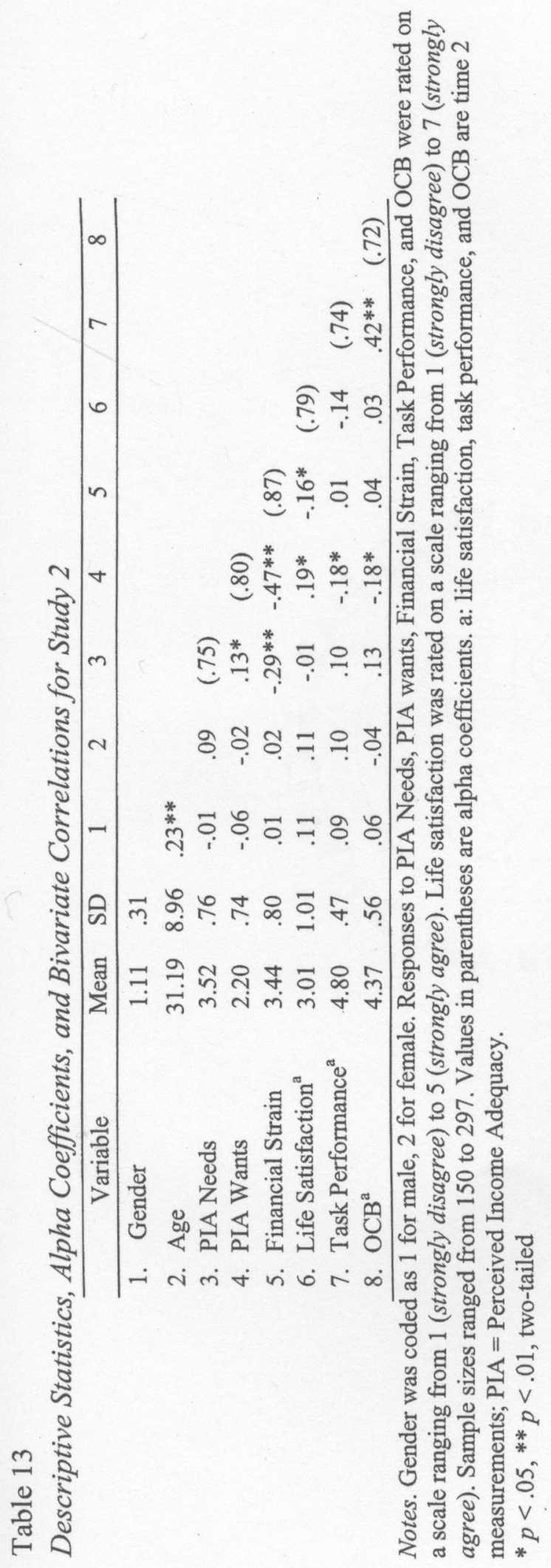


Financial Stress 115

Table 14

Model Comparison Results for Study 2

\begin{tabular}{|c|c|c|c|c|c|c|c|c|}
\hline Model & $X^{2}$ & $d f$ & CFI & SRMR & RMSEA & $\Delta X^{2}$ & $\Delta d f$ & $p$ \\
\hline Saturated Model & 0 & 0 & 1.00 & .00 & .00 & & & \\
\hline $\begin{array}{l}\text { Partial Mediation } \\
\text { Model } 1^{\mathrm{a}}\end{array}$ & 3.26 & 2 & .98 & .03 & .07 & $\begin{array}{c}3.2 \\
6\end{array}$ & 2 & .20 \\
\hline $\begin{array}{l}\text { Partial Mediation } \\
\text { Model } 2^{\mathrm{b}}\end{array}$ & 11.53 & 4 & .91 & .07 & .11 & $\begin{array}{l}11 . \\
53\end{array}$ & 4 & .02 \\
\hline $\begin{array}{l}\text { Full Mediation } \\
\text { Model }\end{array}$ & 14.72 & 6 & .89 & .07 & .10 & $\begin{array}{l}14 . \\
72\end{array}$ & 6 & .02 \\
\hline
\end{tabular}

Notes. All models are compared to the Saturated Model. a: Financial strain partially mediates income adequacy and job performance and fully mediates income adequacy and life satisfaction. b: Financial strain partially mediates income adequacy and life satisfaction and fully mediates income adequacy and job performance. $\mathrm{CFI}=$ comparative fit index; $\mathrm{SRMR}=$ standardized root mean square residual; RMSEA $=$ Root mean square error of approximation. 
Table 15

Bootstrap Confidence Intervals of Indirect Effects Mediated by Financial Strain in Study 2

\begin{tabular}{lll}
\hline Antecedent and Outcome & $95 \%$ CI (PB) & $95 \%$ CI (BCB) \\
\hline Income Adequacy for Needs & & \\
Life Satisfaction & $.000, .102^{*}$ & $.005, .118^{*}$ \\
Task Performance & $-.037, .069$ & $-.030, .084$ \\
OCB & $-.045, .038$ & $-.045, .040$ \\
Income Adequacy for Wants & & \\
Life Satisfaction & $.001, .144^{*}$ & $.008, .159^{*}$ \\
Task Performance & $-.053, .097$ & $-.045, .114$ \\
OCB & $-.058, .052$ & $-.057, .053$ \\
\hline
\end{tabular}

Notes: Unstandardized estimates are reported. $\mathrm{CI}=$ Confidence Interval; $\mathrm{PB}=$ Percentile bootstrap; $\mathrm{BCB}=$ Bias-corrected bootstrap.

$* p<.05$ 
Financial Stress 117

Table 16.

Summary of Findings Across Studies

\begin{tabular}{|l|c|c|}
\hline & Study 1 & Study 2 \\
\hline PIA needs- Financial Strain & n.s. & -.24 \\
\hline PIA wants - Financial Strain & -.82 & -.36 \\
\hline Financial Strain - Life Satisfaction & - & -18. \\
\hline Financial Strain - Job Performance & - & n.s. \\
\hline PIA needs- Task Performance & - & n.s. \\
\hline PIA wants- Task Performance & - & -.21 \\
\hline PIA needs- OCB & - & .16 \\
\hline PIA wants- OCB & - & -.19 \\
\hline
\end{tabular}

Notes. PIA = Perceived Income Adequacy; n.s. = not significant; OCB = Organizational Citizenship Behavior. 
Figure 1.

Voydanoff's (1990) Taxonomy of Economic Distress

\begin{tabular}{|c|c|c|}
\hline & Objective & Subjective \\
\hline Employment & $\begin{array}{l}\quad \text { Employment Instability } \\
\sim \text { extent \& duration of current \& } \\
\text { past unemployment \& } \\
\text { underemployment } \\
\text { extent of downward mobility }\end{array}$ & $\begin{array}{l}\quad \text { Employment Uncertainty } \\
\text { assessment of future prospects } \\
\text { regarding onset of, duration of, \& } \\
\text { recovery from unemployment }\end{array}$ \\
\hline Income & $\begin{array}{l}\quad \text { Economic Deprivation } \\
\text { inability to meet financial needs } \\
\text { L loss of income and financial } \\
\text { resources }\end{array}$ & $\begin{array}{l}\quad \text { Economic Strain } \\
\sim \text { perceived financial adequacy } \\
\sim \text { financial concerns and worries } \\
\text { 〜adjustments to changes in one's } \\
\text { financial situation } \\
\sim \text { one's projected financial situation }\end{array}$ \\
\hline
\end{tabular}


Figure 2.

Economic Stress Concept Map and Terminology

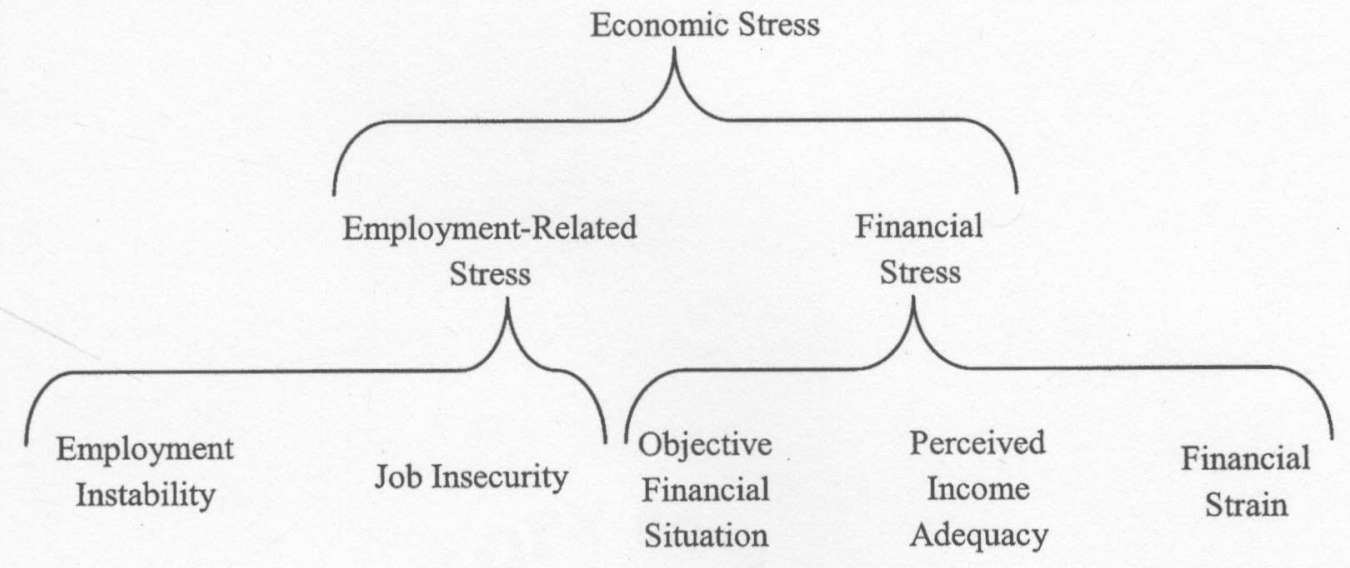


Financial Stress 120

Figure 3.

Two-dimensional Content Domain of Perceived Income Adequacy

\begin{tabular}{c|c|c|} 
& Current & Future \\
\hline Needs & PIA-Current Needs & PIA-Future Needs \\
\hline Lifestyle & PIA-Current Wants & PIA- Future Wants \\
\hline
\end{tabular}

Notes. PIA $=$ Perceived income adequacy. 
Financial Stress $\quad 121$

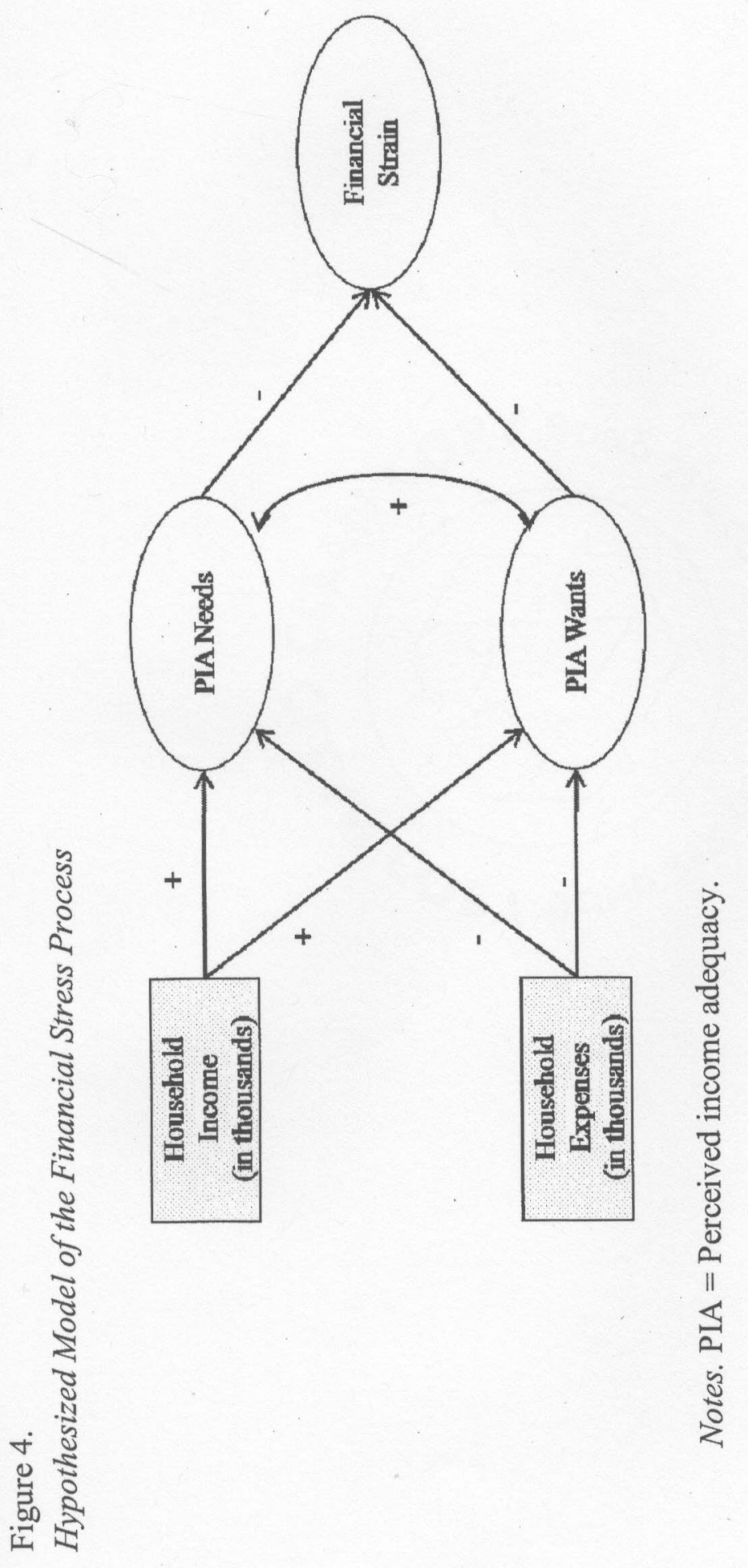


Financial Stress 122

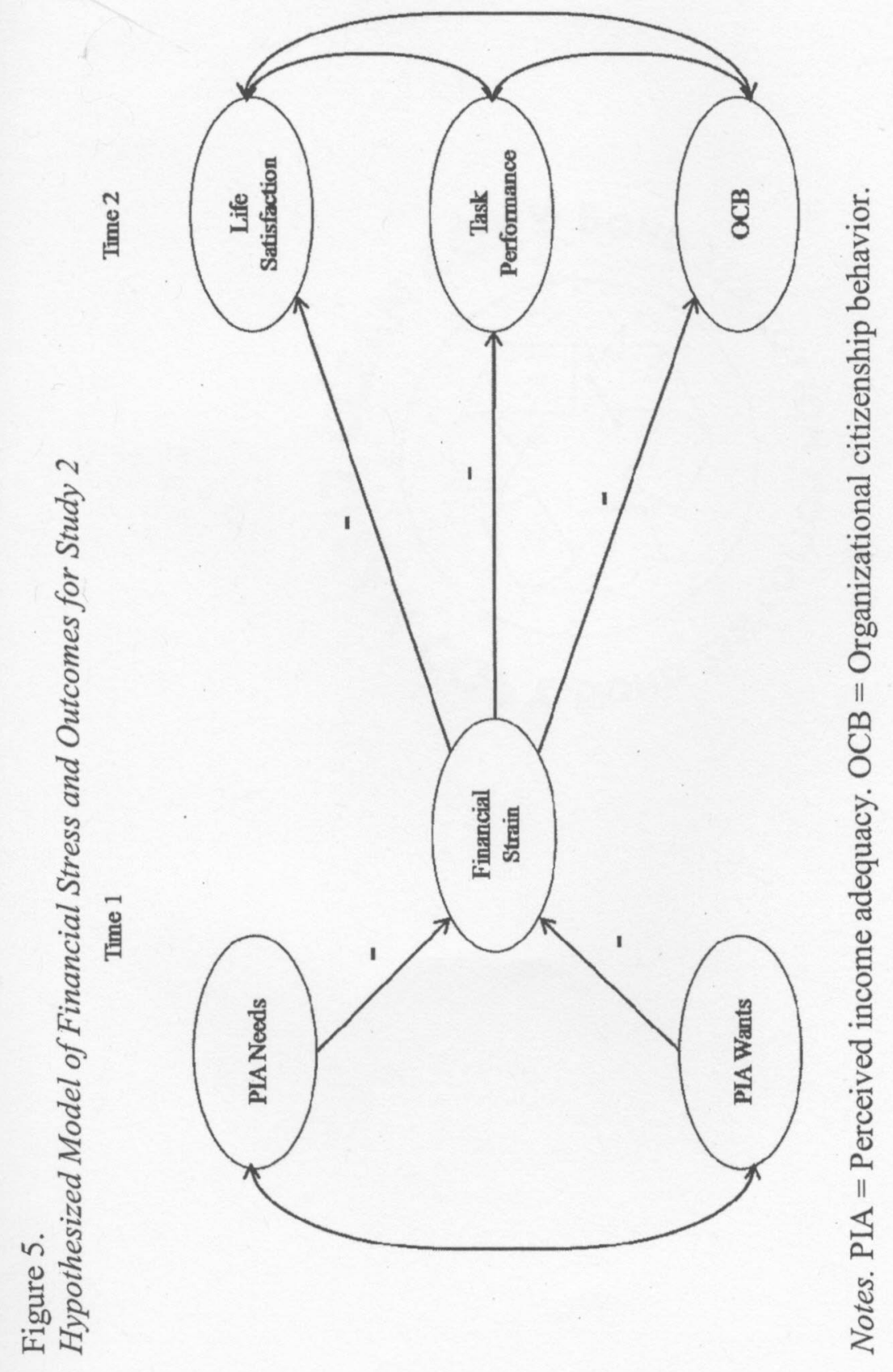


Financial Stress 123

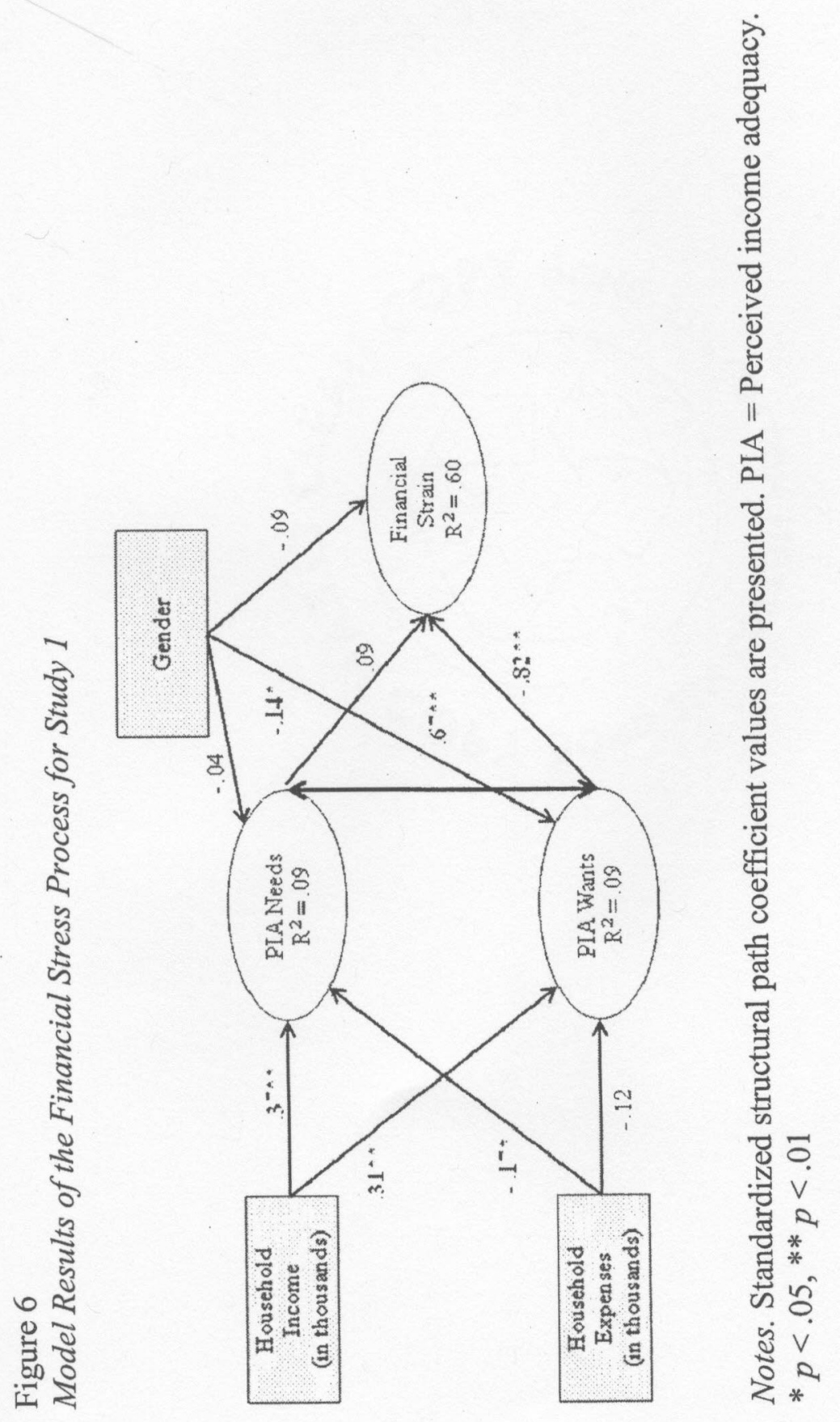


Financial Stress 124

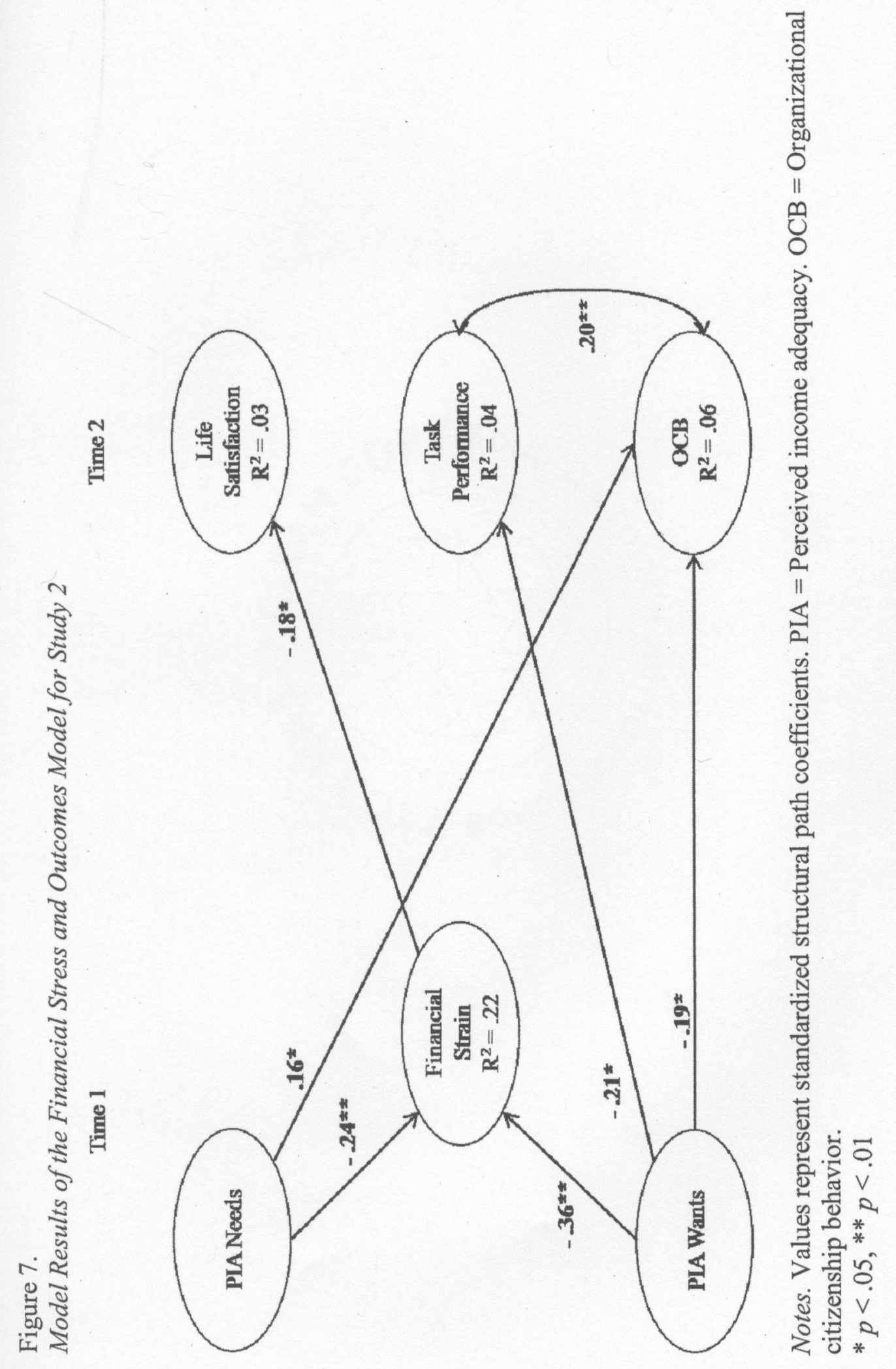




\section{REFERENCES}

Ackerman, N., \& Paolucci, B. (1983). Objective and subjective income adequacy:

Their relationship to perceived life quality measures. Social Indicators Research, 12, 25-48.

Adams, J. (1963). Toward an understanding of inequity. Journal of Abnormal Psychology, 67, 422-436.

American Psychological Association. (1999). Standards for educational and psychological testing. Washington, DC: American Psychological Association.

Andrews, F., \& Withey, S. (1976). Social indicators of well-being: Americans' perceptions of life quality. New York: Plenum Press.

Aryee, S. (1992). Antecedents and outcomes of work-family conflict among married professional women: Evidence from singapore. Human Relations, 45, 813.

Atchley, R. (1991). The influence of aging and frailty on perception and expression of the self: Theoretical and methodological issues. In J. E. Birren, J. Lubben, J. Rowe, \& D. Deutchman (Eds.), The concept and measurement of quality of life in the frail elderly (pp. 207-225). San Diego, CA: Academic Press.

Bailey, W., Woodiel, D., Turner, M., \& Young, J. (1998). The relationship of financial stress to overall stress and satisfaction. Personal Finances and Worker Productivity, 2, 198-206.

Barboza, D. (2008, January 5). In Chinese Factories, Lost Fingers and Low Pay. New York Times. Retrieved on April 15, 2008 from www.nytimes.com/2008/01/05/business/ 
worldbusiness $/ 05$ sweatshop.html? fta $=\mathrm{y}$

Baron, R. A. \& Byrne, D. (1984). Social psychology: Understanding human interaction. (5th ed.). Needham Heights, MA, US: Allyn \& Bacon.

Beaty, J., Jr., Cleveland, J., \& Murphy, K. (2001). The relation between personality and contextual performance in" strong" versus" weak" situations. Human Performance, 14, 125-148.

Beehr, T., \& Franz, T. (1987). The current debate about the meaning of job stress. Journal of Organizational Behavior Management, 8, 5-18.

Beehr, T. A. \& Glazer, S. (2005). Organizational role stress. In J. Barling, E. Kelloway \& M. Frone (Eds.), Handbook of work stress (pp. 267-297). Thousand Oaks, CA: Sage Publications Inc.

Belton, B. (1999, February 17). Fed chief: Tech advances raise job insecurity. USA Today, B2.

Bian, Y. (2002). Chinese social stratification and social mobility. Annual Review of Sociology, 28, 91-116.

Blau, P. M. (1964). Exchange and power in social life. New York: John Wiley.

Bliese, P. D., \& Castro, C. A. (2003). Soldier Adaptation Model: Applications to peacekeeping research. In T. W. Britt, A. B. Adler, \& C. T. Westport (Eds.), The Psychology of the Peacekeeper: Lessons from the Field (pp. 185-203). Westport, CT: Praeger Publishers.

Bono, J., \& Colbert, A. (2005). Understanding responses to multi-source feedback: The role of core self-evaluations. Personnel Psychology, 58, 171-203. 
Borman, W. C., \& Motowidlo, S. J. (1993). Expanding the criterion domain to include elements of contextual performance. In N. Schmitt \& W. C. Borman (Eds.), Personnel Selection in Organizations (pp. 71-98). San Francisco: Jossey-Bass.

Borman, W. (1991). Job behavior, performance, and effectiveness. In M. D. Dunnette \& L. M. Hough (Eds.), Handbook of Industrial and Organizational Psychology ( $2^{\text {nd }}$ ed., Vol. 1, pp. 687-732). Palo Alto, CA: Consulting Psychologists Press.

Boswell, W. R., Olson-Buchanan, J. B., \& LePine, M. A. (2004). The relationship between work-related stress and work outcomes: The role of felt-challenge and psychological strain. Journal of Vocational Behavior, 64, 165-181.

Bradburn, N., \& Noll, C. (1969). The structure of psychological well-being: Chicago, IL: Aldine.

Bradsher, K. (2007, June 8). Rise in China's Pork Prices Signals End to Cheap Output. New York Times, June 8, 2007.

Brett, J., Cron, W., \& Slocum Jr, J. (1995). Economic dependency on work: A moderator of the relationship between organizational commitment and performance. The Academy of Management Journal, 38, 261-271.

Brief, A., Butcher, A., George, J., \& Link, K. (1993). Integrating bottom-up and topdown theories of subjective well-being: The case of health. Journal of Personality and Social Psychology, 64, 646-653.

Brislin, R. W. (1970). Back-translation for cross-cultural research. Journal of CrossCultural Psychology, 1, 185. 
Bureau of Labor Statistics (BLS). (2000). The employment situation: January 2000.

Retrieved April 15, 2008, from

www.bls.gov/news.release/History/empsit_02042000.txt.

Bureau of Labor Statistics (BLS). (2008). The employment situation: January 2008.

Retrieved April 15, 2008, from

www.bls.gov/news.release/archives/empsit_04042008.pdf.

Campbell, J. P., McCloy, R. A., Oppler, S. H., \& Sager, C. E. (1993). A theory of performance. In N. Schmitt \& W. C. Borman (Eds.), Personnel Selection in Organizations (pp. 35-70). San Francisco, CA: Jossey-Bass.

Cannon, W. B. (1929). Bodily changes in pain, hunger, fear and rage. Boston, MA: C. T. Branford.

Casey, H. W., Young, A. Finch, R., \& Broadus, C. (Songwriters). (1993). Gin and juice [Song]. Death Row Records.

Chang, E. C. (1998). Dispositional optimism and primary and secondary appraisal of a stressor: Controlling for confounding influences and relations to coping and psychological and physical adjustment. Journal of Personality and Social Psychology, 74, 1109-1120.

Chiu, R., \& Kosinski Jr, F. (1995). Chinese cultural collectivism and work-related stress: Implications for employment counselors. Journal of Employment Counseling, 32, 98-110.

Chossudovsky, M. (2003). The globalization of poverty and the new world order. $\left(2^{\text {nd }}\right.$ Ed.). Imprint Shanty Bay, Ontario: Global Outlook. 
Chotikapanich, D., Rao, D., \& Tang, K. (2007). Estimating income inequality in China using grouped data and the generalized beta distribution. Review of Income and Wealth, 53, 127-147.

Chou, K., \& Chi, I. (1999). Determinants of life satisfaction in Hong Kong Chinese elderly: A longitudinal study. Aging and Mental Health, 3, 328-335.

Chou, K., \& Chi, I. (2000). Financial strain and depressive symptoms in Hong Kong elderly Chinese: The moderating or mediating effect of sense of control. Aging \& Mental Health, 5, 23-30.

Chou, K., \& Chi, I. (2002). Financial strain and life satisfaction in Hong Kong elderly Chinese: Moderating effect of life management strategies including selection, optimization, and compensation. Aging \& Mental Health, 6, 172-177.

Chou, K., Chi, I., \& Chow, N. (2004). Sources of income and depression in elderly Hong Kong Chinese: Mediating and moderating effects of social support and financial strain. Aging \& Mental Health, 8, 212-221.

Cohen, S., \& Wills, T. (1985). Stress, social support, and the buffering hypothesis. Psychological Bulletin, 98, 310-357.

Conger, R., Elder Jr, G., Lorenz, F., Conger, K., Simons, R., Whitbeck, L., et al. (1990). Linking economic hardship to marital quality and instability. Journal of Marriage and the Family, 52, 643-656.

Conger, R., Ge, X., Elder Jr, G., Lorenz, F., \& Simons, R. (1994). Economic stress, coercive family process, and developmental problems of adolescents. Child Development, 65, 541-561. 
Cowherd, D., \& Levine, D. (1992). Product quality and pay equity between lowerlevel employees and top management: An investigation of distributive justice theory. Administrative Science Quarterly, 37, 302-320.

Crawford, J., \& Henry, J. (2004). The positive and negative affect schedule (PANAS): Construct validity, measurement properties and normative data in a large nonclinical sample. British Journal of Clinical Psychology, 43, 245-265.

Creed, P., \& Evans, B. (2002). Personality, well-being and deprivation theory. Personality and Individual Differences, 33, 1045-1054.

Creed, P., \& Macintyre, S. (2001). The relative effects of deprivation of the latent and manifest benefits of employment on the well-being of unemployed people. Journal of Occupational Health Psychology, 6, 324-331.

Creed, P., Muller, J., \& Machin, M. (2001). The role of satisfaction with occupational status, neuroticism, financial strain and categories of experience in predicting mental health in the unemployed. Personality and Individual Differences, 30 , 435-447.

Creed, P., \& Muller, J. (2006). Psychological distress in the labour market: Shame or deprivation? Australian Journal of Psychology, 58, 31-39.

Cullen, J., \& Hammer, L. (2007). Developing and testing a theoretical model linking work-family conflict to employee safety. Journal of Occupational Health Psychology, 12, 266-278. 
De Jonge, J., \& Dormann, C. (2006). Stressors, resources and strain at work: A longitudinal test of the triple match principle. Journal of applied psychology, 91, 1359-1374.

Diener, E., Suh, E., Smith, H., \& Shao, L. (1995). National differences in reported subjective well-being: Why do they occur? Social Indicators Research, 34, 732.

Diener, E., \& Emmons, R. (1984). The independence of positive and negative affect. Journal of Personality and Social Psychology, 47, 1105-1117.

Diener, E., Oishi, S., \& Lucas, R. (2003). Personality, culture, and subjective wellbeing: Emotional and cognitive evaluations of life. Annual Review of Psychology, 54, 403-425.

Diener, E., Sapyta, J., \& Suh, E. (1998). Subjective well-being is essential to wellbeing. Psychological Inquiry, 9, 33-37.

Doran, L., Stone, V., Brief, A., \& George, J. (1991). Behavioral intentions as predictors of job attitudes: The role of economic choice. Journal of Applied Psychology, 76, 40-45.

Edwards, J. A., Guppy, A., \& Cockerton, T. (2007). A longitudinal study exploring the relationships between occupational stressors, non-work stressors, and work performance. Work \& Stress, 21, 99-116.

Elder Jr, G., \& Caspi, A. (1988). Economic stress in lives: Developmental perspectives. Journal of Social Issues, 44, 25-45. 
Emmons, R., \& Diener, E. (1985). Personality correlates of subjective well-being. Personality and Social Psychology Bulletin, 11, 89.

Fabrigar, L. R., MacCallum, R. C., Wegener, D. T., Strahan, E. J. (1999). Evaluating the use of exploratory factor analysis in psychological research. Psychological Methods, 4, 272-299.

Farh, J., Zhong, C., \& Organ, D. (2004). Organizational citizenship behavior in the People's Republic of China. Organization Science, 15, 241-253.

Feldman, D. (1996). The nature, antecedents and consequences of underemployment. Journal of Management, 22, 385.

Felner, R., Brand, S., DuBois, D., Adan, A., Mulhall, P., \& Evans, E. (1995). Socioeconomic disadvantage, proximal environmental experiences, and socioemotional and academic adjustment in early adolescence: Investigation of a mediated effects model. Child Development, 66, 774-792.

Finch, J., \& West, S. (1997). The investigation of personality structure: Statistical models. Journal of Research in Personality, 31, 439-485.

Folkman, S., \& Moskowitz, J. T. (2000). Positive affect and the other side of coping. American Psychologist, 55, 647-654.

Fox, G., Benson, M., DeMaris, A., \& Wyk, J. (2002). Economic distress and intimate violence: Testing family stress and resources theories. Journal of Marriage and Family, 64, 793-807.

Fox, G., \& Chancey, D. (1998). Sources of economic distress: Individual and family outcomes. Journal of Family Issues, 19, 725. 
Fredrickson, B., \& Losada, M. (2005). Positive affect and the complex dynamics of human flourishing. American Psychologist, 60, 678-686.

Fredrickson, B. L., Mancuso, R. A., Branigan, C., \& Tugade, M. M. (2000). The undoing effect of positive emotions. Motivation and Emotion, 24, 237-258.

Frone, M. R. (2003). Work-family balance. In J. C. Quick \& L. E. Tetrick (Eds.), Handbook of Occupational Health Psychology, (pp. 143-162). Washington, DC: American Psychological Association.

Frone, M. R., Yardley, J. K., \& Markel, K. S. (1997). Developing and testing an integrative model of the work-family interface. Journal of Vocational Behavior, 50, 145-167.

Fryer, D. M. (1995). Benefit agency? Labour market disadvantage, deprivation and mental health. The Psychologist, 265-272.

Fryer, D., \& McKenna, S. (1987). The laying off of hands-unemployment and the experience of time. In S. Fineman (Ed.), Unemployment: Personal and social consequences (pp. 47-73). London: Tavistock.

Garman, E., Junk, V., Kim, J., O’Neill, B., Prochaska-Cue, K., Prawitz, A., et al. (2005). Financial distress among American workers. Retrieved March 1, 2007, from http://www.ethomasgarman.net/

George, J., \& Brief, A. (1990). The economic instrumentality of work: An examination of the moderating effects of financial requirements and sex on the pay-life satisfaction relationship. Journal of Vocational Behavior, 37, p357368. 
Glenn, N. D. (1990). The social and cultural meaning of contemporary marriage. In B. Christiensen (Ed.), The Retreat from Marriage (pp.33-54), Rockford, IL: Rockford Institute.

Goldberg, D. (1978). Manual of the general health questionnaire. Windsor. England: NFER-Nelson.

Goldberg, H., \& Lewis, R. T. (1978). Money madness: The psychology of saving, spending, loving and hating money. London: Springwood Books.

Gorgievski-Duijvesteijn, M., Bakker, A., Schaufeli, W., \& van der Heijden, P. (2005). Finances and well-being: A dynamic equilibrium model of resources. Journal of Occupational Health Psychology, 10, 210-224.

Gouldner, A. (1960). The norm of reciprocity: A preliminary statement. American Sociological Review, 25, 161-178.

Grandey, A. (2000). Emotion regulation in the workplace: A new way to conceptualize emotional labor. Journal of Occupational Health Psychology, 5, 95-110.

Grandey, A., \& Cropanzano, R. (1999). The conservation of resources model applied to work-family conflict and strain. Journal of Vocational Behavior, 54, 350370.

Greenberg, J. (1990). Employee theft as a reaction to underpayment inequity: The hidden cost of pay cuts. Journal of Applied Psychology, 75, 561-568. 
Griffeth, R., Hom, P., \& Gaertner, S. (2000). A meta-analysis of antecedents and correlates of employee turnover: Update, moderator tests, and research implications for the next millennium. Journal of Management, 26, 463.

Gross, E. (1970). Work, organization, and stress. In S. Levine \& N. A. Scotch (Eds.), Social stress (pp.54-110). Chicago: Aldine.

Hagquist, C., \& Starrin, B. (1996). Youth unemployment and mental health-gender differences and economic stress. Scandinavian Journal of Social Welfare, 5, 215-228.

Halleröd, B., Larsson, D., Gordon, D., \& Ritakallio, V. (2006). Relative deprivation: A comparative analysis of Britain, Finland and Sweden. Journal of European Social Policy, 16, 328.

Hammer, L. B., Bauer, T. N., \& Grandey, A. (2003). Effects of spouses' and own work-family conflict on withdrawal behaviors. Journal of Business and Psychology, 17, 419-436.

Hammer, L., Cullen, J., Neal, M., Sinclair, R., \& Shafiro, M. (2005). The longitudinal effects of work-family conflict and positive spillover on depressive symptoms among dual-earner couples. Journal of Occupational Health Psychology, 10, $138-154$.

hardship. (2007, July 27). The American heritage $®$ dictionary of the English language, fourth edition. Retrieved July 27, 2007, from http://dictionary.reference.com/browse/hardship 
Financial Stress 136

Hart, P. M., \& Cooper, C. L. (2001). Occupational stress: Toward a more integrated framework. In A. N. Anderson, D. S. Ones, H. K. Sinangil, \& C. Viswesvaran (Eds.), Handbook of Industrial, Work and Organizational Psychology: Vol. 2. Organizational Psychology (pp. 93-114). London: Sage.

Hayes, J. (2006). Money attitudes, economic locus of control, and financial strain among college students. Unpublished dissertation Retrieved from http://dspace.lib.ttu.edu/bitstream/2346/1019/1/Hayes_John_V_Diss.pdf

Haynes, S., Richard, D., \& Kubany, E. (1995). Content validity in psychological assessment: A functional approach to concepts and methods. Psychological Assessment, 7, 238-247.

Heymann, J. (2006). Forgotten Families: Ending the Growing Crisis Confronting Children and Working Parents in the Global Economy. Oxford University Press.

Heymann, J., \& Barrerra, M. (2008). Addressing Poverty in a Globalised Economy. Policy Network Progressive Governance Paper. Retrieved on March 15, 2008 from http://www.policynetwork.net/uploadedFiles/Publications/Publications/Jody_Heymann_and_Ma gda_Barrera.pdf

Heymann, J., Boynton-Jarrett, R., Carter, P., Bond, J., \& Gallinsky, E. (2002). Workfamily issues and low-income families: Making work pay in the low-income labor market. Retrieved March 1, 2007, from http://www.economythatworks.com/PDFs/ford_analysisfinal.pdf 
Hobfoll, SE (1989). Conservation of resources: A new attempt at conceptualizing stress. American Psychologist, 44, 513-524.

Hobfoll, SE (2001). The influence of culture, community, and the nested-self in the stress process: Advancing conservation of resources theory. Applied Psychology: An International Review, 50, 337.

Hobfoll, S., Freedy, J., Green, B., \& Solomon, S. (1996) Coping in reaction to extreme stress: The roles ofresource loss and resource availability. Handbook of Coping: Theory, Research, Applications. 322-349.

Hobfoll, S., \& Shirom, A. (1993). Stress and burnout in the workplace: Conservation of resources. Handbook of Organizational Behavior, 41-60.

Hoffman, B., Blair, C., Meriac, J., \& Woehr, D. (2007). Expanding the criterion domain? A quantitative review of the OCB literature. Journal of Applied Psychology, 92, 555-566.

Hu, L. T., \& Bentler, P. M. (1999). Cutoff criteria for fit indexes in covariance structure analysis: Conventional criteria versus new alternatives. Structural Equation Modeling: A Multidisciplinary Journal, 6, 1-55.

Hu, Y., Stewart-Brown, S., Twigg, L., \& Weich, S. (2007). Can the 12-item general health questionnaire be used to measure positive mental health? Psychological Medicine, 37, 1005-1013.

Inglehart, R., \& Klingemann, H. (2000). Genes, culture and happiness. Subjective Well-being across Cultures. MIT Press: Cambridge, MA. 
Isen, A. M., Daubman, K. A., \& Nowicki, G. P. (1987). Positive affect facilitates creative problem solving. Journal of Personality and Social Psychology, 52, $1122-1131$.

Jahoda, M. (1984). Social institutions and human needs: A comment on Fryer and Payne. Leisure Studies, 3, 297-299.

Jamal, M. (2007). Job stress and job performance controversy revisited: An empirical examination in two countries. International Journal of Stress Management, 14, 175.

Jex, S. (1998). Stress and job performance: Theory, research, and implications for managerial practice: Sage Publications.

Jex, S. M., \& Crossley, C. D. (2005). Organizational consequences. In J. Baring, E. K. Kelloway, \& M. Frone (Eds.), Handbook of Work Stress (pp. 575-599). Thousand Oaks, CA: Sage Publications.

Johnson, R., Danko, G., Huang, Y., Park, J., Johnson, S., \& Nagoshi, C. (1987). Guilt, shame, and adjustment in three cultures. Personality and Individual Differences, 8, 357-364.

Kalliath, T. J., O'Driscoll, M. P. \& Brough, P. (2004). A confirmatory factor analysis of the General Health Questionnaire-12. Stress and Health, 20, 11-20.

Kanfer, R. \& Ackerman, P. L. (1989). Motivation and cognitive abilities: An integrative/ aptitude-treatment interaction approach to skill acquisition. Journal of Applied Psychology, 74, 657-658. 
Karasek, R., \& Theorell, T. (1990). Healthy work: Stress, productivity, and the reconstruction of working life: Basic Books.

Kessler, R. C., House, J. S., \& Turner, J. B. (1987). Unemployment and health in a community sample. Journal of Health and Social Behavior, 28, 51-59.

Kim, J., \& Garman, E. (2003). Financial stress and absenteeism: An empirically derived research model. Financial Counseling and Planning, 14, 31-42.

Kim, J., \& Garman, E. (2004). Financial stress, pay satisfaction and workplace performance. Compensation \& Benefits Review, 36, 69-76.

Kim, J., Sorhaindo, B., \& Garman, E. (2004). Financial stress and work outcomes of credit counseling clients. Consumer Interests Annual, 50, 128-130.

Kossek, E. E., \& Ozeki, C. (1999). Bridging the work-family policy and productivity gap: A literature review. Community. Work \& Family, 2, 7-32.

Krause, N., Liang, J., \& Gu, S. (1998). Financial strain, received support, anticipated support, and depressive symptoms in the People's Republic of China. Psychology and Aging, 13, 58-68.

Kozma, A., \& Stones, M. (1980). The measurement of happiness: Development of the Memorial University of Newfoundland scale of happiness (MUNSH). Journal of Gerontology, 35, 906-912.

Lawler, E. E., (1971). Pay and organizational effectiveness. New York: McGraw-Hill.

Lazarus, R. S. (1966). Psychological Stress and the Coping Process. New York: McGraw-Hill. 
Lazarus, R. (1991). Progress on a cognitive-motivational-relational theory of emotion. American Psychologist, 46, 819-834.

Lazarus, R., \& Folkman, S. (1984). Stress, appraisal, and coping. New York: Springer.

Lepine, J., Podsakoff, N., \& Lepine, M. (2005). A meta-analytic test of the challengestressor hindrance stressor framework: an explanation for inconsistent relationships among stressors and performance. Academy of Management Journal, 48, 764-775.

Lehman, A.F., 1988. A quality of life interview for the chronically mentally ill. Evaluation Program. Planning 11, 51-62.

Leiter, M. (1991). Coping patterns as predictors of burnout: The function of control and escapist coping patterns. Journal of Organizational Behavior, 12, 123-144.

Li, Y., Aranda, M., \& Chi, I. (2007). Health and life satisfaction of ethnic minority older adults in mainland china: Effects of financial strain. The International Journal of Aging and Human Development, 64, 361-379.

Liden, R., \& Maslyn, J. (1998). Multidimensionafity of leader-member exchange: An empirical assessment through scale development. Journal of Management, 24, 43.

Locke, E., \& Latham, G. (1990). A theory of goal setting \& task performance: Prentice Hall Englewood Cliffs, NJ.

Lovibond, P., \& Lovibond, S. (1995). The structure of negative emotional states: Comparison of the depression anxiety stress scales (DASS) with the Beck 
Depression and Anxiety Inventories. Behaviour Research and Therapy, 33, 335-343.

Luthans, F., Avolio, B., Walumbwa, F., \& Li, W. (2005). The psychological capital of chinese workers: Exploring the relationship with performance. Management and Organization Review, 1, 249-271.

Lyons, A., \& Yilmazer, T. (2005). Health and financial strain: Evidence from the survey of consumer finances. Southern Economic Journal, 71, 873-890.

MacCallum, R., Browne, M., \& Sugawara, H. (1996). Power analysis and determination of sample size for covariance structure modeling. Psychological Methods, 1, 130-149.

MacKenzie, S., Podsakoff, P., \& Fetter, R. (1993). The impact of organizational citizenship behavior on evaluations of salesperson performance. Journal of Marketing, 57, 70-80.

MacKinnon, D.P., Lockwood, C.M., \& Williams, J. (2004). Confidence limits for the indirect effect: Distribution of the product and resampling methods. Multivariate Behavioral Research, 39, 99-128.

Mámor, E. (n.d.). Retrieved on September 25, 2007 from http://www.quotegarden.com/money.html

Martin, J., \& Peterson, M. (1987). Two-tier wage structures: Implications for equity theory. Academy of Management Journal, 30, 297-315.

Mauno, S. \& Kinnunen, U. (2002). Perceived job insecurity among dual-earner couples: Do its antecedents vary according to gender, economic sector and the 
measure used? Journal of Occupational and Organizational Psychology. 75, 295-314.

McKee-Ryan, F., Song, Z., Wanberg, C., \& Kinicki, A. (2005). Psychological and physical well-being during unemployment: A meta-analytic study. Journal of Applied Psychology, 90, 53-76.

McGrath, J. (1976). Stress and behavior in organizations. Handbook of Industrial and Organizational Psychology, 3, 1351-1395.

McGuire, J., Sundgren, A., \& Schneeweis, T. (1988). Corporate social responsibility and firm financial performance. Academy of Management Journal, 31, 854872.

Meglino, B. (1977). Stress and performance: Are they always incompatible. Supervisory Management, 22, 2-12.

Mills, R., Grasmick, H., Morgan, C., \& Wenk, D. (1992). The effects of gender, family satisfaction, and economic strain on psychological well-being. Family Relations, 41, 440-445.

Mitchell, T. R., \& Mickel, A. E. (1999). The meaning of money: An individual difference perspective. Academy of Management Review, 24, 568-578.

Motowidlo, S., \& Van Scotter, J. (1994). Evidence that task performance should be distinguished from contextual performance. Journal of Applied Psychology, $79,475-480$

Muse, L., Harris, S., \& Feild, H. (2003). Has the inverted-U theory of stress and job performance had a fair test? Human Performance, 16, 349-364. 
Netemeyer, R., Johnston, M., \& Burton, S. (1990). Analysis of role conflict and role ambiguity in a structural equations framework. Journal of Applied Psychology, $75,148-157$.

Oishi, S., Diener, E., Lucas, R., \& Suh, E. (1999). Cross-cultural variations in predictors of life satisfaction: Perspectives from needs and values. Personality and Social Psychology Bulletin, 25, 980.

Okun, M., Stock, W., Haring, M., \& Witter, R. (1984). Health and subjective wellbeing: A meta-analysis. International Journal of Aging and Human Development, 19, 111-132.

Olivius, G., Ostergren, P., Hanson, B., \& Lyttkens, C. (2004). Parental economic stress: Evidence of an overlooked public health risk among Swedish families. The European Journal of Public Health, 14, 354.

Organ, D. (1977). A reappraisal and reinterpretation of the satisfaction-causesperformance hypothesis. The Academy of Management Review, 2, 46-53.

Organ, D. (1988). Organizational citizenship behavior: The good soldier syndrome. Lexington, MA: Lexington Books.

Oswald, A. (1997). Happiness and economic performance. The Economic Journal, $107,1815-1831$.

Palmer, B., Donaldson, C., \& Stough, C. (2002). Emotional intelligence and life satisfaction. Personality and Individual Differences, 33, 1091-1100. 
Pavot, W., Diener, E., Colvin, C. R., \& Sandvik, E. (1991). Futher validation of the satisfaction with life scale: Evidence for the cross-method convergence of well-being measures. Journal of Personality Assessment, 57, 149-161.

Pearl, J. (2001) Direct and indirect effects. Proceedings of the Seventeenth Conference on Uncertainty in Artificial Intelligence, Morgan Kaufmann, 411-420.

Pearlin, L., Lieberman, M., Menaghan, E., \& Mullan, J. (1981). The stress process. Journal of Health and Social Behavior, 22, 337-356.

Pearlin, L., \& Radabaugh, C. (1976). Economic strains and the coping function of alcohol. American Journal of Sociology, 82, 652.

Peirce, R.S., Frone, M.R., Russell, M. \& Cooper, M.L. (1994). Relationship of financial strain and psychosocial resources to alcohol use and abuse: The mediating role of negative affect and drinking motives. Journal of Health and Social Behavior, 35, 291-308.

Peirce, R. S., Frone, M., Russell, M., \& Cooper, M. (1996). Financial stress, social support, and alcohol involvement: A longitudinal test of the buffering hypothesis in a general population survey. Health Psychology, 15, 38-47.

Perrewe, P., \& Zellars, K. (1999). An examination of attributions and emotions in the transactional approach to the organizational stress process. Journal of Organizational Behavior, 20, 739-752.

Pinquart, M., \& Sorensen, S. (2000). Influences of socioeconomic status, social network, and competence on subjective well-being in later life: A metaanalysis. Psychology of Aging, 15, 187-224. 
Pittman, J., \& Lloyd, S. (1988). Quality of family life, social support, and stress. Journal of Marriage and the Family, 50, 53-67.

Podsakoff, P., MacKenzie, S., Paine, J., \& Bachrach, D. (2000). Organizational citizenship behaviors: A critical review of the theoretical and empirical literature and suggestions for future research. Journal of Management, 26, 513.

Price, R., Choi, J., \& Vinokur, A. (2002). Links in the chain of adversity following job loss: How financial strain and loss of personal control lead to depression, impaired functioning, and poor health. Journal of Occupational Health Psychology, 7(4), 302-312.

Probst, T. (2003). Development and validation of the job security index and the job security satisfaction scale: A classical test theory and IRT approach. Journal of Occupational and Organizational Psychology, 76, 451-467.

Probst, T. (2004). Economic stressors. In J. Barling, E. Kelloway \& M. Frone (Eds.), Handbook of Work Stress (pp. 267-297). Thousand Oaks, CA: Sage Publications Inc.

Richins, M. L., \& Dawson, S. (1992). A consumer values orientation for materialism and its measurement: Scale development and validation. Journal of Consumer Research, 19, 303-316.

Rousseau, D. M., \& Ho, V. T. (2000). Psychological contact issues in compensation. In S. L. Rynes \& B. Gerhart Eds.). Compensation in organizations: Current research and practice (pp. 273-310). San Francisco: Jossey Bass. 
Russell, D. W. (2002). In search of underlying dimensions: The use (and abuse) of factor analysis in personality and social psychology bulletin. Personality and Social Psychology Bulletin, 28, 1629-1646.

Russell, J. A. (1978). Evidence of convergent validity on the dimensions of affect. Journal of Personality and Social Psychology, 36, 1152-1168.

Russell, J. A., Weiss, A., \& Mendelsohn, G. A. (1989). Affect grid: a single item scale of pleasure and arousal. Journal of Personality and Social Psychology, 57, 493-502.

Sauter, S., Brightwell, W. S., Colligan, M. J., Hurrell, Jr., J. J., Katz, T. M., LeGrande, D. E., Lessin, Lippin, R. A., Lipscomb, J. A., Murphy, L. R., Peters, R. H., Keita, G. P., Robertson, S. R., Stellman, J. M., Swanson, N. G., \& Tetrick, L. E. (2002). The changing organization of work and the safety and health of working people. DHHS (NIOSH) Publication No. 2002-116.

Schaubroeck, J., Cotton, J., \& Jennings, K. (1989). Antecedents and consequences of role stress: A covariance structure analysis. Journal of Organizational Behavior, 10, 35-58.

Scholl, R., Cooper, E., \& McKenna, J. (1987). Referent selection in determining equity perceptions: Differential effects on behavioral and attitudinal outcomes. Personnel Psychology, 40, 113-124.

Scullen, S.E., Mount, M.K., \& Goff, M. (2000). Understanding the latent structure of job performance ratings. Journal of Applied Psychology, 85(6), 956-970.

Selye, H. (1956). The stress of life. New York: McGraw-Hill. 
Selye, H. (1975). Confusion and controversy in the stress field. Journal of Human Stress, 1, 37-44.

Shaw, J., \& Gupta, N. (2001). Pay fairness and employee outcomes: Exacerbation and attenuation effects of financial need. Journal of Occupational and Organizational Psychology, 74, 299-320.

Shek, D. T. L. (2003). Economic stress, psychological well-being and problem behavior in Chinese adolescents with economic disadvantage. Journal of Youth and Adolescence, 32, p. 259.

Sheldon, K., \& Elliot, A. (1999). Goal striving, need satisfaction, and longitudinal well-being: The self-concordance model. Journal of Personality and Social Psychology, 76, 482-497.

Shrout, P., \& Bolger, N. (2002). Mediation in experimental and nonexperimental studies: New procedures and recommendations. Psychological Methods, 7, 422-445.

Simons, R., Lorenz, F., Conger, R., \& Wu, C. (1992). Support from spouse as mediator and moderator of the disruptive influence of economic strain on parenting. Child Development, 63, 1282-1301.

Sinclair, R., \& Martin, J. (2006). Examining some assumptions about lower income entry-level workers. Paper presented at the Annual conference of the Society for Industrial and Organizational Psychology, Dallas, TX.

Staines, G. (1980). Spillover versus compensation: A review of the literature on the relationship between work and nonwork. Human Relations, 33, 111. 
Stanton, J., Balzer, W., Smith, P., Parra, L., \& Ironson, G. (2001). A general measure of work stress: The stress in general scale. Educational and Psychological Measurement, 61, 866-888.

Staw, B. M. (1984) Organizational behavior: A review and reformulation of the field's outcome variables. In M. R. Rosenzweig and L. W. Porter (eds.), Annual Review of Psychology, 35: 627-666. Palo Alto, CA: Annual Reviews.

Stewart, B. \& Archbold, P. (1996). Oregon Family Caregiving Survey. Unpublished manuscript. Portland, OR: Oregon Health Sciences University, School of Nursing.

Sulsky, L., \& Smith, C. (2005). Work stress. Belmont: Thomas Wadsworth.

Swanberg, J. (2005). Job-family role strain among low-wage workers. Journal of Family and Economic Issues, 26(1), 143-158.

Takeuchi, D., Williams, D., \& Adair, R. (1991). Economic stress in the family and children's emotional and behavioral problems. Journal of Marriage and the Family, 53, 1031-1041.

Tang, T. L. P. (1992). The meaning of money revisited. Journal of Organizational Behavior, 13, 197- 202.

Taris, T. (2006). Is there a relationship between burnout and objective performance? A critical review of 16 studies. Work \& Stress, 20, 316-334.

Taylor, G., \& Vest, M. (1992). Pay comparisons and pay satisfaction among public sector employees. Public Personnel Management, 21. 
Tetrick, L. E., Slack, K. J., Da Silva, N., \& Sinclair, R. R. (2000). A comparison of the stress-strain process for business owners and nonowners: Differences in job demands, emotional exhaustion, satisfaction, and social support. Journal of Occupational Health Psychology, 5, 464-476.

Treadway, D., Ferris, G., Hochwarter, W., Perrewe, P., Witt, L., \& Goodman, J. (2005). The role of age in the perceptions of politics--job performance relationship: A three-study constructive replication. Journal of Applied Psychology, 90, 872-881.

Ullah, P. (1990). The association between income, financial strain and psychological well-being among unemployed youths. Journal of Occupational Psychology, $63,317-330$

U.S. Census Bureau. (2007). How the census bureau measures poverty. Retrieved on April 15, 2008. http://www.census.gov/hhes/www/poverty/povdef.html van der Doef, M., \& Maes, S. (1999). The job demand-control (-support) model and psychological well-being: A review of 20 years of empirical research. Work \& Stress, 13, 87-114.

Van Dyne, L., Jehn, K. A., \& Cummings, A. (2002). Differential effects of strain on two forms of work performance: individual employee sales and creativity. Journal of Organizational Behavior, 23, 57-74.

Van Emmerik, I., Jawahar, I., \& Stone, T. (2005). Associations among altruism, burnout dimensions, and organizational citizenship behaviour. Work \& Stress, $19,93-100$. 
Vinokur, A., Price, R., \& Caplan, R. (1996). Hard times and hurtful partners: How financial strain affects depression and relationship satisfaction of unemployed persons and their spouses. Journal of Personality and Social Psychology, 71, $166-179$.

Vinokur \& Shul, 1997

Vittersø J, Røysamb E, Diener E. 2002. The concept of life satisfaction across cultures: exploring its diverse meaning and relation to economic wealth. In E. Gullone, R. Cummins (Eds.). Social Indicators Research Book Series: The Universality of Quality of Life Constructs. Dordrecht: Kluwer Academic.

Voydanoff, P. (1990). Economic distress and family relations: A review of the eighties. Journal of Marriage and the Family, 52, 1099-1115.

Vroom, V. H. (1964). Work and motivation. New York: John Wiley \& Sons.

Wang, M., \& Takeuchi, R. (2007). The role of goal orientation during expatriation: A cross-sectional and longitudinal investigation. Journal of Applied Psychology, $92,1437-1445$.

Warr, P. B. (2005). Work, well-being, and mental health. In J. Barling, E. K. Kelloway, \& M. Frone (Eds.), Handbook of Work Stress (pp. 547-574), Thousand Oaks, CA: Sage Publications, Inc.

Warr, P. B. (1999). Well-being and the workplace. In D. Kahneman, E. Diener, \& N. Schwarz (Eds.), Well-being: The foundations of hedonic psychology (pp.392412), New York: Russell Sage Foundation. 
Waters, R. (Songwriter). (1973). Money [Song]. London, England: Harvest, Capitol, EMI.

Waters, L., \& Moore, K. (2002). Predicting self-esteem during unemployment: The effect of gender, financial deprivation, alternate roles, and social support. Journal of Employment Counseling, 39, 171-189.

Watson, D., Clark, L. A., \& Tellegen, A. (1988). Development and validation of brief measures of positive and negative affect: The PANAS Scales. Journal of Personality and Social Psychology, 34, 1063-1070.

Werner, J. (1994). Dimensions that make a difference: Examining the impact of inrole and extrarole behaviors on supervisory ratings. Journal of Applied Psychology, 79, 98-107.

Werner, J. (2000). Implications of OCB and contextual performance for human resource management. Human Resource Management Review, 10, 3-24.

Westman, M., Vinokur, A., Hamilton, V., \& Roziner, I. (2004). Crossover of marital dissatisfaction during military downsizing among Russian army officers and their spouses. Journal of Applied Psychology, 89, 769-779.

Whelan, C. (1992). The role of income, life-style deprivation and financial strain in mediating the impact of unemployment on psychological distress: Evidence from the republic of ireland. Journal of Occupational and Organizational Psychology, 65, 331-344. 
Whelan, C. (2001). Income, deprivation, and economic strain. An analysis of the European community household panel. European Sociological Review, 17, 357-372.

Williams, M. (1995). Antecedents of employee benefit level satisfaction: A test of a model. Journal of Management, 21, 1097.

Williams, L. J., \& Anderson, S. E. (1991). Job satisfaction and organizational commitment as predictors of organizational citizenship and in-role behaviors. Journal of Management, 17, 601-617.

Witt, L., \& Carlson, D. (2006). The work-family interface and job performance: Moderating effects of conscientiousness and perceived organizational support. Journal of Occupational Health Psychology, 11, 343-357.

Witt, L., \& Wilson, J. (1990). Income sufficiency as a predictor of job satisfaction and organizational commitment: Dispositional differences. The Journal of Social Psychology, 130, 267-268.

Wood, S., Seastian, K., \& Scherr, S. J. (2001). Pilot analysis of global ecosystems: Agroecosystems: International Food Policy Research Institute \& World Resources Institute.

Wright, T. A., \& Cropanzano, R. (1998). Emotional exhaustion as a predictor of job performance and voluntary turnover. Journal of Applied Psychology, 83, 486493. 
APPENDIX A

List of Measures- Study 1

\section{Gender}

What is your gender? M F

\section{$\underline{\text { Age }}$}

What is your age?

\section{Objective Income}

How much money do you typically receive each month (from all sources including work, gifts, loans, interest on savings, family, etc.)?

\section{$\underline{\text { Objective Expenses }}$}

How much money do you typically spend each month (rent, food, utilities, transportation, healthcare, education, entertainment, child/elderly care, etc)?

\section{$\underline{\text { Initial Item Pool for Perceived Income Adequacy }}$}

Instructions: Please answer the following questions for yourself and your household/family (i.e., spouses, dependent children, and/or relatives). Note: Your income may include all sources (e.g., spouse, parents, loans, job, etc.).

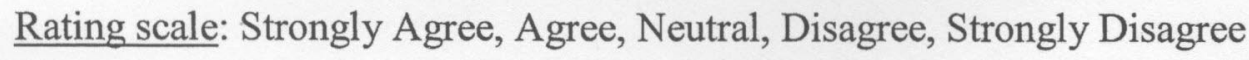

\section{Current Needs}

1. I can afford the health care I need.

2. I do not need to borrow money in order to pay my bills.

3. I cannot pay my bills on time.

4. I can afford to pay my utilities (heat, water, gas, etc).

5. I can afford the child care/elder care my family needs.

6. I am able to manage money without overdrawing my bank account.

7. I cannot pay for the clothes I need.

8. I cannot afford the basic transportation I need.

9. I can afford the basic housing (e.g., rent, mortgage) I need to 
survive.

10. I cannot afford the food I need to survive.

\section{Current Wants}

1. I cannot pay for the clothes I want.

2. I cannot afford the kind of transportation I want.

3. I can afford the type of housing I want.

4. I cannot pay for the food I like to eat.

5. I cannot afford the household items I want.

6. I cannot afford to replace broken or worn out things.

7. I can afford the recreation/ entertainment I like.

8. I can afford to save as much money as I want to be saving.

9. My current income allows me to have the lifestyle I want.

10. I have extra money for unexpected expenses.

11. I cannot save for retirement at the rate I want to save.

12. I am currently unable to meet my financial goals.

13. I can travel where I want.

14. I cannot afford to eat at the kind of restaurant I like.

\section{Future}

Instructions: Now, think about 5 years from now, and please rate the likelihood that the following statements will be true. Please answer the following questions for yourself and your household/family (i.e., spouses, dependent children, and/or relatives). Note: Your income may include all sources (e.g., spouse, parents, loans, job, etc.).

Rating scale: Very Likely, Likely, Neutral/Uncertain, Unlikely, Very Unlikely

\section{Future Needs}

1. I will be able to afford the health care I will need.

2. I will not need to borrow money in order to pay my bills.

3. I will not be able to my bills on time.

4. I will be able to afford my utilities (heat, water, gas, etc).

5. I will be able to afford the child care/ elder care my family needs.

6. I will be able to manage money without overdrawing my bank account.

7. I will not be able to pay for the clothes I will need.

8. I will not be able to afford the basic transportation I need.

9. I will be able to afford the basic housing (e.g., rent, mortgage) I need to survive

10. I will not be able to afford the food I need to survive.

\section{Future Wants}

1. I will not be able to pay for the clothes I want. 
2. I will not be able to afford the kind of transportation I want.

3. I will be able to afford the type of housing I want.

4. I will not be able to buy the food I like.

5. I will not be able to afford the household items I want.

6. I expect that I will have money leftover at the end of every month after paying my living expenses.

7. I will not be able to afford replacing broken or worn out things.

8. I will be able to afford the recreation/ entertainment I like.

9. I will be able to save as much money as I want to be saving.

10. My future income will allow me to have the lifestyle I want.

11. I will have extra money for unexpected expenses.

12. I will not be able to save for retirement at the rate I want to save.

13. I will not be able to meet my financial goals.

14. I will be able to travel where I want.

15. I will not be able to afford to eat at the kind of restaurant I like.

\section{Initial Item Pool for Financial Strain}

Instructions: Please indicate your level of agreement with each of the following statements about your financial situation.

$\underline{\text { Rating Scale: }}$ Strongly Agree, Agree, Neutral, Disagree, Strongly Disagree

1. My financial situation is demanding.

2. I feel pressured by my financial situation.

3. My financial situation is hectic.

4. I feel calm about my financial situation.

5. I am relaxed regarding my financial situation.

6. I feel pushed by my financial situation.

7. My financial situation is irritating.

8. I have my financial situation under control.

9. My financial situation is nerve-wracking.

10. I feel hassled by my financial situation.

11. I am comfortable with my financial situation.

12. My financial situation is more stressful than I'd like.

13. My financial situation is overwhelming.

14. My financial situation makes me nervous/ anxious.

15. My financial situation makes me feel emotionally drained.

16. My financial situation makes me feel unhappy.

17. My financial situation makes me feel depressed. 


\section{APPENDIX B}

\section{List of Measures- Study 2}

Age

1. 出生日期:

DOB

\section{Gender}

2. 性别: 男 女

Gender: M F

\section{Objective Income}

1. 家庭月收入(请在恰当的答案上画圈): Month's family income 低于500 500-1000 1000-1500 $1500-3000 \quad 3000-5000 \quad 5000-8000 \quad 8000$ 10000 高于 10000

\section{Objective Expenses}

\begin{tabular}{|llllll}
2. & 家庭月支出(包括衣食住行，医疗教育，休闲娱乐，负担父母子女，等等): \\
family monthly expenses
\end{tabular}
$\begin{array}{llllll}\text { 低于500 } 500-1000 & 1000-1500 & 1500-3000 & 3000-5000 & 5000-8000 & 8000- \\
10000 & \text { 高于 } 10000\end{array}$

\section{Perceived Income Adequacy}

\section{English Items}

1. My current income allows me to have the lifestyle I want.

2. I am currently unable to meet my financial goals.*

3. I can afford to save as much money as I want to be saving.

4. I have extra money for unexpected expenses.

5. I can afford to travel where I want.

6. I can afford the type of housing I want.

7. I cannot afford the household items I want.*

8. I cannot pay for the clothes I want.*

9. I will not be able to afford the food I need to survive.*

10 . I will not be able to pay my bills on time.*

11 . I will be able to save as much money as I want to be saving.

12. I will be able to travel where I want.

13. I will have extra money for unexpected expenses.

14. My future income will allow me to have the lifestyle I want.

15. I expect that I will have money leftover at the end of every month after 
paying my living expenses.

16. I will be able to afford the type of housing I want.

17. I will be able to afford the recreation/entertainment I like.

18. I will not be able to save for retirement at the rate I want to save.*

19. I will not be able to meet my financial goals.*

\section{Corresponding Chinese Items}

\begin{tabular}{|c|}
\hline 1. 我目前的收入允许我过我想要的生活方式。PIA-CL \\
\hline 2. 我目前不能达到我的经济目标。PIA-CL \\
\hline 3. 我能达到我的存款目标。PIA-CL \\
\hline 4. 我有富余的钱来应付意料外的支出。PIA-CL \\
\hline 5. 我能负担旅行的费用, 去我想去的地方。PIA-CL \\
\hline 6. 我能负担得起我想要得住房。PIA-CL \\
\hline 7：我负担不起我想要的家具。PIA-CL \\
\hline 8. 我负担不起我想要的衣服。PIA-CL \\
\hline 9. 我不能按照我想要的速度来存我的养老金。PIA-CL \\
\hline 10. 我能负担得起我想要的休闲娱乐。PIA-CL \\
\hline 11. 买不起我所需的食物。PIA-BN \\
\hline 12. 我负担不起步行以外的其他交通方式。PIA-BN \\
\hline 13. 我能负担得起水费、电费、和煤气费。PIA-BN \\
\hline 14. 我付不起我的日常开支。PIA-BN \\
\hline 15. 我能负担得起我的基本居住需求。PIA- BN \\
\hline 16. 我将买不起我所需的食物。PIA- BN \\
\hline 17. 我将付不起我的日常开支。PIA- BN \\
\hline 18. 我能达到我的存款目标。PIA-FL \\
\hline 19. 我将能负担旅行的费用, 去我想去的地方。PIA-FL \\
\hline 20. 我将有富余的钱来应付意料外的支出。PIA-FL \\
\hline 21. 我未来的收入将允许我过我想要的生活方式。PIA-FL \\
\hline 22. 我预期支付当月开支后，仍有结余。PIA-FL \\
\hline 23. 我将能负担得起我想要得居住条件。PIA-FL \\
\hline 24. 我将能负担得起我想要的休闲娱乐。PIA-FL \\
\hline 25. 我将不能按照我想要的速度来存养老金。PIA-FL \\
\hline 26. 我将不能达到我的经济目标。PIA-FL \\
\hline
\end{tabular}

\section{Financial Strain}

\section{English Items}

1. I feel pressured by my financial situation.

2. My financial situation is demanding. 
3. I am relaxed regarding my financial situation.*

4. I feel calm about my financial situation.*

5. I feel pushed by my financial situation.

6. My financial situation is irritating.

7. My financial situation is hectic.

8. My financial situation is more stressful than I would like.

9. I am comfortable with my financial situation.*

Corresponding Chinese Items

\begin{tabular}{|l|l|}
\hline 1. & 我的经济状况让我感到有压力。ES \\
\hline 2. & 我的经济状况让我非常压力。ES \\
\hline 3. 我的经济状况让我感到轻松。ES \\
\hline 4. 我的经济状况让我感到没有压力。ES \\
\hline 5. 我的经济状况让我有紧迫感。ES \\
\hline 6. 我的经济状况很烦人。ES \\
\hline 7. 我的经济状况让我紧张。ES \\
\hline 8. 我的经济状况比我所期望的更令我有压力。ES \\
\hline 9. 我对自己的经济状况感到舒服。ES \\
\hline
\end{tabular}

\section{Satisfaction with Life}

\begin{tabular}{|ll|}
\hline 1. & In the most ways my life is close to my ideal. \\
\hline 2. & The condition of my life is excellent. \\
\hline 3. & I am satisfied with my life. \\
\hline 4. & So far I have gotten the important things I want in life. \\
\hline 5. & If I could live my life over, I would change almost nothing. \\
\hline
\end{tabular}

Corresponding Chinese Items

\begin{tabular}{|rl|}
\hline 1. & 在大多数方面, 我的生活接近我的理想状态。 \\
\hline 2. & 我的生活条件很优越。 \\
\hline 3. & 我对自己的生活感到满意。 \\
\hline 4. & 目前为止, 我已经得到了我生活中想要得到的重要东西。 \\
\hline 5. & 如果我能重活一遍, 我不会要改变我生活中的几乎任何东西。 \\
\hline
\end{tabular}

\section{Task Performance}

1. I always complete the duties specified in his/her job description. 他/她总是完成份内的工作。

2. I meet all the formal performance requirements of the job. 他/她完成所有正式的工作绩效要求。 
3. I fulfill all responsibilities required by my job. 他/她履行工作要求的所有职责。

4. I never neglect aspects of the job that I am obligated to perform. 他/她从不忽视份内的工作。

5. I often fail to perform essential duties.* 他/她常常未能履行重要的职责。

\section{Organizational Citizenship Behavior}

Subscales: Altruism (1-3), Conscientiousness (4-6)

1. Help others who have been absent. 帮助那些缺勤的人完成他们的工作。

2. Willingly give of my time to help others with work-related problems. 愿意用自己的时间来帮助别人解决工作相关的问题。

3. Help others who have heavy workloads. 帮助那些工作负担重的人。

4. Completes work earlier than is expected.

5. Obey company rules and regulations even when no one is watching. 即使没有人监督, 也遵守公司 (单位) 的条例和规定。

6. Completes tasks at work promptly. 